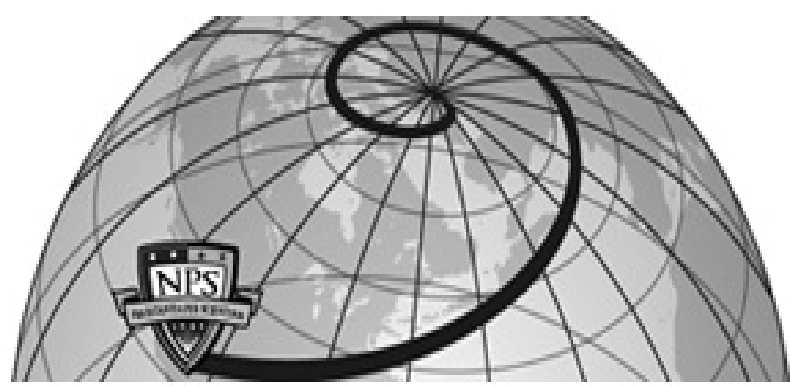

Calhoun: The NPS Institutional Archive DSpace Repository

\title{
JELO: a model of joint expeditionary logistics operations
}

Boensel, Matthew; Schrady, David A.

Monterey, California. Naval Postgraduate School

https://hdl.handle.net/10945/748

This publication is a work of the U.S. Government as defined in Title 17, United States Code, Section 101. Copyright protection is not available for this work in the United States.

Downloaded from NPS Archive: Calhoun

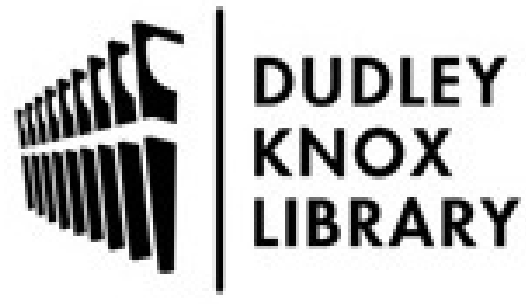

http://www.nps.edu/library
Calhoun is the Naval Postgraduate School's public access digital repository for research materials and institutional publications created by the NPS community. Calhoun is named for Professor of Mathematics Guy K. Calhoun, NPS's first appointed -- and published -- scholarly author.

Dudley Knox Library / Naval Postgraduate School 411 Dyer Road / 1 University Circle Monterey, California USA 93943 


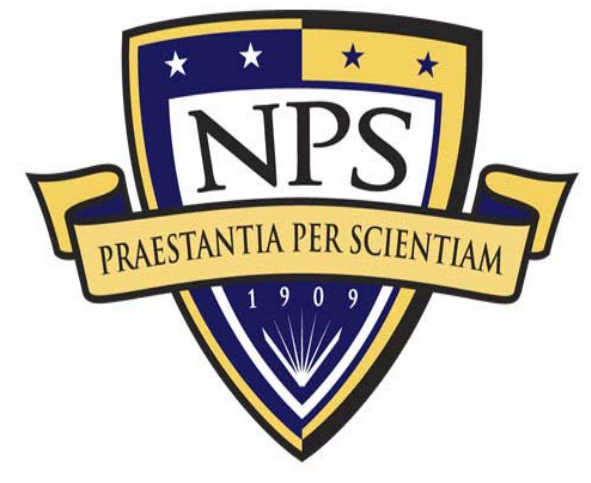

\section{NAVAL \\ POSTGRADUATE SCHOOL}

MONTEREY, CALIFORNIA

\section{JELO: A Model of Joint Expeditionary Logistics Operations}

by

Matthew Boensel

David Schrady

October 2004

Approved for public release; distribution is unlimited.

Prepared for: Office of the Chief of Naval Operations, N81 2000 Navy Pentagon

Washington, D.C. 20350-2000 


\section{Amateurs discuss strategy, Professionals study logistics}

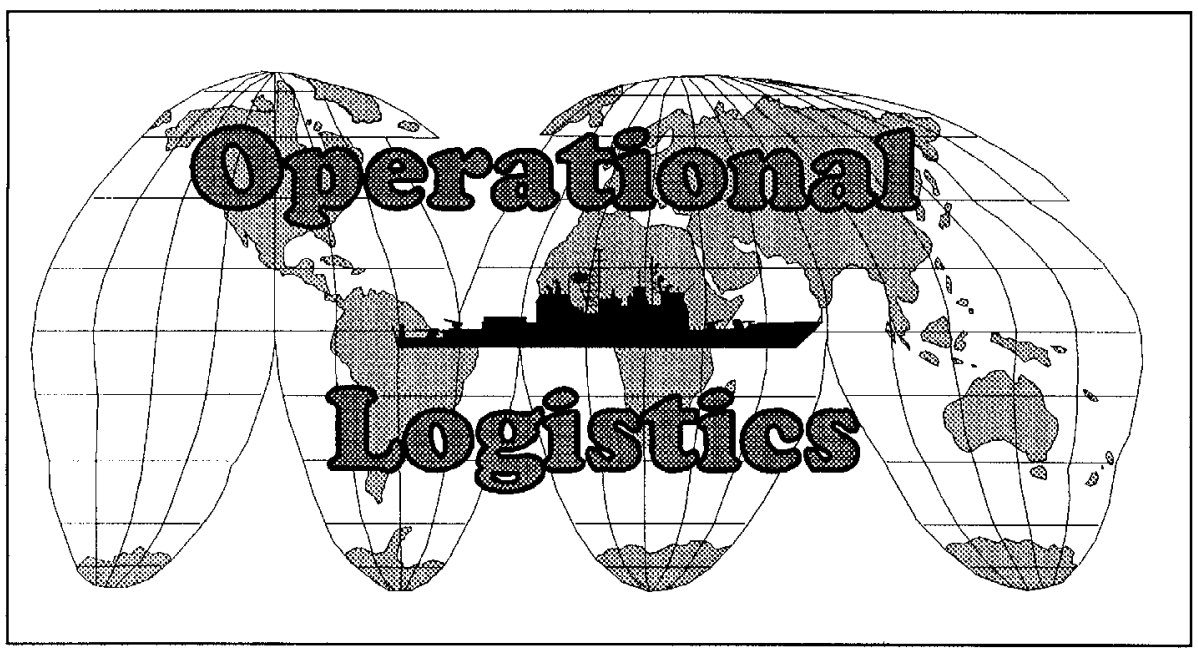




\section{NAVAL POSTGRADUATE SCHOOL MONTEREY, CA 93943-5000}

RDML Patrick W. Dunne, USN

Richard Elster

President

Provost

This report was prepared for and funded by Office of the Chief of Naval Operations, N81, 2000 Navy Pentagon, Washington, D.C. 20350-2000.

Reproduction of all or part of this report is authorized.

This report was prepared by:

MATTHEW BOENSEL

Lecturer of Systems Engineering

Reviewed by:

LYN R. WHITAKER

Associate Chairman for Research

Department of Operations Research
DAVID SCHRADY

Distinguished Professor of

Operations Research

Released by:

JAMES N. EAGLE

LEONARD A. FERRARI, Ph.D.

Chairman

Associate Provost and Dean of Research

Department of Operations Research 
Public reporting burden for this collection of information is estimated to average 1 hour per response, including the time for reviewing instruction, searching existing data sources, gathering and maintaining the data needed, and completing and reviewing the collection of information. Send comments regarding this burden estimate or any other aspect of this collection of information, including suggestions for reducing this burden, to Washington Headquarters Services, Directorate for Information Operations and Reports, 1215 Jefferson Davis Highway, Suite 1204, Arlington, VA 22202-4302, and to the Office of Management and Budget, Paperwork Reduction Project (0704-0188) Washington, DC 20503.

\begin{tabular}{l|l|l|}
\hline 1. AGENCY USE ONLY (Leave blank) & $\begin{array}{c}\text { 2. REPORT DATE } \\
\text { October } 2004\end{array}$ & $\begin{array}{c}\text { 3. REPORT TYPE AND DATES COVERED } \\
\text { Technical Report }\end{array}$ \\
$\begin{array}{l}\text { 4. TITLE AND SUBTITLE: JELO: A Model of Joint Expeditionary Logistics } \\
\text { Operations }\end{array}$ & $\begin{array}{c}\text { 5. FUNDING NUMBERS } \\
\text { RORMV }\end{array}$ \\
\hline 6. AUTHOR(S) Matthew Boensel and David Schrady & $\begin{array}{l}\text { 8. PERFORMING } \\
\text { ORGANIZATION REPORT } \\
\text { NUMBER NPS-0R-05-001 }\end{array}$ \\
$\begin{array}{l}\text { 7. PERFORMING ORGANIZATION NAME(S) AND ADDRESS(ES) } \\
\text { Naval Postgraduate School } \\
\text { Monterey, CA 93943-5000 }\end{array}$ & $\begin{array}{c}\text { 10. SPONSORING / MONITORING } \\
\text { AGENCY REPORT NUMBER }\end{array}$ \\
$\begin{array}{l}\text { 9. SPONSORING / MONITORING AGENCY NAME(S) AND ADDRESS(ES) } \\
\text { Office of the Chief of Naval Operations, N81, 2000 Navy Pentagon, }\end{array}$ & \multicolumn{1}{l}{\begin{tabular}{l} 
Washington, D.C. 20350-2000 \\
\hline
\end{tabular}}
\end{tabular}

11. SUPPLEMENTARY NOTES The views expressed in this thesis are those of the author and do not reflect the official policy or position of the Department of Defense or the U.S. Government.

\begin{tabular}{l|l}
\hline 12a. DISTRIBUTION / AVAILABILITY STATEMENT & 12b. DISTRIBUTION CODE \\
Approved for public release; distribution is unlimited. &
\end{tabular}

\section{ABSTRACT (maximum 200 words)}

JELO is an Excel spreadsheet model of joint expeditionary logistics operations and allows end-to-end analysis of the options for closing forces from CONUS, through the sea base, to objectives ashore. Sustainment operations are included. The model is flexible and, while the examples in the report involve the 2015 Marine Expeditionary Brigade, all model parameters may be user specified. The $\mathrm{MPF}(\mathrm{F})$ is the subject of current discussion and analysis to determine what its capabilities and capacities need to be. Additionally, there are potentially other platforms to build in order to make Sea Basing a reality-high-speed connectors, assault connectors, and rapid strategic lift ships. JELO can be of use in evaluating the alternatives.

14. SUBJECT TERMS joint expeditionary warfare, logistics

\section{SECURITY CLASSIFICATION OF REPORT}

Unclassified
18. SECURITY

CLASSIFICATION OF THIS

PAGE
19. SECURITY CLASSIFICATION OF ABSTRACT

Unclassified

Unclassified
15. NUMBER OF

PAGES

60

16. PRICE CODE

20. LIMITATION

OF ABSTRACT
UL 


\section{Table of Contents}

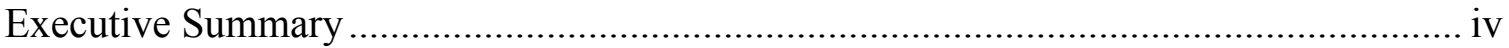

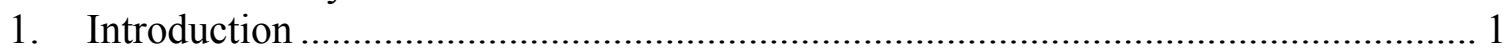

2. Assumptions, Data, Planning Factors, and Uncertainties ...................................... 2

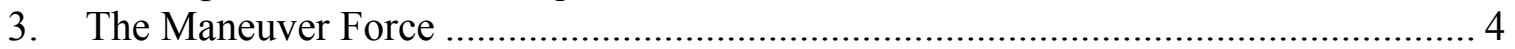

4. The Maritime Preposition Force (Future) ….......................................................... 5

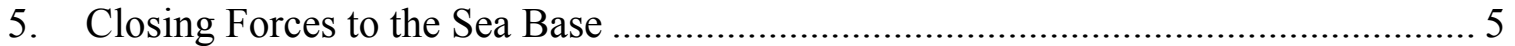

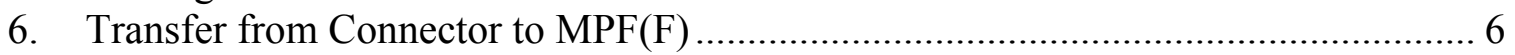

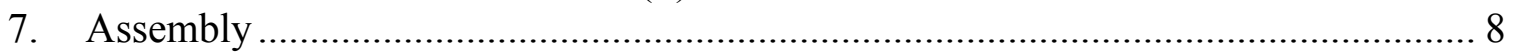

8. Deploying the Maneuver Elements to Objectives Ashore ....................................... 8

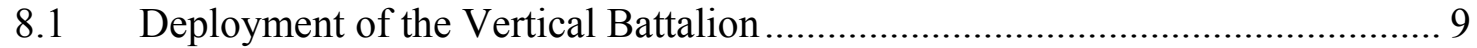

8.2 Deployment of the Surface Battalions ............................................................ 11

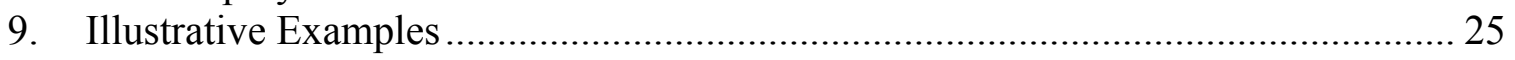

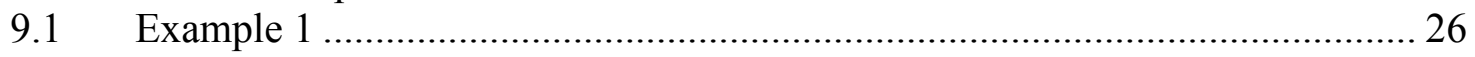

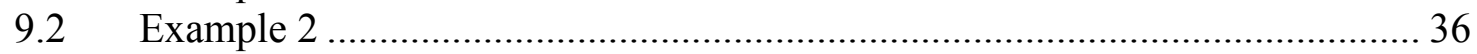

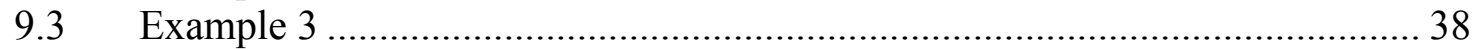

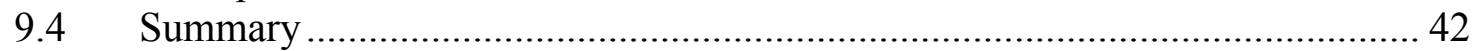

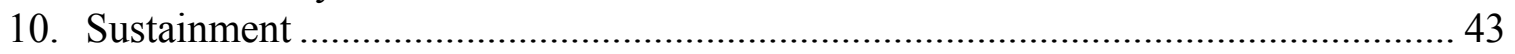

10.1 Resupply of the Maneuver Forces Ashore.................................................. 43

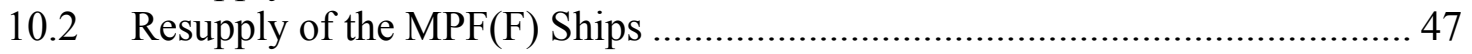

10.3 Resupply of the CSG and ESG Ships of the Sea Base ................................. 48

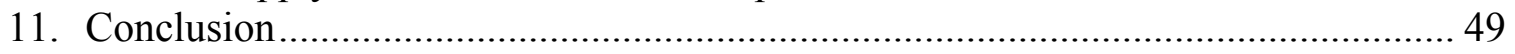

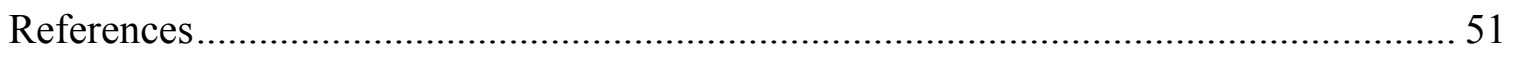




\section{JELO: A Model of Joint Expeditionary Logistics Operations}

\section{Executive Summary}

Joint expeditionary logistics operations are required in Sea Basing. Forcible entry operations are initiated and sustained from ships operating as a sea base until the operation is successfully concluded or until heavier joint forces arrive at the ports and airfields secured by the forcible entry operations. This is very different from traditional ground combat operations initiated from and sustained by bases ashore; e.g., Operation Desert Storm (ODS) and Operation Iraqi Freedom (OIF).

Sea Basing expeditionary maneuver forces for combat operations ashore involves 1) closing troops from CONUS to the sea base, 2) force assembly at the sea base, 3) deployment of forces from the sea base to objectives ashore, and 4) sustainment of the forces ashore and ships of the sea base. These fundamental operations can be performed in a variety of ways.

The sea base consists of one or more carrier strike groups (CSGs), one or more expeditionary strike groups (ESGs), combat logistics force ships, and maritime preposition force (future) (MPF(F)) ships. The unit equipment and combat stores of the maneuver forces are prepositioned forward on the $\mathrm{MPF}(\mathrm{F})$ ships. Troops (and non-self-deploying aircraft) from CONUS must close to the MPF(F) ships. In closing troops and in sustainment there is the notion of an advance base whose availability is assured, but may be up to 2,000 $\mathrm{nm}$ from the sea base. If large, fixed-wing transport aircraft cannot land on ships at sea, troops may need to be transported to the advance base as an intermediate step in closing to the sea base. Troops could be transported from CONUS to the advance base either by aircraft or by ships. Whereas aircraft cannot proceed directly to the sea base, ships from CONUS could steam either to the advance base or to the sea base. The MPF(F) ships could steam directly from their preposition site to the sea base or to the advance base.

If the troops are transported from CONUS to the advance base by aircraft and the MPF(F) ships do not call at the advance base to onload them, a connector vessel must transport them from the advance base to the $\mathrm{MPF}(\mathrm{F})$ ships. If the troops are transported from CONUS to the advance base in rapid strategic lift ships (RSLS) and the MPF(F) do not call at the advance base, a connector is again needed to take the troops from the advance base to the MPF(F) ships. Alternatively, the RSLS could transport the troops from CONUS to the $\operatorname{MPF}(\mathrm{F})$. The troops could transfer to the $\operatorname{MPF}(\mathrm{F})$ ships either at the sea base or while the MPF(F) and connector or RSLS are en route to the sea base, if this is feasible. An option that eliminates the need to transfer troops between ships in open ocean is to have the $\operatorname{MPF}(\mathrm{F})$ ships call at the advance base and onload troops at the pier. A convenient scenario may be that the advance base is the port where the $\operatorname{MPF}(\mathrm{F})$ ships are prepositioned. 
Clearly there are a variety of ways of closing troops to the sea base. Sea Basing capability requires new preposition ships and possibly RSLSs and/or high-speed connectors (HSC). Analysis is required to choose between the various alternatives and the platforms that enable them. One measure of performance of any alternative is the time it takes to close troops to the sea base or the time it takes to close to the sea base and deploy to objectives ashore.

JELO is an expected value Excel spreadsheet-based model that represents a number of closure alternatives, transfer, deployment, and sustainment. Most of the flows and rates are treated as parameters characterized only by their expected values. Whether the flow is the transfer rate of personnel from a $\operatorname{HSC}$ to a $\operatorname{MPF}(\mathrm{F})$ ship or the rate is the consumption of ammunition by forces ashore, only deterministic planning factors are available for current operations and systems and only goals are available for future systems. Analysis more sophisticated than expected value analysis requires treating many of these parameters as random variables and requires specification of the mean, variance, and distribution of the parameters. Such data is generally unavailable for current, as well as future, capabilities and systems.

The model is transparent, clearly indicating its structure and logic. It is not practical to build a completely general model that encompasses all the alternatives. An analyst familiar with JELO can build on the basic structure to represent any operations of interest. The goal has been to create a useful tool for examining and evaluating various sea basing architectures. Examples are shown only to demonstrate use of the model.

The Navy and Marine Corps are currently defining the $\mathrm{MPF}(\mathrm{F})$. Additionally, there are potentially other platforms to build in order to make Sea Basing a realityhigh-speed connectors, assault connectors, and rapid strategic lift ships. The goal has been to develop a model that the OPNAV staff can use to provide insight about sea basing operations, end-to-end, and support programmatic decision-making. 


\section{Introduction}

While ground combat operations in Operation Iraqi Freedom in the Spring of 2003 were very successful, a pause in the fighting was called on about the $29^{\text {th }}$ of March - eight or nine days after the operation began-because the $3^{\text {rd }}$ Infantry Division and the $1^{\text {st }}$ Marine Expeditionary Force (I MEF) forces were low on MREs, fuel, and ammunition. These units were being resupplied through the movement of these commodities over the ground from depots also on the ground in Kuwait. In Sea Basing, forces will arrive to ships of a sea base, assemble with their equipment and stores at sea, deploy from ships of the sea base to objective areas ashore and conduct combat operations. Their resupply will flow from ships of the sea base. As difficult as it was to deploy and resupply forces in Iraq from bases and depots ashore, sea basing such operations will be much more difficult and require a system of systems consisting of preposition ships, high-speed sealift ships, high-speed connector vessels, the means to transfer troops, equipment, stores between platforms in open ocean, and air and surface connectors for deploying and resupplying the forces.

Figure 1 depicts one of a large number of ways of closing troops and non-self-deployed aircraft to the sea base, specifically to the $\operatorname{MPF}(\mathrm{F})$ ships. Only the $\operatorname{MPF}(\mathrm{F})$ ships in the sea base have the maneuver force unit equipment and stores and can accommodate the troops on-board. Unless the $\operatorname{MPF}(\mathrm{F})$ call at the advance base, a transfer is required to move the troops and cargo to the $\mathrm{MPF}(\mathrm{F})$ ships. The figure also reflects the deployment of the maneuver forces to objectives ashore from the $\operatorname{MPF}(\mathrm{F})$ ships after their arrival and assembly. There is another transfer operation in which the troops and their equipment and stores are loaded from the $\operatorname{MPF}(\mathrm{F})$ to connectors that take them from the sea base to objective areas ashore. These connectors may be aircraft or surface craft. Finally, the figure indicates resupply of the forces ashore and of the ships of the sea base including not only the $\operatorname{MPF}(\mathrm{F})$, but the ships of associated carrier strike groups (CSG) and expeditionary strike groups (ESG) as well.

The focus here is on flowing forces to, and subsequently deploying from, the MPF(F). ESG operations are not modeled though the Marine Expeditionary Unit (MEU) battalion landing team could be part of the operations.

A common definition of military logistics is that it is the set of activities concerned with the establishment, maintenance, and movement of forces. It follows then that expeditionary logistics operations encompassing the closure of troops to the sea base, the assembly of force units, the deployment of these forces to objectives ashore, and the resupply of all concerned - forces and ships - should be described as Joint Expeditionary Logistics Operations, and the model itself named JELO. 


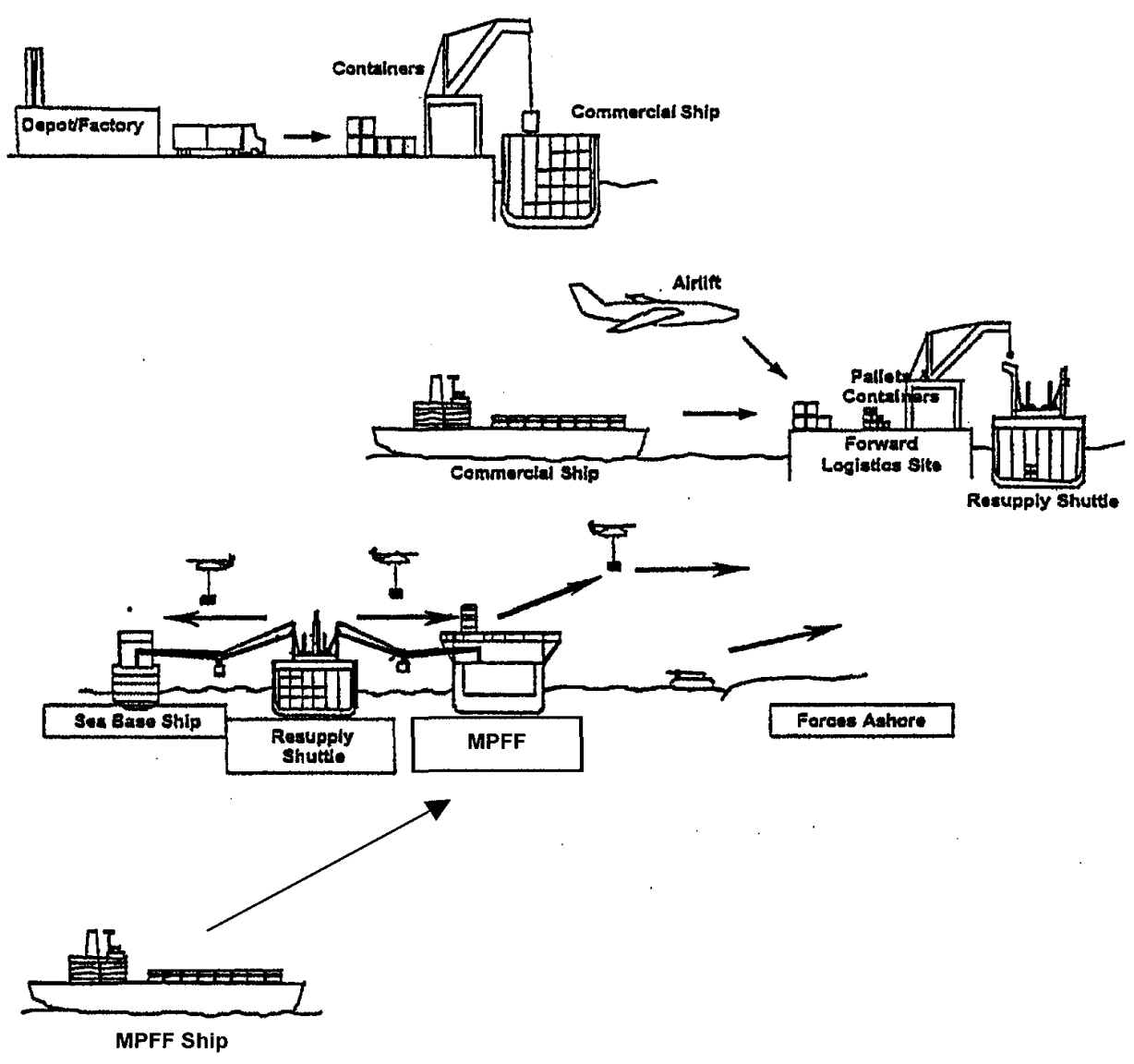

Figure 1. Expeditionary Logistics Operations

\section{Assumptions, Data, Planning Factors, and Uncertainties}

The first assumption is really about the scenario reflected in the model. It includes the flow of an $\operatorname{MPF}(\mathrm{F})$ Marine Expeditionary Brigade (MEB) to MPF(F) ships at a sea base. The $\operatorname{MPF}(\mathrm{F}) \mathrm{MEB}$ troops that flow to the sea base are the Seabased Maneuver Element (SBME) and the Seabased Support Element (SBSE), plus a Naval Support Element (NSE). The SBME and some direct support from the SBSE are subsequently deployed from the $\operatorname{MPF}(\mathrm{F})$ ships to objective areas ashore. The SBME consists of three reinforced infantry battalions of which one is intended for vertical deployment and two are to be deployed on the surface. The Vertical battalion is to be lifted $110 \mathrm{~nm}$ to an objective inland and the Surface battalions will be carried $25 \mathrm{~nm}$ to the shore with the beach as their initial objective.

There are several ways to move the troops of the SBME, SBSE, and NSE from CONUS to the sea base and a few of these are described in Section 5. Aircraft will not be 
prepositioned on the $\mathrm{MPF}(\mathrm{F})$ and non self-deploying aircraft will have to be airlifted into the theater. The tiltrotor aircraft will self-deploy. LCACs and EFVs will be prepositioned on the $\mathrm{MPF}(\mathrm{F})$ ships. An advance base may be used in the flow of forces to the sea base. The advance base must be a facility with an airport and a seaport, and controlled by the United States through ownership or treaty. While we probably know where the $\operatorname{MPF}(\mathrm{F})$ squadrons will be prepositioned, we don't know where the sea base will be required and what advance base will be utilized. Troops flown to the advance base may be transshipped by high-speed connector (HSC) vessels from the advance base to the sea base. The capabilities of the HSC are unknown and it is not yet a program of record. All we know about it is that the Initial Capabilities Document for a High Speed Connector [2] states that they will reside in the numbered fleets and be forward deployed in the geographical combatant commander's areas of responsibility in order to provide responsive support to the Combatant and Joint Force Commanders. In order to include the HSC in this modeling, some assumptions have to be made about the numbers of such vessels and their speed, range, and capacities for transporting troops, cargo, and aircraft.

Once the HSCs arrive at the sea base or earlier, their troops must be transferred to the $\mathrm{MPF}(\mathrm{F})$ ships. All Concept of Operations (CONOPS) documents note the requirement for such transfer capabilities, but none say how this capability is achieved and this requires assumptions for modeling purposes. An alternative way of flowing maneuver forces to the sea base is for them to embark rapid strategic lift ships (RSLS) in CONUS and sail to the advance base or directly to the sea base. Again, such high-speed shipping is not a program of record and one has only available PowerPoint briefings that bracket achievable speeds and ranges without commenting on capacities, aircraft operational spots, etc.

Perhaps the largest assumptions involve the $\operatorname{MPF}(\mathrm{F})$ itself because it is so central to sea basing. While the Analysis of Alternatives has been completed [3], there are a number of ship and squadron alternatives, and no doubt more alternatives yet to come. Though a program of record, the MPF(F) ship's basic characteristics (things like speed, number of aircraft operating spots, number and type of surface connector loading points, etc.) are as yet undetermined. Again, for modeling purposes, assumptions have to be made. The assumption is that there are eight like ships in the $\operatorname{MPF}(\mathrm{F})$ squadron, all with a single aircraft operating spot and single surface connector load point. From [3], the distributed capability designs have four or five aircraft operating spots per ship, while the specialized ship designs have one or two aircraft operating spots per ship. MPF(F) ship speed, number of spots, and surface craft load points in a squadron are treated as parameters and the JELO user can input the numbers or range of numbers of interest.

The maneuver forces on the $\operatorname{MPF}(\mathrm{F})$ are deployed ashore to conduct a forcible entry operation in which they will use combat stores at assault rates for the first five days and at sustained rates for another 15 days. The $\operatorname{MPF}(\mathrm{F})$ is to have stores for 20 days of operations [3]. If the 20 days of supply is in terms of the full MEB, stores on the MPF(F) will support just the SBME, SBSE, and NSE for even longer. The assumption is that either the operation achieved all objectives and is ended or that by the $20^{\text {th }}$ day joint 
heavy forces arrived in number through the air and sea ports secured in the forcible entry operation.

Data-hard data-exists for very little of the overall problem. There is operational or test data available for the LCAC and the MV-22. It cannot be known from the available literature whether the EFV speed on water should be assumed to be $20 \mathrm{kts}$ or the long-advertised $25 \mathrm{kts}$. It is known that sea state affects the LCAC's speed and payload and that it cannot operate at all above sea state 4 [4]. What the mission-capable rates of the various connectors will be over time are not known, though there is an estimate for the LCAC [4] and other studies have made assumptions about the MV-22 and CH-53E mission-capable rates in sustained operations.

OPNAV N42 and Fleet Forces Command are compiling logistics planning factors from a number of sources and selecting and documenting approved numbers [5]. If all analyses use the same inputs, comparing the results should be possible.

These considerations apply as well to Marine maneuver forces. The $2015 \mathrm{MPF}(\mathrm{F}) \mathrm{MEB}$ is different in numbers, kinds of units, and table of equipment from the Marine Corps Bulletin 3501 MEB. The published logistics planning factors for the consumption of fuel and ammo are based on the MCB 3501 MEB or even earlier versions. Logistics planning factors for the 2015 MEB have yet to be published.

The methodology adopted for estimating SBME daily fuel and ammo requirements is to take the existing planning factors and the existing table of organization personnel numbers for each type of unit (infantry battalion, artillery battery, LAV company, etc.) and compute the commodity use planning factor in terms of pounds or gallons per Marine per day. These factors are then applied to the SBME table of organization for each of the three reinforced infantry battalions and their direct support personnel. This methodology produces smaller daily requirements for fuel and ammo than most of the numbers in the literature, but are perhaps consistent with the changes being made by the Marine Corps to sea base smaller, lighter maneuver forces.

\section{The Maneuver Force}

The maneuver force modeled is the $2015 \mathrm{MPF}(\mathrm{F})$ Marine Expeditionary Brigade (MEB) [1]. While the 2015 MEB is always 14,484 troops, whether it is an amphibious MEB or an $\operatorname{MPF}(\mathrm{F}) \mathrm{MEB}$, the MPF(F) MEB consists of a Seabased Echelon of 8,062 troops plus a Naval Support Element and only the Seabased Echelon is flowed to the sea base. The Seabased Echelon consists of the Seabased Maneuver Element (SBME) and the Seabased Support Element (SBSE). Most of the SBSE and all of the NSE stays aboard the MPF(F). The Assault Element/Direct Support CSS that is deployed ashore is composed of a reinforced battalion-sized maneuver element configured for vertical lift and two reinforced battalion-sized maneuver elements configured for surface lift. The battalion to be vertically deployed consists of 1,164 troops whose major equipment includes $28 \mathrm{LAVs}, 8 \mathrm{EFSS}$, and $143 \mathrm{HMMWV}$ variants. The battalions to be surface deployed each consist of 1,840 troops with 53 EFVs, 14 M1A1 tanks, 28 LAVs, 
6 LW155 artillery pieces, 6 HIMARSs, 157 HMMWV variants, 45 MTVRs, and 18 LVSs. The unit equipment and most of the supporting combat stores are prepositioned on the $\operatorname{MPF}(\mathrm{F})$ ships.

\section{The Maritime Preposition Force (Future)}

The requirements of $\operatorname{MPF}(\mathrm{F})$ have been examined in detail and a number of alternative designs were presented in the $\operatorname{MPF}(\mathrm{F})$ Analysis of Alternatives [3]. Still, the Navy Research Advisory Committee, in its report on Sea Basing to ASN (RD\&A) on 5 August 2004, said the "MPF(F) vision is unclear, there are too many unknowns, and it is not ready to build." This is reflected by the fact that construction was delayed from 2007 to 2009 . However, in order to proceed with modeling, some assumptions about the $\mathrm{MPF}(\mathrm{F})$ are necessary.

It will be assumed that the $\operatorname{MPF}(\mathrm{F})$ squadron will consist of identical (distributed) ships. This will avoid what the Marines call a "single point of failure." The number of such ships in the squadron need not be explicitly specified. Instead, the user specified input parameter is the number of aircraft spots in the squadron and the number of surface connector loading points in the squadron. Ship speed is also a user specified input parameter. It is assumed that the squadron of $\mathrm{MPF}(\mathrm{F})$ ships can accommodate at least 8,500 troops collectively. Also implicit is that the design of the $\operatorname{MPF}(\mathrm{F})$ is such that it collectively can carry all the needed unit equipment for the MEB, 20 days' supply of all stores including fuel and ammunition, has assembly areas of sufficient size, and has selective offload capability. Further assumptions are that the $\operatorname{MPF}(\mathrm{F})$ ships will collectively have 16-20 LCACs, 48 MV-22 tiltrotor aircraft, and $20 \mathrm{CH}-53 \mathrm{X}$ heavy-lift helicopters [3]. The LCACs will be prepositioned on the MPF(F) ships, but the aircraft will have to deploy to the $\mathrm{MPF}(\mathrm{F})$. The $\mathrm{MV}-22 \mathrm{~s}$ will self-deploy and the non-self-deploying $\mathrm{CH}-53 \mathrm{X}$ and $\mathrm{AH} / \mathrm{UH}$ helos will be transported to the sea base [3]. The LCAC is the surface connector because there is no other surface connector likely to be available in 2015. The LCAC is characterized by its speed as a function of sea state, range, and transport capabilities (vehicle and troop capacities, loading and unloading times). Connectors that might be available in 2020 or 2025 can be incorporated by changing the characteristics of the deployment connector.

The question of where the connectors (air and surface) are on C-day is critical. The aircraft are not prepositioned and must self-deploy or be transported to the sea base [3]. If HSC vessels are utilized, the assumption is that they were forward deployed with the numbered fleets and thus available in theater [2]. The LCAC is the other major connector and [3] speaks of it being organic to the $\operatorname{MPF}(\mathrm{F})$ and indeed it's cost is included in the sea base total ownership cost.

\section{Closing Forces to the Sea Base}

There are many possibilities for closing forces to the sea base. Troops (and non-self-deploying aircraft (NSDA)) from CONUS must close to the MPF(F) ships of the sea base. In closing troops and in sustainment there is the notion of an advance base 
whose availability is assured, but may be up to 2,000 $\mathrm{nm}$ from the sea base. If large, fixed-wing transport aircraft cannot land on ships at sea, troops need to be transported to the advance base as an intermediate step in closing to the sea base. Troops could be transported from CONUS to the advance base either by aircraft or by ships. Whereas aircraft cannot proceed directly to the sea base, ships from CONUS could steam either to the advance base or to the sea base. The MPF(F) ships could steam directly from their preposition site to the sea base or to the advance base.

If the troops are transported from CONUS to the advance base by aircraft and the $\operatorname{MPF}(\mathrm{F})$ ships do not call at the advance base to onload them, a connector vessel must transport them from the advance base to the $\mathrm{MPF}(\mathrm{F})$ ships. If the troops are transported from CONUS to the advance base in rapid strategic lift ships (RSLS) and the MPF(F) do not call at the advance base, a connector is again needed to take the troops from the advance base to the $\mathrm{MPF}(\mathrm{F})$ ships. Alternatively, the RSLS could transport the troops from CONUS to the MPF(F). The troops could transfer to the $\operatorname{MPF}(\mathrm{F})$ ships either at the sea base or while the MPF(F) and connector or RSLS are en route to the sea base, if this is feasible. An option that eliminates the need to transfer troops between ships in open ocean, is to have the $\operatorname{MPF}(\mathrm{F})$ ships call at the advance base and onload troops at the pier. A convenient scenario may be that the advance base is the port where the $\operatorname{MPF}(\mathrm{F})$ ships are prepositioned.

NSDA must also be considered. The NSDA will include the heavy-lift helicopters $(\mathrm{CH}-53 \mathrm{X})$ and the tactical helicopters (AH-1 and UH-1). If carried from CONUS to the advance base in cargo aircraft (C-17), they must be partially disassembled prior to loading and then reassembled and flight checks performed prior to being operational. These things add considerable time to the closing process. If the NSDA can be flown to RSLS and transported in folded, but not disassembled condition, considerable delay can be avoided.

Clearly there are a variety of ways of closing troops and NSDA to the sea base. Sea Basing capability requires new preposition ships and possibly RSLSs and/or high-speed connectors. Analysis is required to choose between the various alternatives and the platforms that enable them. One measure of performance of any alternative is the time it takes to close troops to the sea base or the time it takes to close to the sea base and deploy to objectives ashore. Closure time will also depend on whether a warning order was issued prior to the deployment order. One could assume that the decision to establish a sea base to support expeditionary maneuver warfare did not come as a surprise and that an alert order and warning order were issued sufficiently early to allow the troops, aircraft, and ships to be ready to go on receipt of the deployment order without delay. If this is not the case, then a preparation time prior to movement may be specified. JELO allows the user to specify preparation times.

\section{Transfer from Connector to $\operatorname{MPF}(\mathrm{F})$}

Two of the possibilities for closing forces to the sea base require the transfer of the troops transported by the HSC or the RSLS to the MPF(F) ships at sea. As already noted, we 
are uninformed as to the nature of this transfer operation. While it may be possible to accomplish this troop transfer with the use of a causeway, such an option would surely be sea state limited. Using a span wire and six-person transfer box yields a transfer rate of perhaps 90 troops per hour and is also likely sea state dependent [9]. A safer and more robust means of transfer is to airlift the troops from the HSC or RSLS to the MPF(F) using available aircraft. If the MV-22 aircraft self-deploy to the $\operatorname{MPF}(\mathrm{F})$ ships, they should be able to arrive within five days no matter the location of the sea base [7].

In order to see how long this transfer takes, something has to be assumed about the HSC or RSLS. The HSC is assumed to be something other than the HSV catamaran. What is known is that the HSC is a ship capable of at least $40 \mathrm{kts}$ speed, configured to embark battalion-sized units, and potentially capable of operating tiltrotor aircraft [2]. The assumption in the example transfer below is that there are eight HSC vessels, each carrying 1,100 troops and having one aircraft operating spot. Alternatively, there might be four RSLSs, each carrying 2,200 Marines and having two aircraft operating spots.

JELO's movement model, explained in Section 8, is used to estimate how long such a transfer will take. This is a simple operation with a single connector (MV-22), a single commodity to be transferred (troops), and a very short distance. Planning factors for MV-22 troop transfers are taken from [4]. Assuming 24 troops per trip, loading time is taken to be ten minutes, lift and clear is two minutes, approach and land is two minutes, and offload of troops is five minutes. If the distance between the sending and receiving ships is small, say 1,000 yards, flight time is negligible and assumed included in the clear and approach operations. The movement model result is that it will take 9.95 hours to complete troop transfer to the $\mathrm{MPF}(\mathrm{F})$ using $14 \mathrm{MV}-22 \mathrm{~s}$, which cumulatively use 139.3 hours of the 384 available assuming an eight-hour crew-day. Also presented is the time for $\mathrm{CH} 53 \mathrm{~s}$ to accomplish the same task -8.79 hours with 13 helos, should they have reached the $\operatorname{MPF}(\mathrm{F})$ in time to perform this task.

\begin{tabular}{|c|c|c|c|c|c|c|c|c|}
\hline \multicolumn{9}{|c|}{ HSC MPFF PAX transfer at 1 NM / 48 MV22 or 20 CH53 / 8 Loading Spots } \\
\hline Loads & Start Total & Start Time & End Time & End Total & Spot \#'s & Connector & $\begin{array}{c}\text { \# of } \\
\text { connectors }\end{array}$ & $\begin{array}{l}\text { Crew Day } \\
\text { Used }\end{array}$ \\
\hline PAX & 8062 & 0 & 995 & $\sum$ & 123.8 & MV & 14 & 1393 \\
\hline PAX & 8062 & 0 & 8.79 & 0 & $1,2,3, \ldots 8$ & $\mathrm{CH}$ & 13 & 114.27 \\
\hline Time & PAX - MV & $\mathrm{PAX}-\mathrm{CH}$ & & & & & & \\
\hline 0 & 0 & 0 & & & & & & \\
\hline 8.79 & 7003 & 8062 & & & & & & \\
\hline 9.95 & 8062 & 8062 & & & & & & \\
\hline Crew Day Used & \# units & hrs/unit & Total hrs & Used & & & & \\
\hline $\mathrm{CH}$ & 20 & 8 & 160 & 114.27 & & & & \\
\hline MV & 48 & 8 & 384 & 139.3 & & & & \\
\hline LCAC & 20 & 12 & 240 & $\overline{0}$ & & & & \\
\hline
\end{tabular}




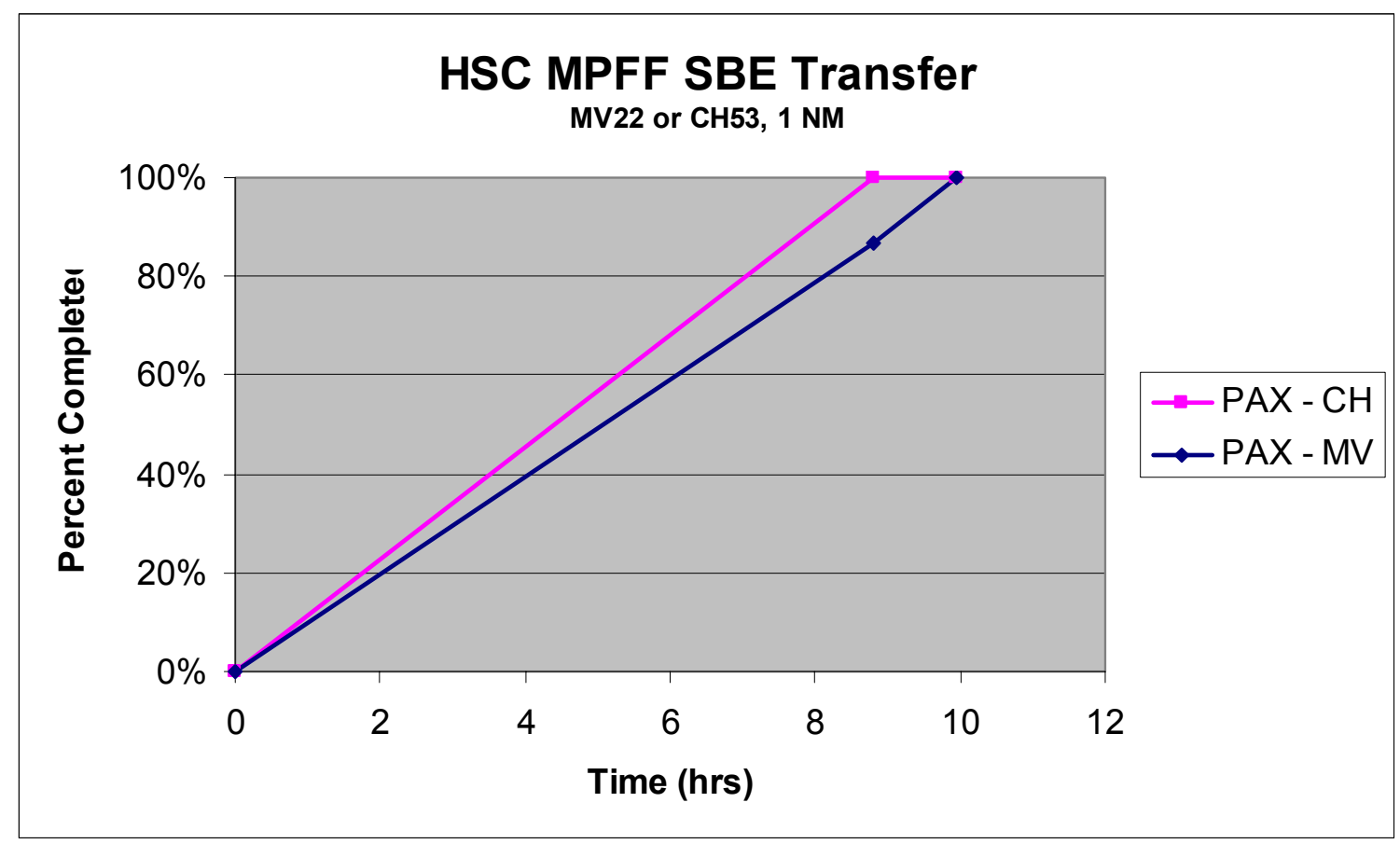

\section{Assembly}

Assembly is the selective breakout of the unit equipment and combat stores by the troops who will utilize both once deployed ashore. The operational status of the unit equipment (vehicles, weapons) must be determined and the equipment and stores on the $\operatorname{MPF}(\mathrm{F})$ staged for the deployment operation. The length of time needed depends on the status of the equipment and the physical characteristics of the MPF(F) ships. Assembly is not modeled. The goal for assembly is 24-48 hours [6], and the model has this as an input parameter.

\section{Deploying the Maneuver Elements to Objectives Ashore}

The seabased maneuver element of the MEB consists of three reinforced infantry battalions and associated direct support. As already noted, there is a lighter battalion that is to be deployed vertically (airlifted from the $\operatorname{MPF}(\mathrm{F})$ to the shore objective area), and two heavier mechanized battalions that are to be deployed by surface means; implicitly the beach is the initial objective area. Vertical deployment will utilize MV-22 and CH-53X aircraft. Surface deployment will utilize the EFV and LCAC craft. Both vertical and surface deployments involving moving troops, equipment, and two days of supply (DOS) of combat stores from the MPF(F) ships to objective areas ashore. The draft Sea Basing Concept of Operations [6] says there must be a minimum of supplies held ashore, no more than 2-4 days of supply. The daily resupply requirement is one day of supply, no matter the days of supply maintained ashore, but the safety level increases with the number of days of supply maintained ashore. 


\subsection{Deployment of the Vertical Battalion}

The battalion to be vertically deployed consists of 1,164 troops whose major equipment includes 28 LAVs, eight EFSSs, and 143 HMMWVs variants [10]. The troops will be transported by MV-22s and MV-22s will also be involved in transporting the lighter vehicles. The heavier systems will be lifted by the $\mathrm{CH}-53 \mathrm{X}$ helicopter. The assumption is that $48 \mathrm{MV}-22 \mathrm{~s}$ and $20 \mathrm{CH}-53 \mathrm{Xs}$ are available in the $\mathrm{MPF}(\mathrm{F})$ squadron [3], [10]. The length of time the vertical deployment requires will depend on the numbers to be lifted, the number of aircraft available, and the number of trips each aircraft can make to the required distance. The distance to the landing zone for the Vertical battalion is specified as $110 \mathrm{~nm}[10]$. In the movement model, the distance from the $\operatorname{MPF}(\mathrm{F})$ to the landing zone of the Vertical battalion is an input parameter.

The term "trips" is used instead of sortie. For fixed wing aircraft, a sortie begins with a mission briefing, then engine start, flight, landing, engine shutdown, and debrief. This term is less useful for rotary wing or tiltrotor aircraft whose day's activities may consist of a briefing, engine start, load, fly out, unload, fly back, load again, fly out again, etc., with hot refueling as required. This sort of activity is best described in terms of the number of trips.

The MV-22 tiltrotor aircraft will be the most numerous aircraft on the $\operatorname{MPF}(F)$ ships. They self-deploy to the MPF(F) ships for CONUS locations and can do this in five days or less to anywhere in the world [7]. The MV-22 can transport 24 troops internally and the speed is assumed to be $240 \mathrm{kts}$. With external load (either a vehicle, a sling of cargo pallets, or fuel bladders) speed is limited to $100 \mathrm{kts}$. Speed with external load is limited by the characteristics of the load rather than the aircraft lifting it. Maximum external load weight is 10,000 pounds and may be carried a distance of $110 \mathrm{~nm}$. The other asset for vertical deployment is the $\mathrm{CH}-53 \mathrm{X}$, a program of record. The $\mathrm{CH}-53 \mathrm{X}$ is to be a new airframe $\mathrm{CH}-53 \mathrm{E}$ with upgraded engines, blades, transmission, and avionics. The CH-53X will lift 6,700 pounds more than the 53E over the same distances as the 53E [11]. Vehicles weighing more than the 10,000-pound lift capacity of the MV-22 will be flown by CH-53X aircraft. Its speed with external load is $100 \mathrm{kts}$ and its speed clean is 130 kts.

The movement model used to determine the time required to deploy the battalion calculates the productivity at each aircraft operational spot and then applies that to the number of units to be deployed [12]. This cannot be totally automated because there are two types of connectors (MV-22 and $\mathrm{CH}-53 \mathrm{X}$ ), and troops, equipment, and stores to be deployed. There is a need to have a deployment plan that specifies the pairings between cargos and aircraft and the order in which the various commodities will be deployed. The movement model noted in Section 6 and resident in the spreadsheet is used to produce battalion deployment times that depend on the deployment plan, number of connectors available, number of operational spots available, and distance to which the commodities are to be flown. The user should evaluate one or several deployment plans and import the results of the better plan into the main part of the JELO model. 
As an example of a deployment plan and use of the movement model, deployment of the Vertical battalion begins with the assignment of MV-22 aircraft to the lifting of the 1,164 troops to the landing zone $110 \mathrm{~nm}$ distant using two of the assumed four operating spots available (one spot per ship and four ships with the troops and equipment of the Vertical battalion; alternatively, the battalion on two ships and each ship has two spots). In order to avoid queuing of aircraft assets, only 12 of the available 48 are assigned. Simultaneously, on spot number 3, 16 of the $20 \mathrm{CH}-53 \mathrm{Xs}$ start lifting the battalion's 28 LAVs, 8 EFSSs, and pallets while on spot number 4, 13 other MV-22s begin lifting the battalion's 143 HMMWVs. The troops are deployed in 6.44 hours and at that time spots 1 and 2, along with spot 4 are utilized by MV-22s to move HMMWVs. The $\mathrm{CH}-53 \mathrm{Xs}$ finish lifting the $36 \mathrm{LAVs} / \mathrm{EFSSs}$ and the pallets and bladders representing two DOS of provisions, water, fuel, and ammo at 10.23 hours, after which all four spots have MV-22s moving HMMWVs. This deployment plan results in the deployment of the Vertical battalion in 12.36 hours and utilizes 342 of the 384 MV-22 crew-day hours available and 147 of the $160 \mathrm{CH}-53 \mathrm{X}$ crew-day hours available. Details of the application of the movement model to the deployment plan are presented in the spreadsheet display. Think of this estimated deployment time as "representative" only, as the actual deployment plan will surely be different in detail.

The movement model takes inputs such as the types and numbers of units to be moved, the distance, the number of spots, and the types and numbers of connectors, and computes the movement times and displays them in the following tables and graph.

Vertical Battalion at 110 NM / 48 MV22 / 20 CH53

\begin{tabular}{|l|r|r|r|r|r|r|r|r|}
\hline Loads & Start Total & Start Time & End Time & End Total & Spot \#'s & Connector & $\begin{array}{c}\text { \# of } \\
\text { connectors }\end{array}$ & $\begin{array}{c}\text { Crew Day } \\
\text { Used }\end{array}$ \\
\hline & & & & & & & & \\
\hline PAX & 1164 & 0 & 6.44 & 0 & 1,2 & $\mathrm{MV}$ & 12 & 77.28 \\
\hline LAV/EFSS/Pallets & 42 & 0 & 6.8 & 0 & 3 & $\mathrm{CH}$ & 16 & 108.8 \\
\hline HMMWV & 143 & 0 & 6.44 & 95 & 4 & $\mathrm{MV}$ & 13 & 83.72 \\
\hline Bladders & 22 & 6.8 & 10.23 & 0 & 3 & $\mathrm{CH}$ & 11 & 37.73 \\
\hline HMMWV & 95 & 6.44 & 10.23 & 28 & $1,2,4$ & $\mathrm{MV}$ & 32 & 121.28 \\
\hline HMMWV & 28 & 10.23 & $\mathbf{1 2 . 3 6}$ & 0 & $1,2,3,4$ & $\mathrm{MV}$ & & 28 \\
\hline
\end{tabular}

\begin{tabular}{|r|r|r|r|r|r|r|}
\hline Time & \multicolumn{1}{c|}{ PAX } & \multicolumn{1}{c|}{ LAV } & \multicolumn{1}{l|}{ EFSS } & \multicolumn{1}{l|}{ Pallet } & Bladder & HMMWV \\
\hline 0 & 0 & 0 & 0 & 0 & 0 & 0 \\
\hline 6.44 & 1164 & 27 & 7 & 5 & 0 & 48 \\
\hline 6.8 & 1164 & 28 & 8 & 6 & 0 & 52 \\
\hline 10.23 & 1164 & 28 & 8 & 6 & 22 & 115 \\
\hline 12.36 & 1164 & 28 & 8 & 6 & 22 & 143 \\
\hline
\end{tabular}

\begin{tabular}{|l|r|r|r|r|}
\hline Crew Day Use & \multicolumn{1}{|c|}{ \# units } & hrs/unit & Total hrs & Used \\
\hline $\mathrm{CH}$ & 20 & 8 & 160 & 146.53 \\
\hline $\mathrm{MV}$ & 48 & 8 & 384 & 341.92 \\
\hline
\end{tabular}




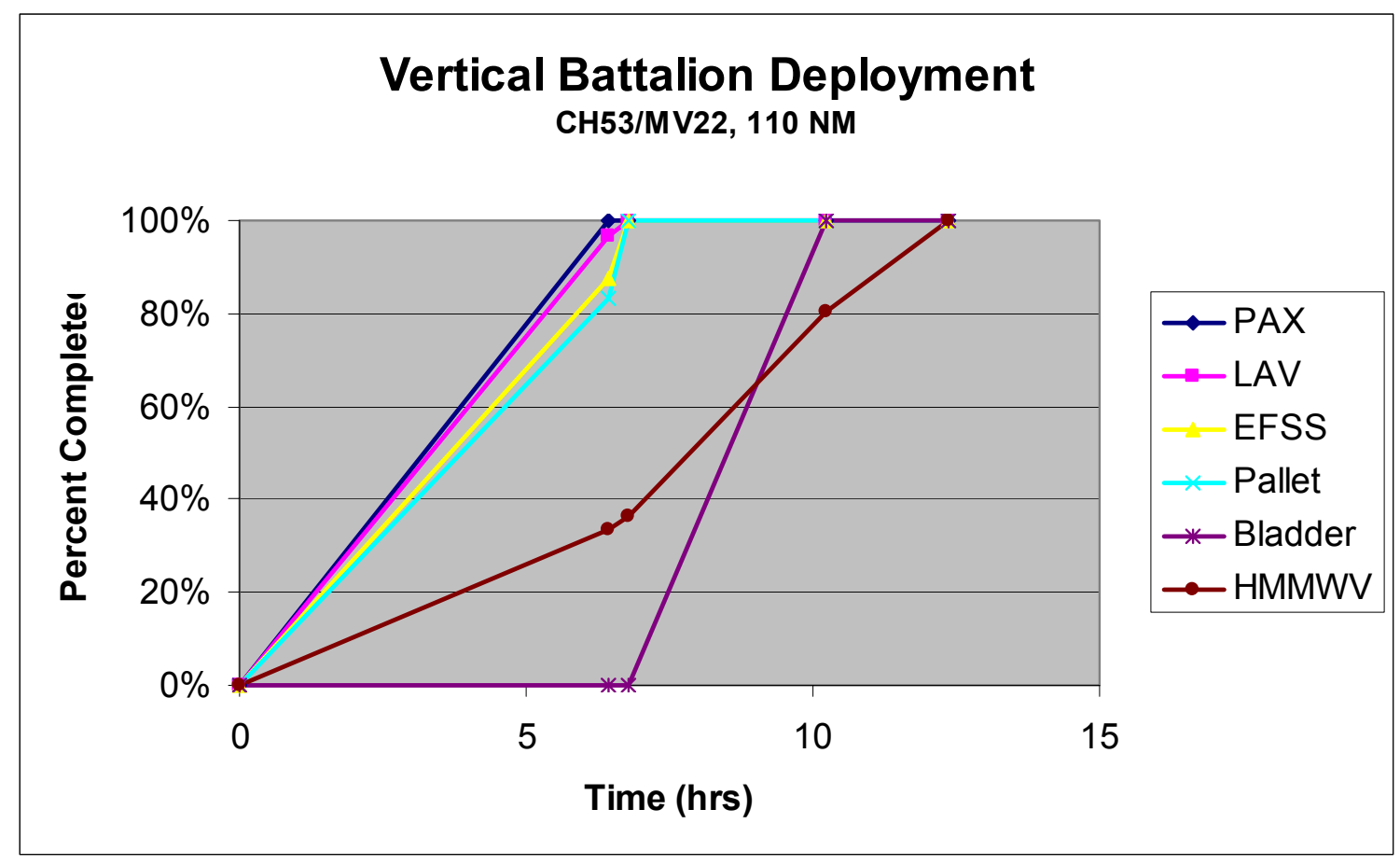

\subsection{Deployment of the Surface Battalions}

There are two mechanized battalions that are to be surface deployed from $25 \mathrm{~nm}$ at sea to the shore with the beach as their initial objective. The deployment of the first Surface battalions is to begin simultaneously with the deployment of the Vertical battalion. As the vertical deployment uses almost all of the available aircraft crew-hours, the surface deployment operation is conducted by surface connectors (LCAC) exclusively. It is assumed the MPF(F) squadron will have 16-20 LCACs available for surface deployment and resupply [3]. The report of the Defense Science Board notes that the threat from Mach 3 sea-skimming missiles argues for keeping the ships of the sea base 100 miles from the shore [13]. However, connector limitations make this distance a most difficult prospect both in deployment operations and in resupply. The developing Sea Basing CONOPS assumes that during deployment MPF(F) ships will come to within $25 \mathrm{~nm}$ of the coast in consideration of LCAC delivery times, EFV transit times and fuel consumption, and aircraft deployment of forces to objectives inland from the coast. While operating at this distance from the coast, Sea Shield provided by combatants of the CSG and ESG must defend the sea base ships.

The surface-deployed battalions each consist of 1,840 troops with 53 EFVs, 14 M1A1 tanks, 28 LAVs, 6 LW155 artillery pieces, 6 HIMARSs, 157 HMMWV variants, 45 MTVRs, and 18 LVSs [10]. The 53 EFVs self-deploy from the MPF(F) ships to the shore with 20 Marines per vehicle ( 3 crew and 17 pax). This deployement carries 1,060 of the 1,840 troops to the shore. The other 780 troops are carried by LCACs while they deploy the battalion's vehicles and stores. The vehicles/weapon systems to be deployed include HMMWVs, LAVs, M1A1 tanks, MTVRs, HIMARS, 
LVSs, and light-weight $155 \mathrm{~mm}$ howitzers. Each vehicle/weapon system has its own load and unload times, and number the LCAC can transport in a single trip, necessitating use of the transfer model separately for each.

The movement model is a circulation model used to calculate time required to deploy material and personnel considering loads, connectors, loading spots, and distance as major parameters. The model was used in connection with transferring troops from the HSC or RSLS to the $\operatorname{MPF}(\mathrm{F})$ ships in Section 6 and with the deployment of the Vertical battalion in Section 8.1 as well, but a full explanation is given here.

The JELO movement model is based on a fundamental calculation of connector cycle time as proposed by Keith McAllister in [12]. Below is a screenshot of the complete JELO movement model implemented in an Excel spreadsheet. 


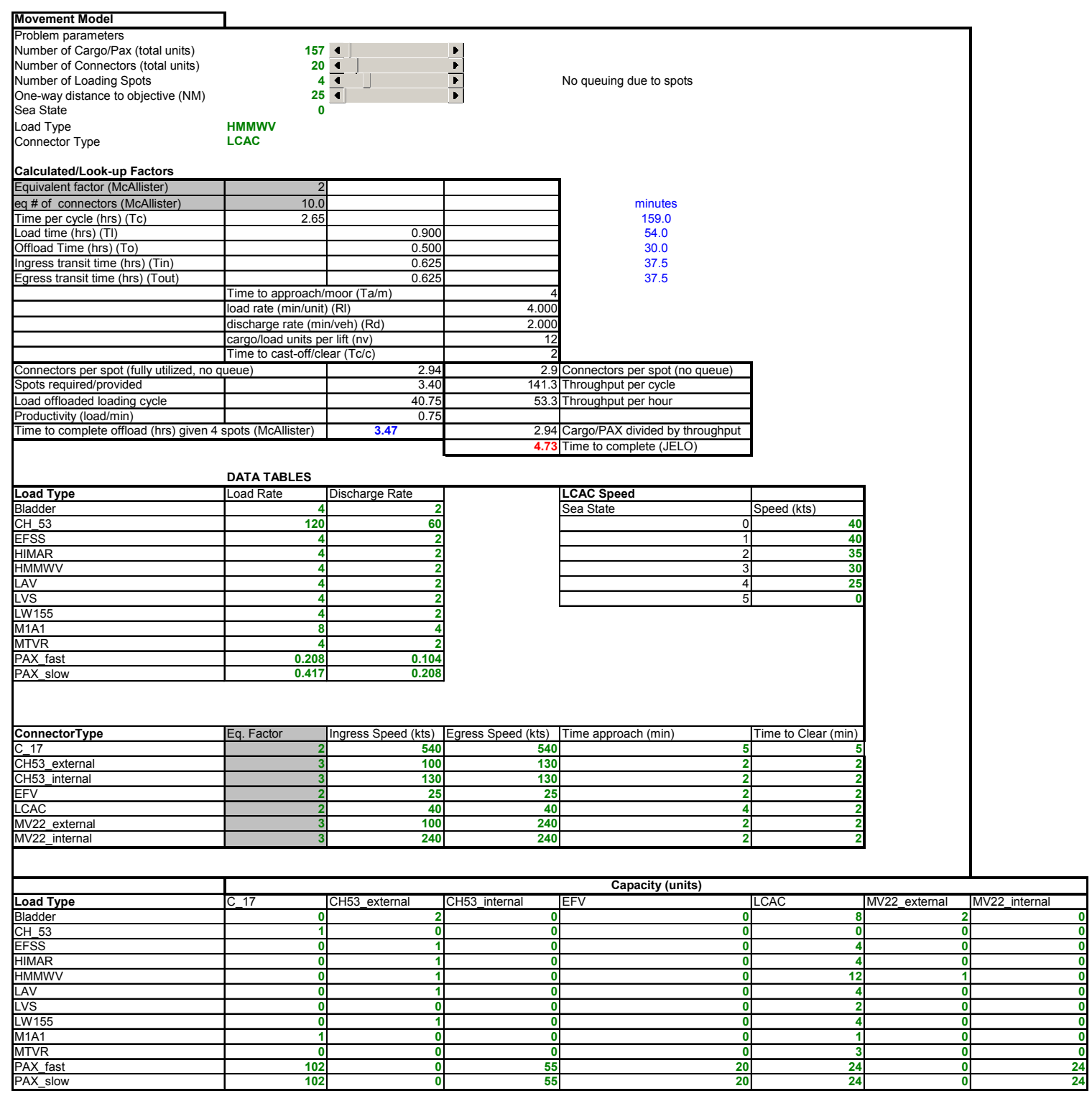

As an example of the movement model, the following computations and Excel screenshots illustrate the cycle time calculation per [12] and JELO modifications to account for surge operations and minimum achievable movement times.

Suppose the requirement is transfer of 157 HMMWVs $25 \mathrm{~nm}$ to the ashore objective using as many as 20 LCACs and 4 loading spots with Sea State 0. Parameters are entered as shown - the first four values may be entered directly into their cell, or may be manipulated by the associated scroll bar; Sea State, Load, and Connector Type are entered into their cells with data validation checks to limit the model choices. 


\begin{tabular}{|l|l|}
\hline Problem parameters & \\
\hline Number of Cargo/Pax (total units) & \\
\hline Number of Connectors (total units) & \\
\hline Number of Loading Spots & \\
\hline One-way distance to objective (NM) & \\
\hline Sea State & HMMWV \\
\hline Load Type & LCAC \\
\hline Connector Type & \\
\hline
\end{tabular}

Next, a number of parameter values are set. For example, each load type is assigned characteristics for load and discharge rates. Rates are entered as minutes per unit of load; for example, HMMWVs are loaded to various connectors at a rate of four minutes per vehicle loaded and discharged at a rate of two minutes per vehicle unloaded.

\begin{tabular}{|l|r|r|}
\hline Load Type & Load Rate & Discharge Rate \\
\hline Bladder & 4 & 2 \\
\hline CH_53 & 120 & 60 \\
\hline EFSS & 4 & 2 \\
\hline HIMAR & 4 & 2 \\
\hline HMMWV & 4 & 2 \\
\hline LAV & 4 & 2 \\
\hline LVS & 4 & 2 \\
\hline LW155 & 4 & 2 \\
\hline M1A1 & 8 & 4 \\
\hline MTVR & 4 & 2 \\
\hline PAX_fast & 0.208 & 0.104 \\
\hline PAX_slow & 0.417 & 0.208 \\
\hline
\end{tabular}

Connector capacities, with respect to load types, are contained in a feasibility matrix. In this table, load types are cross-walked to specific connector configurations. In this instance, either CH-53s or MV-22s externally carry one HMMWV per lift, or LCACs transport 12 HMMWVs per lift.

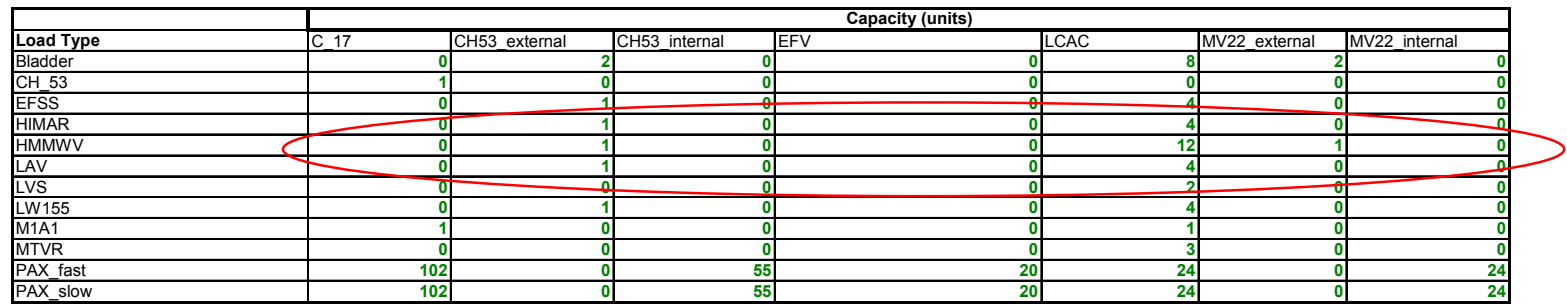

Ingress and egress speeds are assigned by connector configuration, as are approach and clearing times. In this example, an LCAC has ingress and egress speeds of $40 \mathrm{kts}$, a four-minute approach time, and a two-minute clearing time. The Sea State parameter in the JELO movement model is used to impose degraded surface craft speeds in higher Sea States. 


\begin{tabular}{|l|r|r|r|r|r|}
\hline ConnectorType & Eq. Factor & Ingress Speed (kts) & Egress Speed (kts) & Time approach (min) & Time to Clear (min) \\
\hline C_17 & 2 & 540 & 540 & 5 & \\
\hline CH53_external & 3 & 100 & 130 & 2 \\
\hline CH53_internal & 3 & 130 & 130 & 2 \\
\hline EFV & 25 & 25 & 2 \\
\hline LCAC & 2 & 2 & 40 & 2 & 2 \\
\hline MV22_external & 3 & 100 & 240 & 2 \\
\hline MV22_internal & 3 & 240 & 240 & 2 \\
\hline
\end{tabular}

\begin{tabular}{|c|c|}
\hline \multicolumn{2}{|l|}{ LCAC Speed } \\
\hline Sea State & Speed (kts) \\
\hline C & 40 \\
\hline 1 & 40 \\
\hline 2 & 35 \\
\hline 3 & 30 \\
\hline 4 & 25 \\
\hline 5 & 0 \\
\hline
\end{tabular}

Load $\left(\mathrm{T}_{\mathrm{L}}\right)$ and Offload $\left(\mathrm{T}_{\mathrm{O}}\right)$ times are a result of approach and clearing times and loading or discharge rates multiplied by the number of load units per lift. Cycle time $\left(T_{C}\right)$ is calculated as the sum of load, offload, ingress, and egress times. In the table below, we see an example of LCAC transport of HMMWVs for a distance of $25 \mathrm{~nm}$ with $\mathrm{T}_{\mathrm{C}}=2.65 \mathrm{hrs}, \mathrm{T}_{\mathrm{L}}=0.90 \mathrm{hrs}$, and $\mathrm{T}_{\mathrm{O}}=0.50 \mathrm{hrs}$.

\begin{tabular}{|c|c|c|c|c|}
\hline \multicolumn{4}{|l|}{ Calculated/Look-up Factors } & \multirow{13}{*}{$\begin{array}{c}\text { minutes } \\
159 \\
54.00 \\
30.00 \\
37.5 \\
37.5\end{array}$} \\
\hline Equivalent factor (McAllister) & 2 & & & \\
\hline eq \# of connectors (McAllister) & 10.5 & & & \\
\hline Time per cycle (hrs) (Tc) & 2.65 & & $\triangle$ & \\
\hline Load time $(\mathrm{hrs})(\mathrm{Tl})$ & & 0.900 & 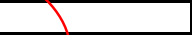 & \\
\hline Offload Time (hrs) (To) & & 0.500 & & \\
\hline Ingress transit time (hrs) (Tin) & & 0.625 & 2 & \\
\hline \multirow[t]{6}{*}{ Egress transit time (hrs) (Tout) } & & 0.625 & & \\
\hline & \multicolumn{2}{|c|}{ Time to approach/moor $(\mathrm{Ta} / \mathrm{m})$} & 4 & \\
\hline & \multicolumn{2}{|c|}{ load rate (min/unit) (RI) } & 4.000 & \\
\hline & \multicolumn{2}{|c|}{ discharge rate ( $\mathrm{min} / \mathrm{veh})(\mathrm{Rd})$} & 2.000 & \\
\hline & \multicolumn{2}{|c|}{ cargo/load units per lift (nv) } & 12 & \\
\hline & \multicolumn{2}{|c|}{ Time to cast-off/clear (Tc/c) } & 2 & \\
\hline
\end{tabular}

A series of intermediate calculations are performed to determine the maximum number of connectors per loading spot and throughput rates - which are then applied to the total requirement to calculate the time for movement completion.

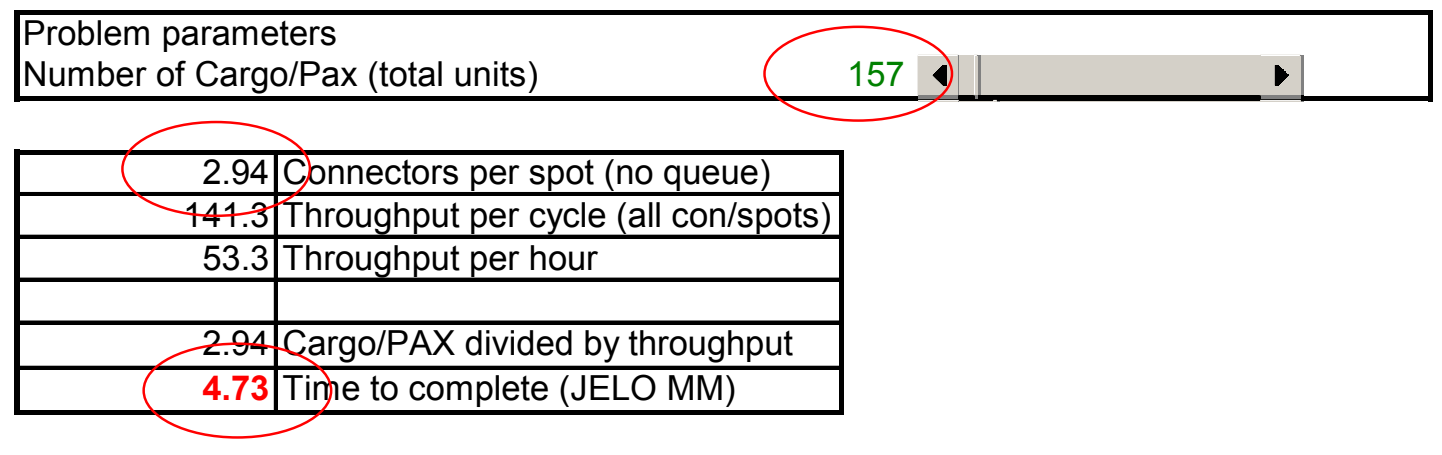


Specific calculation details are described below.

Per [12], to calculate the round-trip cycle time $\left(\mathrm{T}_{\mathrm{C}}\right)$ for LCACs:

$$
T_{C}=\text { load time }\left(T_{L}\right)+2 x \text { one-way transit time }\left(T_{T}\right)+\text { offload time }\left(T_{O}\right)
$$

We modify this calculation in the JELO movement model by allowing different ingress/egress transit speeds, so that:

$$
\mathrm{T}_{\mathrm{C}}=\mathrm{T}_{\mathrm{L}}+\text { ingress time }\left(\mathrm{T}_{\mathrm{IN}}\right)+\text { egress time }\left(\mathrm{T}_{\mathrm{OUT}}\right)+\mathrm{T}_{\mathrm{O}}
$$

Where:

$$
\mathrm{T}_{\mathrm{L}} \text { or } \mathrm{T}_{\mathrm{O}}=\mathrm{T}_{\mathrm{A} / \mathrm{M}}+\left(\mathrm{R} \mathrm{x} \mathrm{n_{V } )}+\mathrm{T}_{\mathrm{C} / \mathrm{C}}\right.
$$

With:

$$
\begin{aligned}
& \mathrm{T}_{\mathrm{A} / \mathrm{M}}=\text { time to approach and moor } \\
& \mathrm{R}=\text { load or discharge rate (min per unit of load) } \\
& \mathrm{n}_{\mathrm{V}}=\text { units of load per connector lift } \\
& \mathrm{T}_{\mathrm{C} / \mathrm{C}}=\text { time to cast-off/take-off and clear }
\end{aligned}
$$

So:

$$
\begin{aligned}
\mathrm{T}_{\mathrm{L}}= & \mathrm{T}_{\mathrm{A} / \mathrm{M}}+\left(\mathrm{R} \mathrm{x} \mathrm{n_{V } )}+\mathrm{T}_{\mathrm{C} / \mathrm{C}}\right. \\
= & 4 \mathrm{~min}+[(4 \mathrm{~min} / \text { vehicle }) \times(12 \text { vehicles })]+2 \mathrm{~min} \\
& =54 \mathrm{~min}=0.90 \mathrm{hrs} \\
\mathrm{T}_{\mathrm{O}}= & \mathrm{T}_{\mathrm{A} / \mathrm{M}}+\left(\mathrm{R} \mathrm{x} \mathrm{n} \mathrm{n}_{\mathrm{V}}\right)+\mathrm{T}_{\mathrm{C} / \mathrm{C}} \\
= & 4 \mathrm{~min}+[(2 \mathrm{~min} / \text { vehicle }) \times(12 \text { vehicles })]+2 \mathrm{~min} \\
= & 30 \mathrm{~min}=0.50 \mathrm{hrs}
\end{aligned}
$$

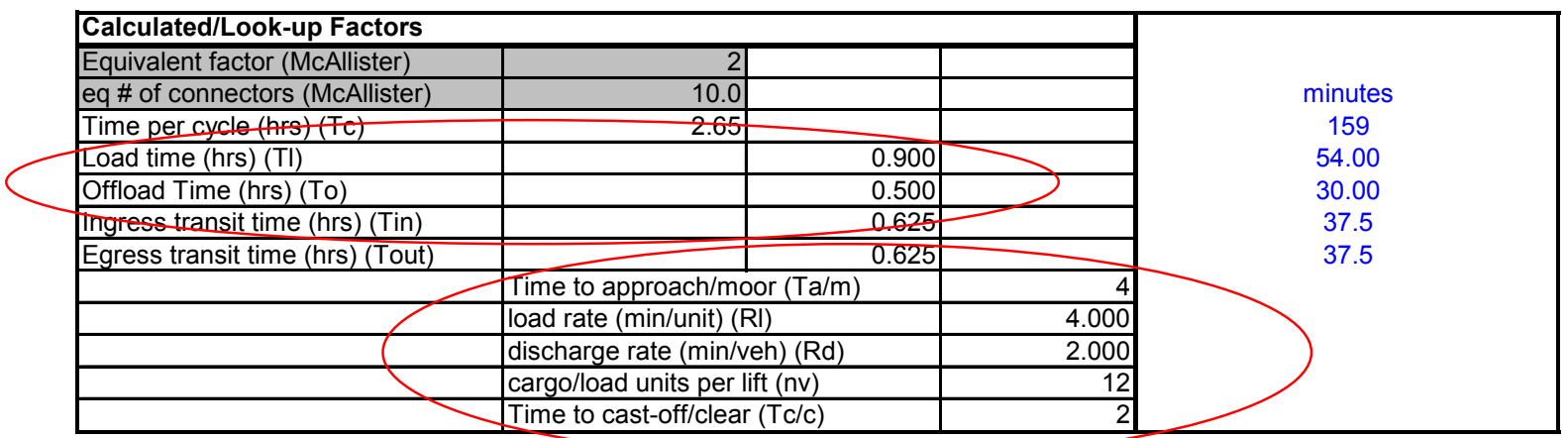


The time for the ingress trip from $25 \mathrm{~nm}$ will be:

D

$\mathrm{T}_{\mathrm{IN}}=\frac{--\cdot--\cdot-\cdot----}{\mathrm{V}}$

Where: $\quad \mathrm{D}=$ distance, $\mathrm{V}=$ velocity

So:

$$
\begin{aligned}
& 25 \mathrm{~nm} \\
& \mathrm{~T}_{\mathrm{IN}}=\text {------------- } \\
& 40 \mathrm{kts} \\
& =0.63 \mathrm{hrs} \text { or } 37.5 \mathrm{~min}
\end{aligned}
$$

\begin{tabular}{|c|c|c|c|c|}
\hline \multicolumn{4}{|l|}{ Calculated/Look-up Factors } & \multirow{13}{*}{$\begin{array}{c}\text { minutes } \\
159 \\
54.00 \\
30.00 \\
37.5 \\
37.5\end{array}$} \\
\hline Equivalent factor (McAllister) & 2 & & & \\
\hline eq\# of connectors (McAllister) & 70.0 & E & & \\
\hline Time per cycle (hrs) (Tc) & 2.65 & $\sum$ & & \\
\hline Load time (hrs) (Tl) & & 0.900 & & \\
\hline Offload Time (hrs) (To) & & 0.500 & & \\
\hline Ingress transit time (hrs) (Tin) & & 0.625 & & \\
\hline \multirow[t]{6}{*}{ Egress transit time (hrs) (Tout) } & & $\begin{array}{r}0.625 \\
\end{array}$ & & \\
\hline & \multicolumn{2}{|c|}{ Time to approach/moor (Ta/m) } & 4 & \\
\hline & \multicolumn{2}{|c|}{ load rate (min/unit) (RI) } & 4.000 & \\
\hline & \multicolumn{2}{|c|}{ discharge rate (min/veh) $(\mathrm{Rd})$} & 2.000 & \\
\hline & \multirow{2}{*}{\multicolumn{2}{|c|}{\begin{tabular}{|l|} 
cargo/load units per lift (nv) \\
Time to cast-off/clear (Tc/c)
\end{tabular}}} & 12 & \\
\hline & & & 2 & \\
\hline
\end{tabular}

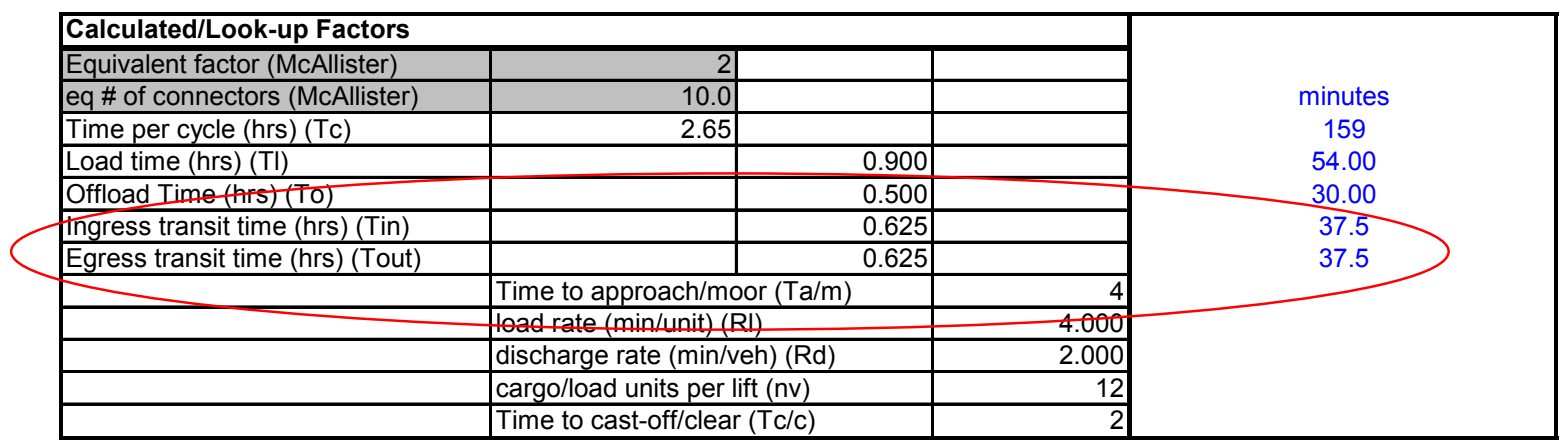

In this case, $T_{I N}=T_{\text {OUT }}$, so:

$$
\begin{aligned}
\mathrm{T}_{\mathrm{C}}=\mathrm{T}_{\mathrm{L}} & +\mathrm{T}_{\mathrm{IN}}+\mathrm{T}_{\text {OUT }}+\mathrm{T}_{\mathrm{O}} \\
& =54 \mathrm{~min}+37.5 \mathrm{~min}+37.5 \mathrm{~min}+30 \mathrm{~min} \\
& =159 \mathrm{~min} \text { or } 2.65 \mathrm{hrs}
\end{aligned}
$$


To calculate the number of connectors required to utilize fully one loading spot:

$$
\begin{aligned}
& \mathrm{N}_{\text {CONNMAX }}=\frac{\mathrm{T}_{\mathrm{C}}}{--------} \\
& =\frac{159 \mathrm{~min}}{----}
\end{aligned}
$$

$=2.94 \mathrm{LCACs}$ are required to utilize fully one loading spot

\begin{tabular}{|r|l|}
\hline 2.94 & Connectors per spot (no queue) \\
\hline 441.3 & hroughput per cycle (all con/spets) \\
\hline 53.3 & hroughput per hour \\
\hline & \\
\hline 2.94 & Cargo/PAX divided by throughput \\
\hline 4.73 & ime to complete (JELO MM) \\
\hline
\end{tabular}

Note that this value also represents the maximum number of connectors that we would plan for any loading spot to prevent intentional queuing (that is, queuing caused by an oversupply of connector assets with respect to the cycle time/loading time ratio at a particular loading spot).

Connectors per spot $\left(\mathrm{CONN}_{\mathrm{SPOT}}\right)$ is the minimum of:

1) McAllister's fully utilized spot ( $\left.\mathrm{N}_{\text {CONNMAX }}\right)$ and,

2) the ratio of number of connectors $\left(\mathrm{N}_{\mathrm{CONN}}\right)$ to number of loading spots $\left(\mathrm{N}_{\mathrm{SPOTS}}\right)$.

$$
\begin{aligned}
\operatorname{CONN}_{\mathrm{SPOT}}= & \min \left(\mathrm{N}_{\mathrm{CONNMAX}},\left(\mathrm{N}_{\mathrm{CONN}} / \mathrm{N}_{\mathrm{SPOTS}}\right)\right) \\
& =\min (2.94,20 / 4) \\
& =2.94
\end{aligned}
$$

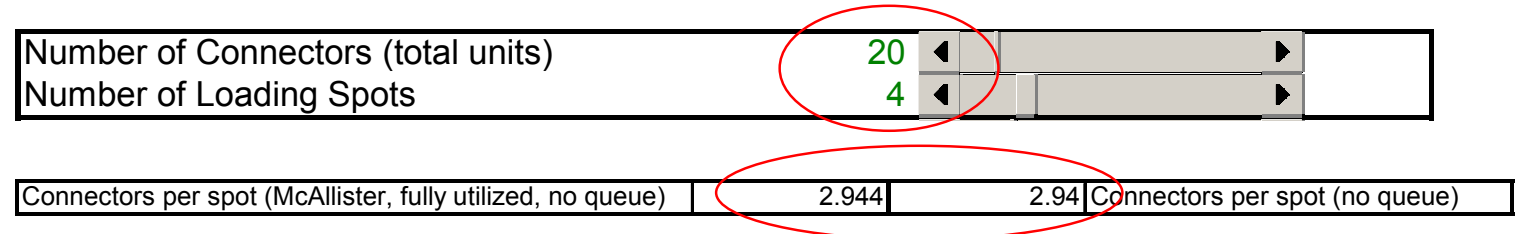

This ensures that we do not calculate a lift capability per spot that is greater than the physical assets we have assigned. McAllister's model assumes full utilization per spot, while the JELO movement model uses $\mathrm{N}_{\text {CONNMAX }}$ as an upper bound and allows partial utilization of a loading spot. 
Throughput per cycle (THRU $\left.\mathrm{CYC}_{\mathrm{CYC}}\right)$ is the product of the number of loading spots $\left(\mathrm{N}_{\mathrm{SPOTS}}\right)$, units of cargo per connector lift $\left(\mathrm{n}_{\mathrm{V}}\right)$, and Connectors per spot $\left(\mathrm{CONN}_{\mathrm{SPOT}}\right)$.

$$
\begin{aligned}
\operatorname{THRU}_{\mathrm{CYC}}=\left(\mathrm{N}_{\mathrm{SPOTS}}\right)\left(\mathrm{n}_{\mathrm{V}}\right)\left(\mathrm{CONN}_{\mathrm{SPOT}}\right) \\
=(4 \text { spots/cycle })(12 \mathrm{HMMWVs} / \mathrm{LCAC})(2.94 \mathrm{LCACs} / \text { Spot }) \\
=141.3 \text { HMMWVs per cycle }
\end{aligned}
$$

\begin{tabular}{|r|l|}
\hline 2.94 & Connectors per spot (no queue) \\
\hline 141.3 & Throughput per cycle (all con/spots) \\
\hline 53.3 & Throughput per hour \\
\hline & \\
\hline 2.94 & Cargo/PAX divided by throughput \\
\hline 4.73 & Time to complete (JELO MM) \\
\hline
\end{tabular}

Throughput per hour (THRU $U_{\mathrm{HR}}$ ) is the throughput per cycle (THRU $\mathrm{CYC}_{\mathrm{C}}$ divided by the Time per cycle $\left(\mathrm{T}_{\mathrm{C}}\right)$. In this example:

$$
\begin{aligned}
& \mathrm{THRU}_{\mathrm{HR}}=\begin{array}{c}
\mathrm{THRU}_{\mathrm{CYC}} \\
\mathrm{T}_{\mathrm{C}}
\end{array} \\
& \text { 141.3 HMMWVs/cycle } \\
& \text { = } \\
& =53.3 \text { HMMWVs per } \mathrm{hr}
\end{aligned}
$$

Finally, the time to complete the offload ( $\left.\mathrm{T}_{\mathrm{TOTAL}}\right)$ - that is, the HMMWVs arrive at the ashore objective-is the maximum of:

1) the total cargo movement requirement $\left(\mathrm{N}_{\mathrm{CARGO}}\right)$ divided by the hourly throughput $\left(\mathrm{THRU}_{\mathrm{HR}}\right)$ and

2) the sum of the running time for all loading evolutions, plus the ingress time $\left(\mathrm{T}_{\mathrm{IN}}\right)$, plus the offload time $\left(\mathrm{T}_{\mathrm{O}}\right)$.

The sum of the running time for all loading evolutions is calculated as the Time to load $\left(\mathrm{T}_{\mathrm{L}}\right)$ multiplied by the maximum whole number of concurrent loading evolutions that must take place - that is, the ceiling (or round-up to the next integer) of $\mathrm{N}_{\text {CARGO }}$ divided by the product of the minimum of the number of connectors $\left(\mathrm{N}_{\mathrm{CONN}}\right)$ or number of loading spots $\left(\mathrm{N}_{\mathrm{SPOTS}}\right)$ and number of units lifted per connector load $\left(\mathrm{n}_{\mathrm{V}}\right)$. Specifically:

$$
\begin{aligned}
& \mathrm{T}_{\text {TOTAL }}=\max \left\{\left(\mathrm{N}_{\mathrm{CARGO}} / \mathrm{THRU}_{\mathrm{HR}}\right), \sum\left[( \mathrm { T } _ { \mathrm { L } } ) \mathrm { x } \text { Ceiling } \left(\mathrm{N}_{\mathrm{CARGO}} /\left(\min \left(\mathrm{N}_{\mathrm{CONN}}, \mathrm{N}_{\mathrm{SPOTS}}\right) \mathrm{x}\right.\right.\right.\right. \\
& \left.\left.\left.\left.\mathrm{n}_{\mathrm{V}}\right)\right), \mathrm{T}_{\mathrm{IN}}, \mathrm{T}_{\mathrm{O}}\right]\right\}
\end{aligned}
$$




$$
\begin{aligned}
& =\max \left\{(157 / 53.3), \sum[(0.9) \times \text { Ceiling }(157 /(\min (20,4) \times 12)), 0.5,0.625]\right\} \\
& =\max (2.95,4.73)=4.73 \mathrm{hrs} \text { to complete the HMMWV offload }
\end{aligned}
$$

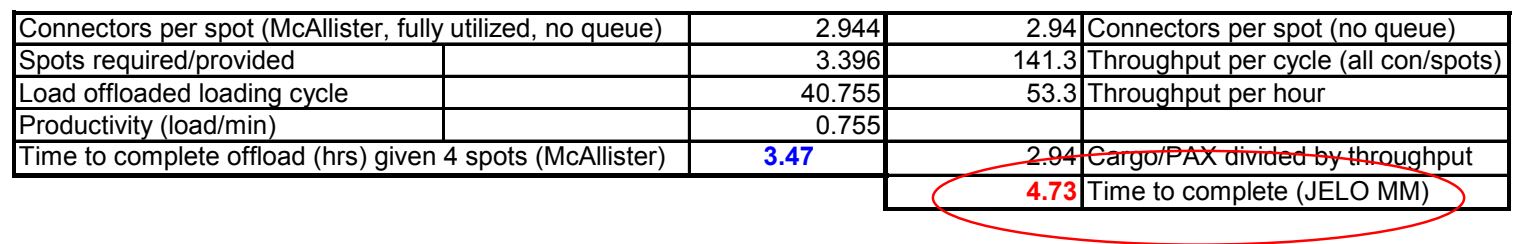

It should be noted that the same result can be accomplished with far fewer assets - that is, a 4.73-hour completion with fewer than 20 LCACs. Since we had calculated a maximum of 2.94 connectors per spot to avoid queuing, and we currently employ five LCACs per spot (20 LCACs divided by four spots), we should be able to decrease the total number of LCACs and achieve the same completion time. This is the case, as pictured below, where 12 LCACs are using four loading spots.

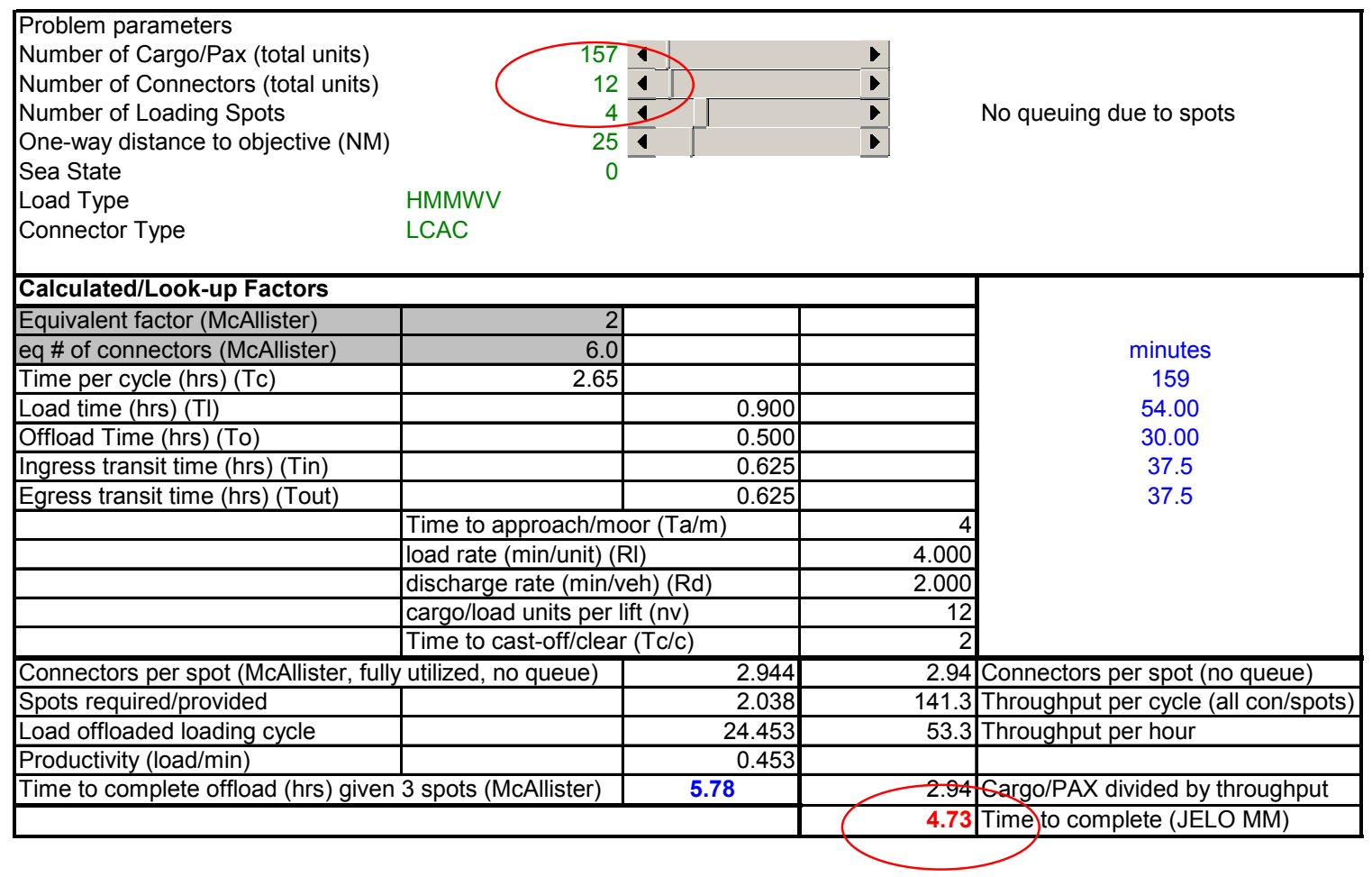

And, in fact, the number of LCACs can be decreased to as few as eight, and the 4.73-hour completion time is achieved. 


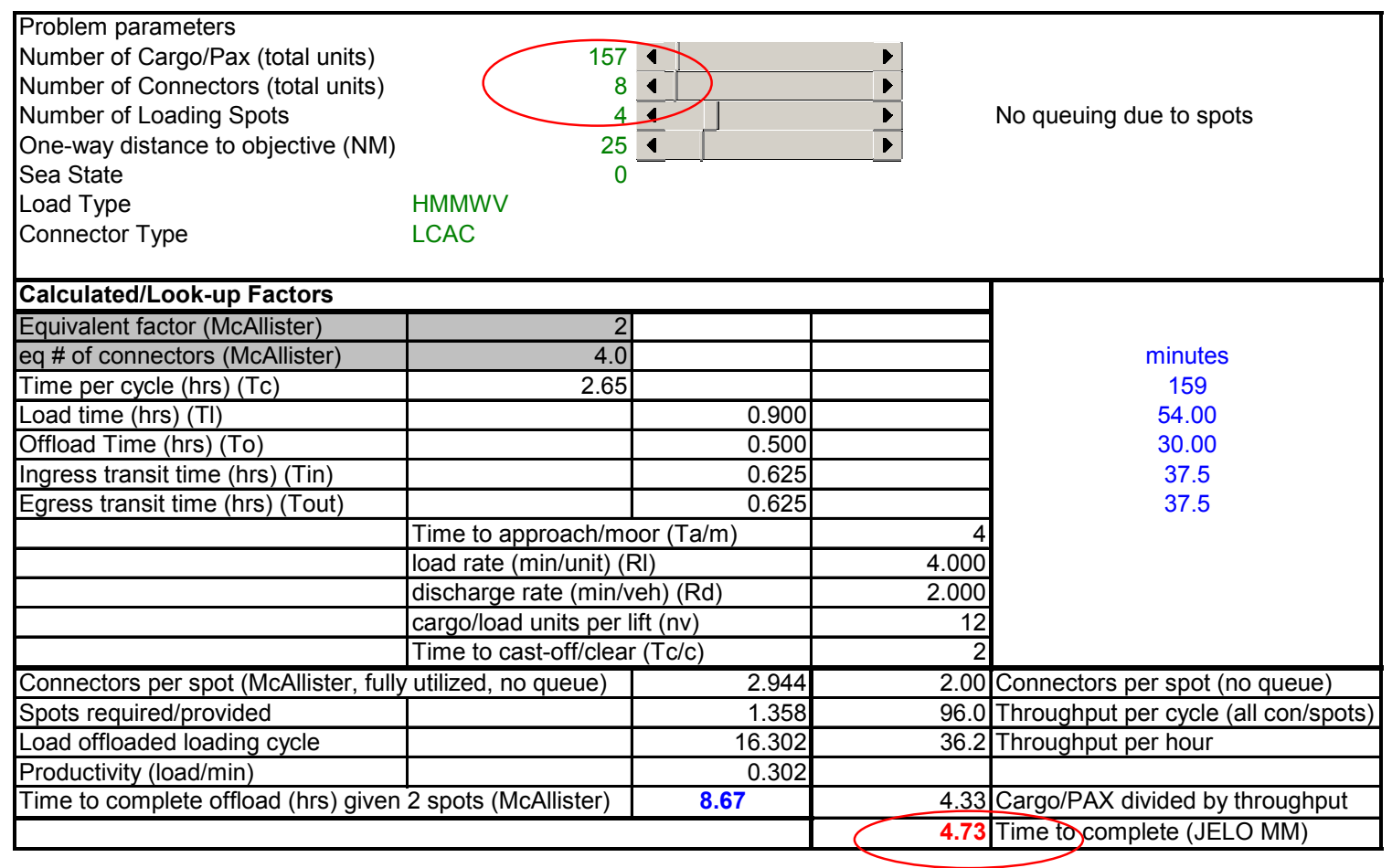

This example detailed the calculations necessary for a single Load and Connector Type. There is a governing requirement to have a deployment plan that specifies the pairings between cargos and connectors and the order in which the various commodities will be deployed. The plan presented makes trade-offs among the connector assets and load types to achieve an overall timeline that is less than a simple serial deployment time, which sequentially focuses on individual load types. Prudent tactical employment likely argues against offloading load types serially, however, these tactical considerations have not been fully explored, and the calculations presented in this report should be considered reasonable surrogates for the detailed deployment plan that would be executed.

As an example of a full deployment plan using the movement model, envision deployment of a Surface battalion (see table below). Deployment begins with the assignment of 53 EFVs to transporting 1,060 troops to a landing zone $25 \mathrm{~nm}$ distant using all four of the assumed loading spots available (one spot per ship and four ships with the troops and equipment of the Surface battalion; alternatively, the battalion on 2 ships and each ship has two spots). There is no circulation of these EFV assets, so the end time of 1.75 hours reflects queuing for departure from the Sea Base. Once the EFVs have cleared the loading spots, deployment of the other load types can begin. In order to avoid queuing of LCACs, only 15 of the available 20 are initially assigned. Simultaneously, on spot numbers 1 and 2, ten of the 20 LCACs start lifting the battalion's 14 M1A1s, while on spot numbers 3 and 4, five of the 20 LCACs start lifting the battalion's 157 HMMWVs. 


\begin{tabular}{|c|c|c|c|c|c|c|c|c|}
\hline \multicolumn{9}{|c|}{ Surface Battalion at 25 NM / 20 LCAC / 4 Loading Spots } \\
\hline Loads & Start Total & Start Time & End Time & End Total & Spot \#'s & Connector & $\begin{array}{c}\text { \# of } \\
\text { connectors }\end{array}$ & $\begin{array}{c}\text { Crew Day } \\
\text { Used }\end{array}$ \\
\hline PAX & 1840 & 0 & 1.75 & 780 & $1,2,3,4$ & $\overline{E F V}$ & 53 & $\mathrm{n} / \mathrm{a}$ \\
\hline M1A1 & 14 & 1.75 & 4.18 & 0 & 1,2 & LCAC & 10 & 24.3 \\
\hline LAV & 28 & $\overline{4.18}$ & 7.61 & 0 & 1 & LCAC & 4 & 13.72 \\
\hline LW155 & 6 & 4.18 & 5.77 & 0 & 2 & LCAC & 2 & 3.18 \\
\hline HIMARS & 6 & 577 & 7.36 & 0 & 2 & LCAC & 2 & 3.18 \\
\hline HMMWV & 157 & 1.75 & 9.18 & 0 & 3,4 & LCAC & 5 & 37.15 \\
\hline MTVR & 45 & 7.61 & 10.89 & 0 & $T, 2$ & LCAC & 9 & 29.52 \\
\hline LVS & 18 & 9.18 & 11.14 & 0 & 3,4 & LCAC & 8 & 15.68 \\
\hline Time & $\overline{P A X}$ & M1A1 & LAV & LW155 & HIMARS & HMMWV & MTVR & LVS \\
\hline 0 & 0 & 0 & 0 & 0 & 0 & 0 & 0 & 0 \\
\hline 1.75 & 1060 & 0 & 0 & 0 & 0 & 0 & 0 & 0 \\
\hline 4.18 & 1261 & 14 & 0 & 0 & 0 & 51 & 0 & 0 \\
\hline 5.77 & 1392 & 14 & 12 & 6 & 0 & 84 & 0 & 0 \\
\hline 7.36 & 1523 & 14 & 24 & 6 & 6 & 117 & 0 & 0 \\
\hline 7.61 & 1543 & 14 & 28 & 6 & 6 & 122 & 0 & 0 \\
\hline 9.18 & 1673 & 14 & 28 & 6 & 6 & 157 & 21 & 0 \\
\hline 10.89 & 1814 & 14 & 28 & 6 & 6 & 157 & 45 & 15 \\
\hline 11.14 & 1840 & 14 & 28 & 6 & 6 & 157 & 45 & 18 \\
\hline Crew Day Used & \# units & hrs/unit & Total hrs & Used & & & & \\
\hline $\mathrm{CH}$ & 20 & 8 & 160 & 0 & & & & \\
\hline MV & 48 & 8 & 384 & 0 & & & & \\
\hline LCAC & 20 & 12 & 240 & 126.73 & & & & \\
\hline
\end{tabular}

Note: In the movement model detailed previously, we found that the minimum time for deployment of 157 HMMWVs was accomplished using four spots with as few as eight LCACs. We're now proposing use of only two loading spots, and the minimum time for the HMMWV deployment is achieved with only five LCACs. Thus, HMMWV deployment time is 7.43 hours (below) and reflected in the deployment plan (above) as the difference between 1.75 and 9.18 hours. 


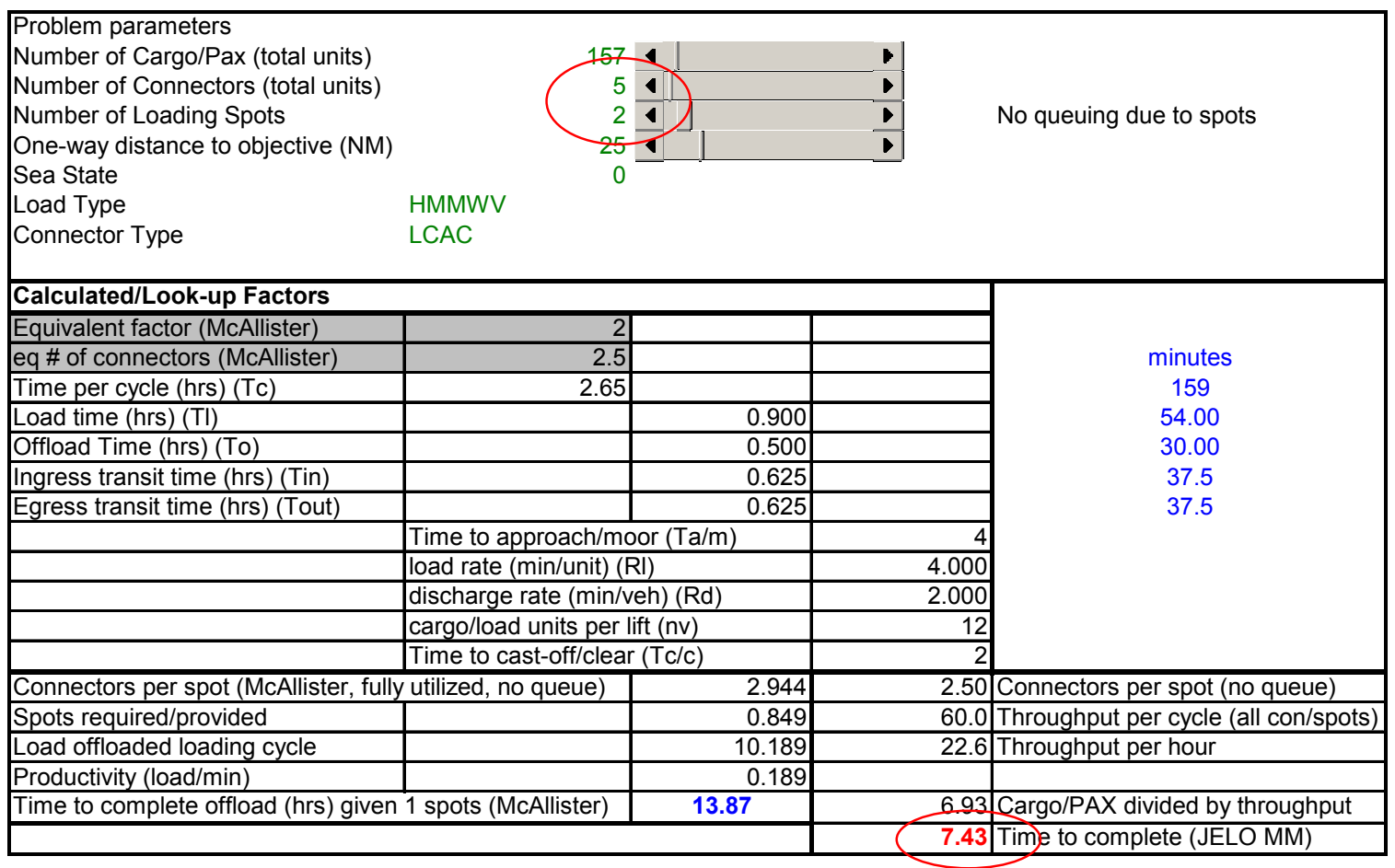

M1A1 deployment is complete at 4.18 hours, so LAV and LW155 deployments begin on loading spots 1 and 2 using four and two LCACs, respectively. HIMARS deployment begins on loading spot 2 at 5.77 hours. MTVR deployment begins at both spots 1 and 2 at 7.61 hours. HMMWV deployment is complete at 9.18 hours, so LVS deployment can begin on loading spots 3 and 4 . The two DOS of combat stores are carried in tactically loaded vehicles as they are deployed from the $\operatorname{MPF}(\mathrm{F})$. This deployment plan results in the deployment of a Surface battalion in 11.14 hours and utilizes nearly 127 of the 240 LCAC crew-day hours available. 


\begin{tabular}{|c|c|c|c|c|c|c|c|c|}
\hline \multicolumn{9}{|c|}{ Surface Battalion at 25 NM / 20 LCAC / 4 Loading Spots } \\
\hline Loads & Start Total & Start Time & End Time & End Total & Spot \#'s & Connector & $\begin{array}{c}\text { \# of } \\
\text { connectors }\end{array}$ & $\begin{array}{c}\text { Crew Day } \\
\text { Used }\end{array}$ \\
\hline PAX & 1840 & 0 & 1.75 & 780 & $1,2,3,4$ & EFV & 53 & $\mathrm{n} / \mathrm{a}$ \\
\hline M1A1 & 14 & 1.75 & 4.18 & 0 & 1,2 & LCAC & 10 & 24.3 \\
\hline LAV & 28 & 4.18 & 7.61 & 0 & 1 & LCAC & 4 & 13.72 \\
\hline LW155 & 6 & 4.18 & 5.77 & 0 & 2 & LCAC & 2 & 3.18 \\
\hline HIMARS & 6 & 5.77 & 7.36 & 0 & 2 & LCAC & 2 & 3.18 \\
\hline HMMWV & 157 & 1.75 & 9.18 & 0 & 3,4 & LCAC & 5 & 37.15 \\
\hline \begin{tabular}{|l|} 
MTVR \\
\end{tabular} & 45 & 7.61 & 10.89 & 0 & 1,2 & LCAC & 9 & 29.52 \\
\hline LVS & 18 & 9.18 & 11.14 & 0 & 3,4 & LCAC & 8 & 15.68 \\
\hline Time & PAX & M1A1 & LAV & LW155 & HIMARS & HMMWV & MTVR & LVS \\
\hline 0 & 0 & 0 & 0 & 0 & 0 & 0 & 0 & 0 \\
\hline 1.75 & 1060 & 0 & 0 & 0 & 0 & 0 & 0 & 0 \\
\hline 4.18 & 1261 & 14 & 0 & 0 & 0 & 51 & 0 & 0 \\
\hline 5.77 & 1392 & 14 & 12 & 6 & 0 & 84 & 0 & 0 \\
\hline 7.36 & 1523 & 14 & 24 & 6 & 6 & 117 & 0 & 0 \\
\hline 7.61 & 1543 & 14 & 28 & 6 & 6 & 122 & 0 & 0 \\
\hline 9.18 & 1673 & 14 & 28 & 6 & 6 & 157 & 21 & 0 \\
\hline 10.89 & 1814 & 14 & 28 & 6 & 6 & 157 & 45 & 15 \\
\hline 11.14 & 1840 & 14 & 28 & 6 & 6 & 157 & 45 & 18 \\
\hline Crew Day Used & \# units & hrs/unit & Total hrs & Used & & & & \\
\hline $\mathrm{CH}$ & 20 & 8 & 160 & 0 & & & & \\
\hline MV & 48 & 8 & 384 & $=0$ & & & & \\
\hline LCAC & 20 & 12 & 240 & 126.73 & & & & \\
\hline
\end{tabular}

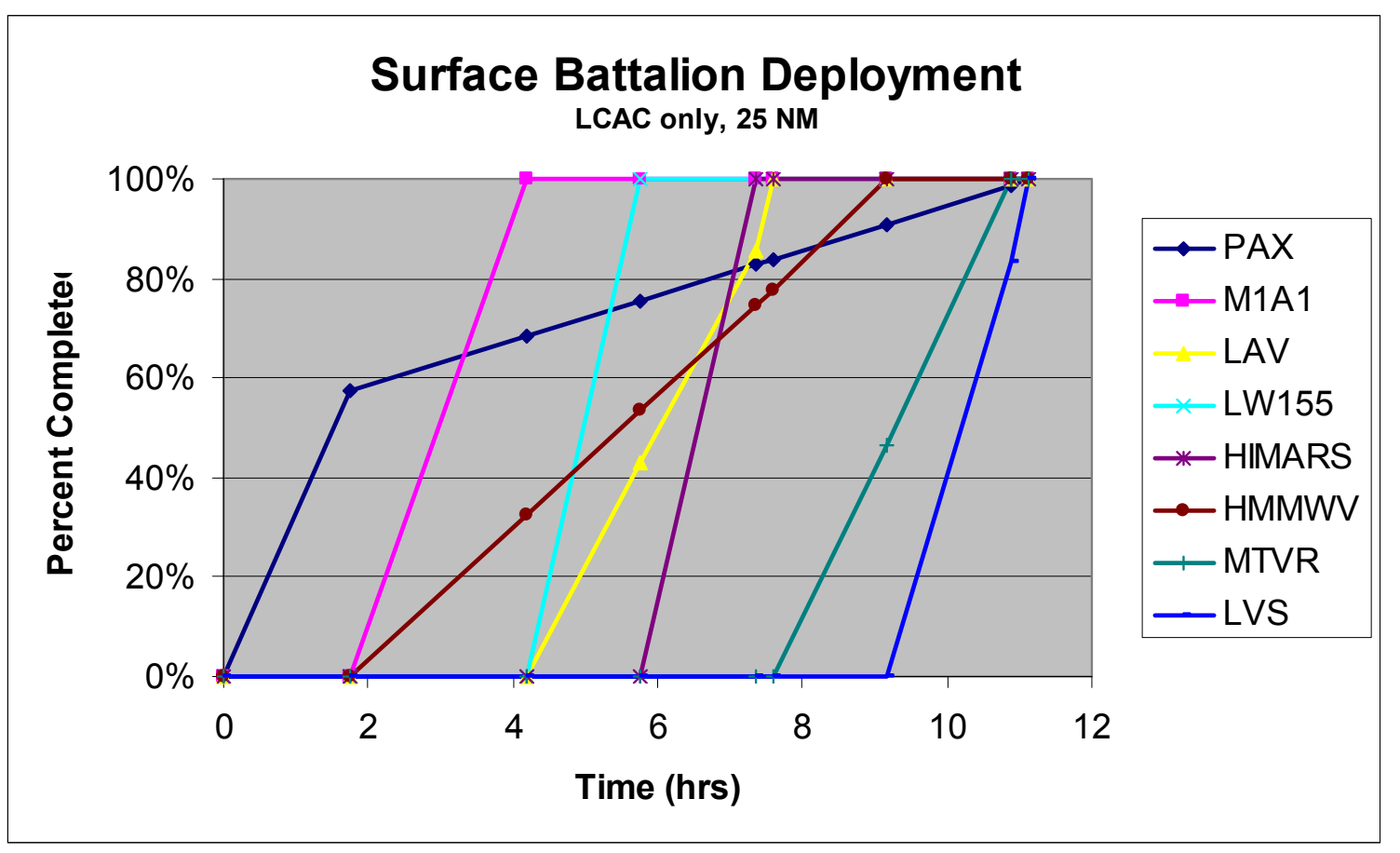


Decisions regarding how many loading spots and connectors to assign to each load type were made by considering the total numbers of loading spots and connectors available, the impact on crew-day used by the connectors, and the desirability for balanced arrival of load types to the objective. The table below details some of the trade-offs with regard to the Surface battalion movement. Highlighted rows are the selections made for the example detailed above.

\begin{tabular}{|l|r|r|r|r|r|}
\hline \multicolumn{6}{|c|}{ Choices considered for number of LCACs and Spots per load } \\
\hline Loads & Total req & LCACs & Spots & Time & Cr Day Use \\
\hline M1A1 & 14 & 8 & 1 & 4.06 & 32.48 \\
\hline & 14 & 10 & 2 & 2.43 & 24.3 \\
\hline & 14 & 12 & 3 & 1.96 & 23.52 \\
\hline LAV & 28 & 4 & 1 & 3.43 & 13.72 \\
\hline & 28 & 6 & 2 & 2.33 & 13.98 \\
\hline & 28 & 7 & 3 & 1.96 & 13.72 \\
\hline LW155 & 6 & 2 & 1 & 1.59 & 3.18 \\
\hline & 6 & 3 & 2 & 1.23 & 3.69 \\
\hline HIMARS & 6 & 2 & 1 & 1.59 & 3.18 \\
\hline & 6 & 3 & 2 & 1.23 & 3.69 \\
\hline HMMWV & 157 & 3 & 1 & 13.73 & 41.19 \\
\hline & 157 & 5 & 2 & 7.43 & 37.15 \\
\hline & 157 & 7 & 3 & 5.63 & 39.41 \\
\hline MTVR & 45 & 6 & 1 & 5.33 & 31.98 \\
\hline & 45 & 9 & 2 & 3.28 & 29.52 \\
\hline & 45 & 12 & 3 & 2.33 & 27.96 \\
\hline LVS & 18 & 6 & 1 & 2.89 & 17.34 \\
\hline & 18 & 8 & 2 & 1.96 & 15.68 \\
\hline & 18 & 10 & 3 & 1.49 & 14.9 \\
\hline
\end{tabular}

\section{Illustrative Examples}

To demonstrate the use of the JELO spreadsheet model, a few of the many possible ways of flowing expeditionary ground forces from CONUS to the sea base are explored as examples. The examples vary the methods and parameters of closing forces to the sea base. These examples use the transfer results from Section 6 if applicable, and the deployment results from Section 8.

The examples involve a few of the many possible combinations of rapid strategic lift ships, strategic airlift, and high speed connectors in accomplishing the closure of troops and non-self deploying aircraft (NSDA) to the sea base. Example 1 involves using strategic airlift and high speed connectors under various (four in total) assumptions regarding the timeliness and availability of strategic airlift aircraft. Example 2 involves using high speed rapid strategic lift ships to move troops and NSDA to the sea base without the requirement for strategic airlift or high speed connectors transiting between the advance base and the sea base. Example 3 involves either strategic airlift or rapid strategic lift ships transporting troops and NSDA to the advance base and being loaded onto the $\operatorname{MPF}(\mathrm{F})$ ships at the advance base thus eliminating the need for transfers at sea. The results of all seven examples are optimistic in the sense that they assume the issuance of a warning order sufficiently in advance of the deployment order that many of the 
"preparation" delays may be avoided. The model accepts various preparation delays if this is not the case.

\subsection{Example 1}

In this example, and three variations on it, the troops of the Seabased Echelon plus the Naval Support Element (NSE) are flown by CRAF aircraft from CONUS to the advance base. At the advance base the troops transfer in port to HSC vessels for transport to the sea base. The number of HSCs and their passenger capacities are assumed to be sufficient to carry the full Seabased Echelon without making multiple roundtrips. It is assumed that the MV-22 self deploy from CONUS to the sea base. MPF(F) proceed direct to the sea base (see Figure 5).

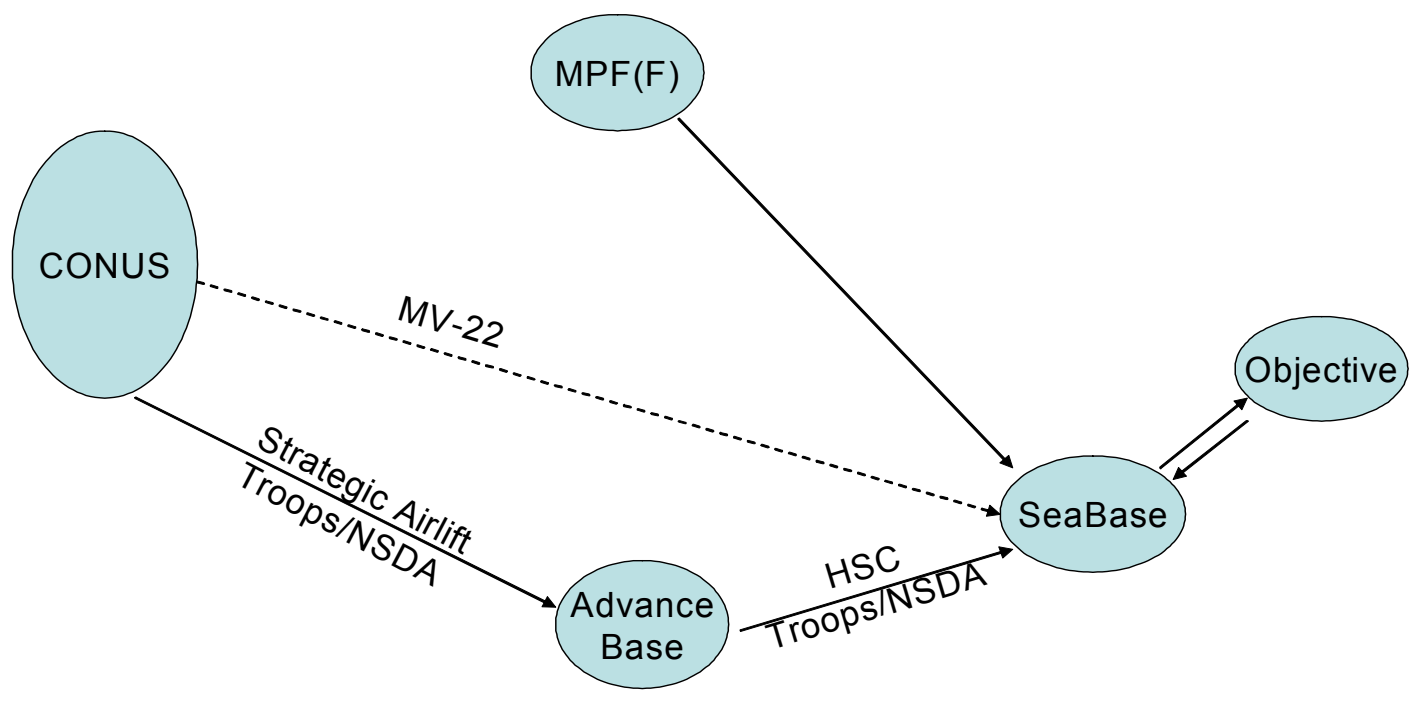

Figure 5. MPF(F) Direct to Sea Base, HSCs Utilized

Non-self-deploying aircraft (NSDA) are flown by strategic airlift to the advance base and sealifted onward to the $\operatorname{MPF}(\mathrm{F})$ ships at the sea base; details will be presented directly. Once the HSCs carrying the troops arrive at the sea base, the troops must be transferred to the $\operatorname{MPF}(\mathrm{F})$ ships.

This example was evaluated with the JELO Excel model (Figure 6) using notional parameter entries, resulting in troop closure at the ashore objective in 194.6 hours, or approximately 8.1 days. This is the most optimistic of the example results and assumes, 
in addition to an early warning order being issued, that strategic airlift can begin with sufficient aircraft made available directly on issuance of the deployment order.

In general, all parameter values are user selectable — the color convention is:

Blue - values that are entered elsewhere in the spreadsheet and are simply referenced at the current cell.

Green - values that are directly entered at the current cell. Currently, some of these values have Data Validation to facilitate rational data entry.

Black - calculated values.

Light Yellow highlight (first column to the right of data parameters) intermediate results that may be of interest.

Deep Yellow highlight (column furthest to the right) - output of interest.

Entries circled in Figure 6 will be discussed in detail below, along with an explanation of the logic used to calculate the model output. 
1 MPFF Transit

1.0 MPFF SeaState

1.1 MPFF preparation time for underway (hrs)

1.2 SubOutput: MPFF transit time to SeaBase (NM)

1.2.1 MPFF transit distance to SeaBase (NM)

1.2.2 MPFF transit speed (kts)

1.2.2.1 MPFF Effective Speed

1.3 Output: Time from deployment order to MPFF arrives SeaBase (hrs)

2 Troop Movement to $A B$

2.1 Troop POM delay at CONUS origin (hrs)

2.1.1 Number of troops for lift (pax)

2.2 Troops transported to APOE (hrs)

2.3 Time to schedule airlift (hrs)

2.4 Time sequence for airlift arrival/departure APOE (hrs)

2.5 Time to load airlift at APOE (hrs)

2.6 SubOutput: Time to fly CONUS to $A B$ (hrs)

2.6.1 Distance APOE to AB (NM)

2.6.2 Speed APOE to AB (kts)

2.7 Output: Time from deployment order until Troops arrive $A B$

3 Troop Movement to MPFF Ships

3.0 HSC SeaState

3.1 Troops deplane at $A B$, move to HSC (hrs)

3.2 SubOutput: HSC time to AB (post deployment order) (hrs)

3.2.1 HSC distance to $A B$ at deployment order (NM)

3.2.2 HSC transit speed (kts)

3.2.2.1 HSC unladen Effective Speed

3.3 SubOutput: Troop delay awaiting HSC (hrs)

3.4 HSC parameters:

3.4.1 Vessel capacity (pax)

3.4.2 Number of vessels (units)

3.4.2.1 SubOutput: HSC shuttle required (Yes/No)

3.5 Troop onload to HSC (hrs)

3.6 SubOutput: HSC Transit time AB to SeaBase (hrs)

3.6.1 HSC transit distance AB to SeaBase (NM)

3.6.2 HSC transit speed (kts)

3.6.2.1 HSC burdened Effective Speed

3.7 SubOutput: Time to move Troops from AB to SeaBase (hrs)

3.8 Time to transfer Troops from HSC to SeaBase (hrs)

3.9 SubOutput: Delay of HSC/Troops waiting for MPFF

3.10 SubOutput: Time to move Troops from AB to MPFF ships (hrs)

3.11 Output: Total time Deployment Order to Troops close MPFF at SeaBase (hrs)

$3 A$ Non-self deploying aircraft (NSDA) movement CONUS to AB/SeaBase

3A.0 NSDA SeaState

3A.1 Time to reposition NSDA at APOE in CONUS (hrs)

3A.1.1 Time to assemble airlift

3A.2 Time to disassemble NSDA for transport flight to AB (hrs)

3A.3 SubOutput: Transport flight time CONUS APOE to AB (hrs)

3A.3.1 NSDA Transport Distance (NM)

3A.3.2 NSDA Transport Speed (kts)

3A.3.3 Airlift time by circulation model (hrs - compute offline)

3A.4 SubOutput: Time for NSDA ready for onload HSC (hrs)

3A.4.1 Reassembly time of NSDA at AB (hrs)

3A.4.2 Flight test of NSDA at AB (hrs)

3A.4.3 Preparation of NSDA for onload to HSC (hrs)

3A.5 NSDA Delay at AB awaiting HSC (hrs)

3A.5.1 Dedicated HSC available for NSDA?

3A.6 NSDA onload to HSC

3A.7 NSDA transit on HSC from AB to MPFF/SeaBase (hrs)

3A.7.1 Distance (NM)

3A.7.2 HSC burdened speed (kts)

3A.7.2.1 HSC NSDA Effective Speed

3A.8 NSDA transfer from HSC to MPFF (hrs)

3A.9 Output: NSDA close at SeaBase (hrs)

4 Assembly of Force Package

4.1 Mating-up of Troops and unit equipment (hrs)

4.2 Output: Time force package available for transport MPFF to shore (hrs)

4.3 SubOutput: Delay awaiting NSDA for foreward movement (hrs)

5 Deploy Force Package to Objectives Ashore

5.0 Assault Package Deployment Time (hrs)

5.0.1 Vertical Battalion Deployment Times (hrs)

5.0.2 First Surface Battalion Deployment Time (hrs)

5.0.3 Operational Pause/Crew-Rest delay (hrs)

5.0.4 Second Surface Battalion Deployment Time (hrs)

5.1 Output: Time to put Troops at objective area - since deployment order (hrs)

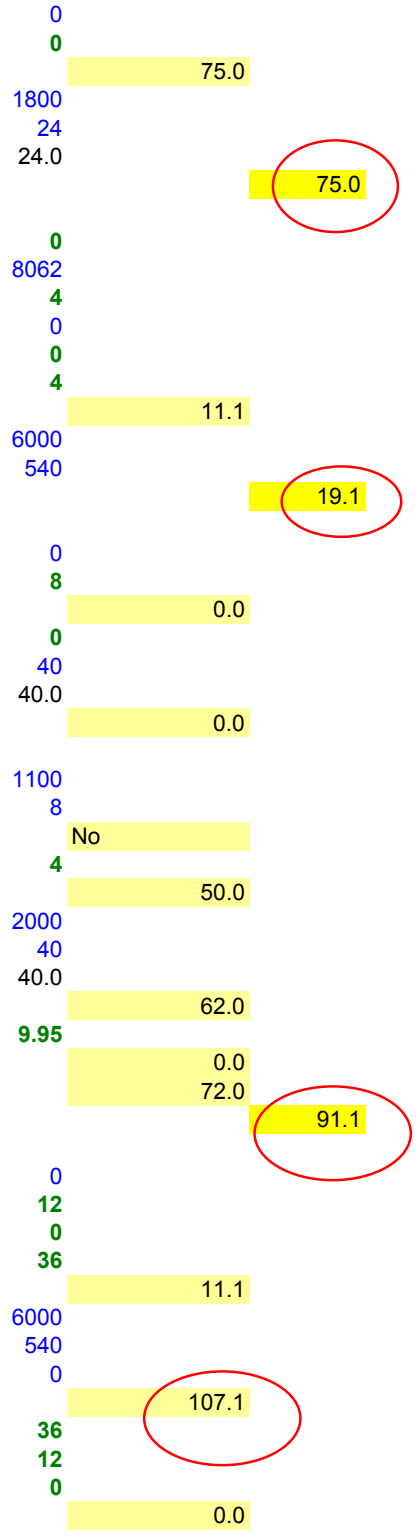

Yes

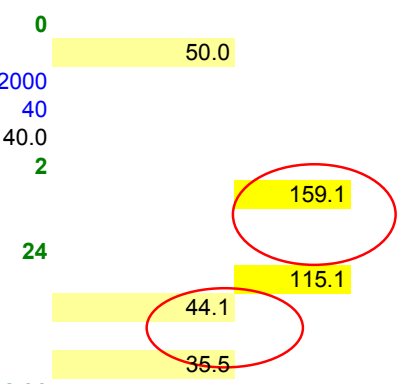

12.36

11.14

12

11.14

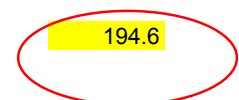

Figure 6. JELO Excel Model, Example 1: MPF(F) Direct to Sea Base, HSCs Utilized 
Several of the JELO time components are simple distance/speed calculations. The time for the $\operatorname{MPF}(\mathrm{F})$ to transit to the sea base is $1,800 \mathrm{~nm} / 24 \mathrm{kts}=75.0$ hours. The three Blue entries are all entered on a common worksheet and are Global parameters - that is, they will be referenced by one, or more, of the possible closure models. Note that Sea State will impact effective speed for surface vessels - higher Sea States degrade speed. Except for the LCACs used in the movement ashore, we do not have valid data for the Sea State effect, but a placeholder model has been used to keep this computation capability in the JELO model.
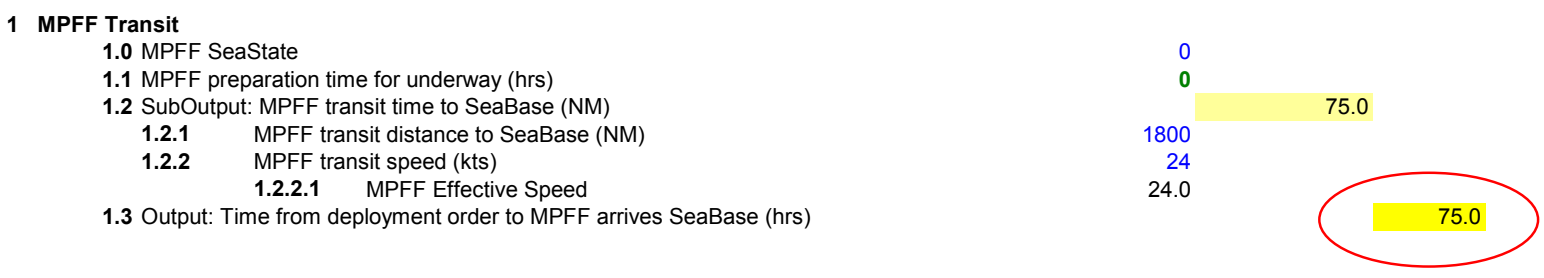

Other time components within JELO may be sequences of events that occur in series and/or parallel. The time for completion of the sequence is the sum of the individual events, with consideration for concurrent events. As an example of concurrent (or parallel) events, we model the sequential series "Troop Preparation for Overseas Movement (POM) and Transport time to the APOE" as occurring in parallel with the sequential series "Time to schedule airlift and Time for airlift to assemble at the APOE," so only the maximum of these two serial times would count against the total for the entire sequence. Troop movement to the advance base is calculated as the sum of:

MAX(Troop Preparation for Overseas Movement (POM) + Transport time to the APOE, Time to schedule airlift + Time for airlift to assemble at the APOE)

+ Time to load aboard the airlift + Time to fly to the advance base

In this example, some of these times are assumed equal to 0 (zero) due to issuance of a warning order prior to an execution order. Note that troop closure to the advance base takes 19.1 hours.
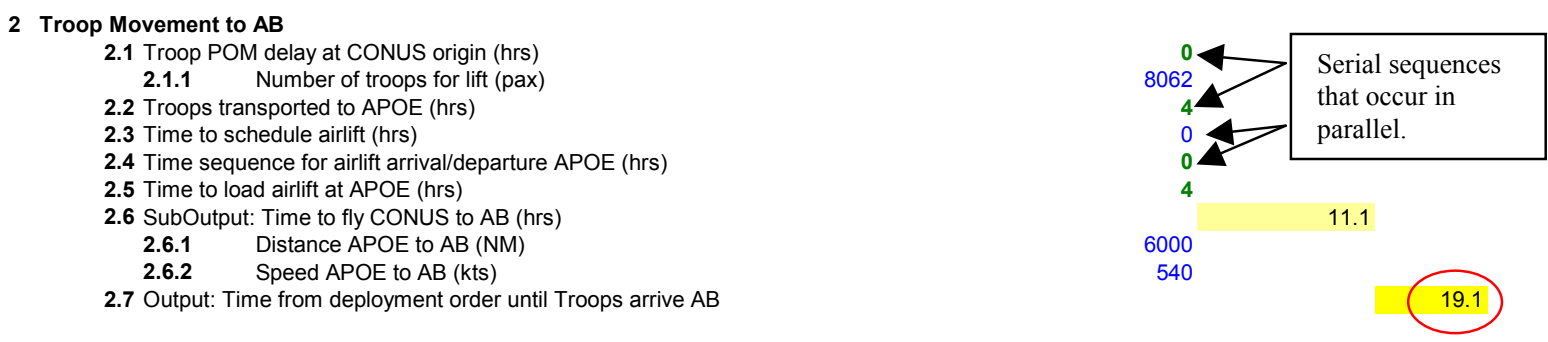

After arriving at the advance base, the troops take time to deplane (eight hours) and then embark (four hours) on the HSCs. HSCs are assumed to be located at the advance base, though there is provision to calculate any delay that may be incurred if that were not the case. Travel to the sea base is again a distance/speed calculation $(2,000 \mathrm{~nm} / 40 \mathrm{kts}=$ 50 hours). Transfer from the $\operatorname{HSC}$ to the $\operatorname{MPF}(\mathrm{F})$ was calculated as 9.95 hours using the JELO movement model and then was entered into this closure model. Troops close the sea base at 91.1 hours after the deployment execution order, or 3.8 days. 
3.1 Troops deplane at AB, move to HSC (hrs)

3.2 SubOutput: HSC time to $A B$ (post deployment order) (hrs)

3.2.1 HSC distance to $A B$ at deployment order (NM)

3.2.2 HSC transit speed (kts)

3.2.2.1 HSC unladen Effective Speed

3.3 SubOutput: Troop delay awaiting HSC (hrs)

3.4 HSC parameters:

3.4.1 Vessel capacity (pax)

3.4.2 Number of vessels (units)

3.4.2.1 SubOutput: HSC shuttle required (Yes/No)

3.5 Troop onload to HSC (hrs)

3.6 SubOutput: HSC Transit time AB to SeaBase (hrs)

3.6.1 HSC transit distance AB to SeaBase (NM)

3.6.2 HSC transit speed (kts)

3.6.2.1 HSC burdened Effective Speed

3.7 SubOutput: Time to move Troops from AB to SeaBase (hrs)

3.8 Time to transfer Troops from HSC to SeaBase (hrs)

3.9 SubOutput: Delay of HSC/Troops waiting for MPFF

3.10 SubOutput: Time to move Troops from AB to MPFF ships (hrs)

3.11 Output: Total time Deployment Order to Troops close MPFF at SeaBase (hrs)

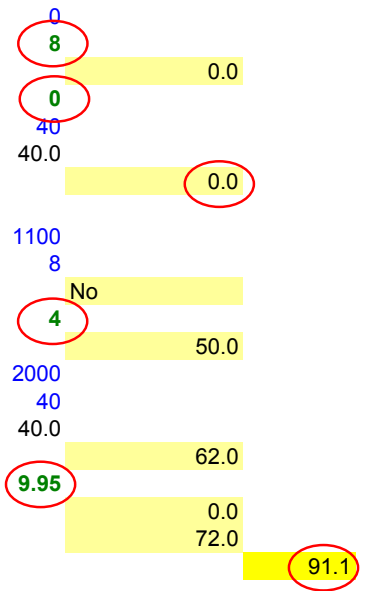

The non-self-deploying aircraft (NSDA) present a straightforward series of events related to movement by strategic airlift. Note that the delay in the availability of strategic airlift, data element 3A.1.1, is set to zero in this example. NSDA will take 48 hours to position and prepare for transport, then incur a distance/speed time for travel to the advance base, then must reassemble and conduct check flights (another 48 hours) for a total delay of 107.1 hours prior to loading aboard the HSC for lift to the sea base. Transit to the sea base is a simple distance/speed calculation, to which we add the flyoff transfer time and calculate a total time for NSDA sea base closure at 159.1 hours, or 6.6 days.
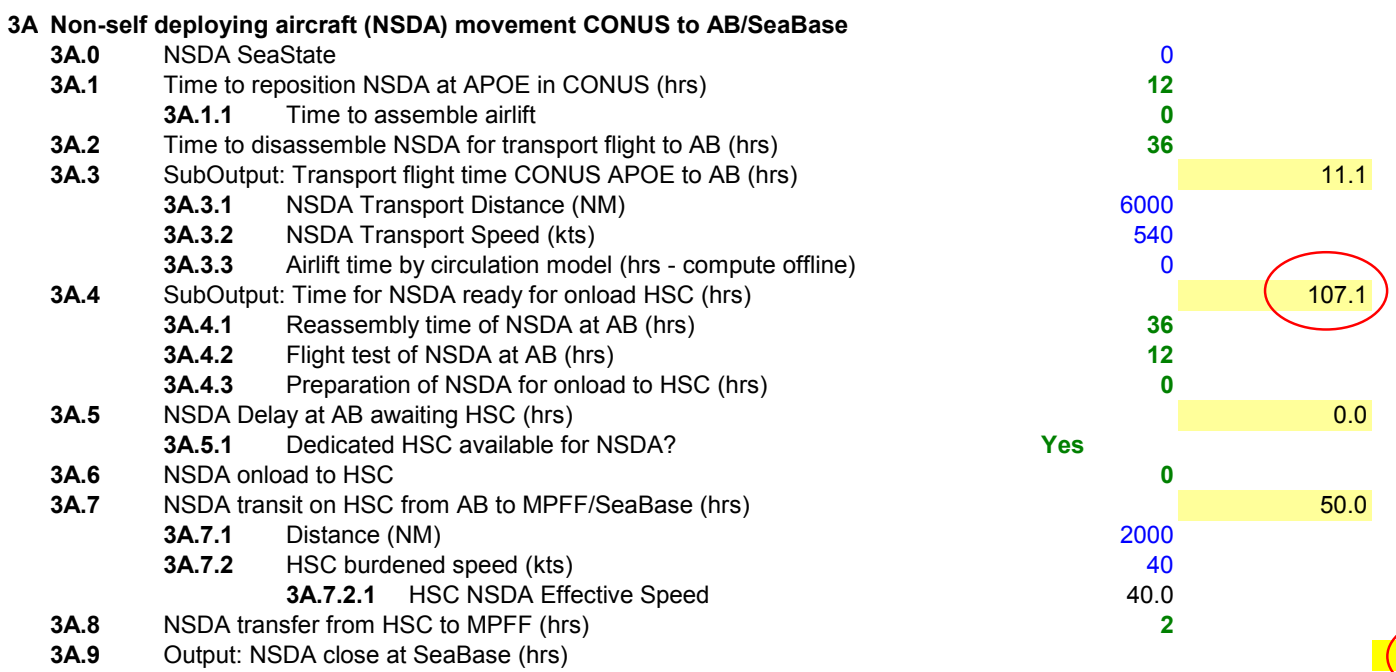

Adding 24 hours, for mating-up with equipment, to the 91.1 required for Troop closure on the $\operatorname{MPF}(\mathrm{F})$, we calculate that the troops are ready for onward movement 115.1 hours (4.8 days) after the deployment order. However, we had just calculated that the NSDA would not arrive until 159.1 hours, so there is a delay of at least 44 hours waiting for the NSDA.

\footnotetext{
4 Assembly of Force Package

4.1 Mating-up of Troops and unit equipment (hrs)

4.2 Output: Time force package available for transport MPFF to shore (hrs)

4.3 SubOutput: Delay awaiting NSDA for foreward movement (hrs)
}

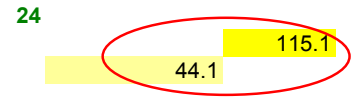


Finally, with all required elements having closed the sea base, onward movement to the ashore objectives can commence. As demonstrated in Section 8, the JELO movement model can be used to calculate deployment times for the Vertical- and Surface-deployed battalions. As before, this time is the sum of individual event times - in this case, the Vertical and first Surface battalions deploy simultaneously, so the maximum of those two is added to the operational pause (driven by limited connector assets) and deployment of the second Surface battalion for a total of 35.5 hours. Deployment closure is achieved at 194.6 hours, or 8.1 days.
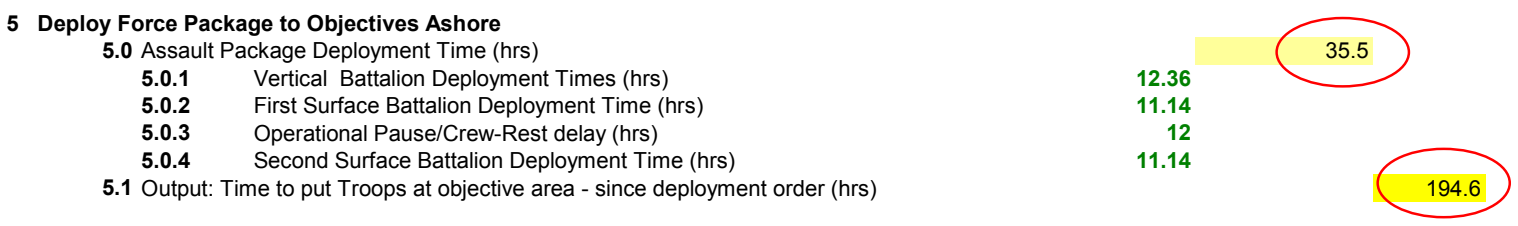

\section{Example 1.1}

Example 1 assumed both immediate and sufficient strategic airlift availability to move NSDA in a single wave from CONUS to the advance base without delay. If this is not the case, additional time for the deployment can be expected. In Example 1.1 there is a 96-hour delay to the start of flights transporting NSDA to the advance base. Note that data element 3A.1.1 in the spreadsheet screenshot that follows now has the value of 96 hours. The delay is perhaps the time needed to establish the air bridge from CONUS to the advance base. It is assumed, however, that once airlift begins (at $\mathrm{C}$-day +96 hours) aircraft are available in sufficient quantity for a single wave carrying $20 \mathrm{CH}-53 \mathrm{~s}$. This example results in overall closure to the objective at 278.6 hours vice the 194.6 hours required in Example 1. 
1 MPFF Transit

1.0 MPFF SeaState

1.1 MPFF preparation time for underway (hrs)

1.2 SubOutput: MPFF transit time to SeaBase (NM)

1.2.1 MPFF transit distance to SeaBase (NM)

MPFF transit speed (kts)

1.2.2.1 MPFF Effective Speed

1.3 Output: Time from deployment order to MPFF arrives SeaBase (hrs)

2 Troop Movement to $A B$

2.1 Troop POM delay at CONUS origin (hrs)

2.1.1 Number of troops for lift (pax)

2.2 Troops transported to APOE (hrs)

2.3 Time to schedule airlift (hrs)

2.4 Time sequence for airlift arrival/departure APOE (hrs)

2.5 Time to load airlift at APOE (hrs)

2.6 SubOutput: Time to fly CONUS to AB (hrs)

2.6.1 Distance APOE to $A B(N M)$

2.6.2 Speed APOE to AB (kts)

2.7 Output: Time from deployment order until Troops arrive $A B$

3 Troop Movement to MPFF Ships

3.0 HSC SeaState

3.1 Troops deplane at AB, move to HSC (hrs)

3.2 SubOutput: HSC time to AB (post deployment order) (hrs)

3.2.1 HSC distance to $A B$ at deployment order (NM)

3.2.2 HSC transit speed (kts)

3.2.2.1 HSC unladen Effective Speed

3.3 SubOutput: Troop delay awaiting HSC (hrs)

3.4 HSC parameters:

3.4.1 Vessel capacity (pax)

3.4.2 Number of vessels (units)

3.4.2.1 SubOutput: HSC shuttle required (Yes/No)

3.5 Troop onload to HSC (hrs)

3.6 SubOutput: HSC Transit time AB to SeaBase (hrs)

3.6.1 HSC transit distance AB to SeaBase (NM)

3.6.2 HSC transit speed (kts)

3.6.2.1 HSC burdened Effective Speed

3.7 SubOutput: Time to move Troops from AB to SeaBase (hrs)

3.8 Time to transfer Troops from HSC to SeaBase (hrs)

3.9 SubOutput: Delay of HSC/Troops waiting for MPFF

3.10 SubOutput: Time to move Troops from AB to MPFF ships (hrs)

3.11 Output: Total time Deployment Order to Troops close MPFF at SeaBase (hrs)

3A Non-self deploying aircraft (NSDA) movement CONUS to AB/SeaBase

3A.0 NSDA SeaState

3A.1 Time to reposition NSDA at APOE in CONUS (hrs)

3A.1.1 Time to assemble airlift

3A.2 Time to disassemble NSDA for transport flight to AB (hrs)

3A.3 SubOutput: Transport flight time CONUS APOE to AB (hrs)

3A.3.1 NSDA Transport Distance (NM)

3A.3.2 NSDA Transport Speed (kts)

3A.3.3 Airlift time by circulation model (hrs - compute offline)

3A.4 SubOutput: Time for NSDA ready for onload HSC (hrs)

3A.4.1 Reassembly time of NSDA at AB (hrs)

3A.4.2 Flight test of NSDA at AB (hrs)

3A.4.3 Preparation of NSDA for onload to HSC (hrs)

3A.5 NSDA Delay at AB awaiting HSC (hrs)

3A.5.1 Dedicated HSC available for NSDA?

3A.6 NSDA onload to HSC

3A.7 NSDA transit on HSC from AB to MPFF/SeaBase (hrs)

3A.7.1 Distance (NM)

3A.7.2 HSC burdened speed (kts)

3A.7.2.1 HSC NSDA Effective Speed

3A.8 NSDA transfer from HSC to MPFF (hrs)

3A.9 Output: NSDA close at SeaBase (hrs)

4 Assembly of Force Package

4.1 Mating-up of Troops and unit equipment (hrs)

4.2 Output: Time force package available for transport MPFF to shore (hrs)

4.3 SubOutput: Delay awaiting NSDA for foreward movement (hrs)

5 Deploy Force Package to Objectives Ashore

5.0 Assault Package Deployment Time (hrs)

5.0.1 Vertical Battalion Deployment Times (hrs)

5.0.2 First Surface Battalion Deployment Time (hrs)

5.0.3 Operational Pause/Crew-Rest delay (hrs)

5.0.4 Second Surface Battalion Deployment Time (hrs)

5.1 Output: Time to put Troops at objective area - since deployment order (hrs)

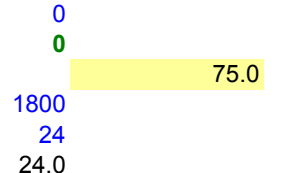

11.1

6000

540

19.1

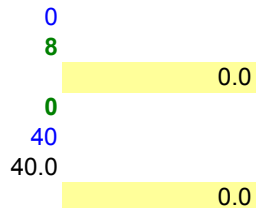

1100

4 No

2000

40

40.0

9.95

72.0

91.1

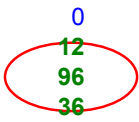

$\begin{array}{rr}6000 & 11.1 \\ 540 & \\ 0 & 191.1 \\ 36 & \\ 12 & \\ 0 & \end{array}$

Yes

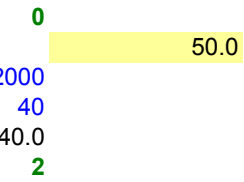

243.1

24

115.1

128.1

35.5

12.36

11.14

12

11.14 


\section{Example 1.2}

In this example, NSDA strategic airlift for the $20 \mathrm{CH}-53 \mathrm{~s}$ is delayed 96 hours and, once it begins, is limited to four sorties per day. In this case, closure to the objective is achieved at 395.3 hours vice 194.6 hours. Note that the limited number of connectors, assumed to be C-17s in this example, is reflected in the JELO Movement Model. The output of the Movement Model is then transferred to the main spreadsheet; data element 3A.3.3.

\begin{tabular}{|c|c|c|c|c|}
\hline \multicolumn{5}{|l|}{ Movement Model } \\
\hline \multicolumn{5}{|l|}{ Problem parameters } \\
\hline Number of Cargo/Pax (total units) & 20 & 4 & - & \\
\hline Number of Connectors (total units) & 4 & 4 & $\bullet$ & \\
\hline Number of Loading Spots & 1 & 4 & $\bullet$ & \\
\hline One-way distance to objective (NM) & 6000 & 4 & D & \\
\hline Sea State & 0 & & & \\
\hline Load Type & CH_53 & & & \\
\hline Connector Type & C_17 & & & \\
\hline \multicolumn{5}{|l|}{ Calculated/Look-up Factors } \\
\hline Equivalent factor (McAllister) & 2 & & & \\
\hline eq \# of connectors (McAllister) & 2.0 & & & \\
\hline \multicolumn{5}{|l|}{ Time per cycle (hrs) (Tc) } \\
\hline Load time (hrs) (TI) & & 2.167 & & \\
\hline Offload Time (hrs) (To) & & 1.167 & & \\
\hline Ingress transit time (hrs) (Tin) & & 11.111 & & \\
\hline \multirow{6}{*}{ Egress transit time (hrs) (Tout) } & & 11.111 & & \\
\hline & \multicolumn{2}{|c|}{ Time to approach/moor $(\mathrm{Ta} / \mathrm{m})$} & & 5 \\
\hline & \multicolumn{2}{|c|}{ load rate (min/unit) $(\mathrm{RI})$} & & 120.000 \\
\hline & \multicolumn{2}{|c|}{ discharge rate $(\mathrm{min} / \mathrm{veh})(\mathrm{Rd})$} & & 60.000 \\
\hline & \multicolumn{2}{|c|}{ cargo/load units per lift (nv) } & & 1 \\
\hline & \multicolumn{2}{|c|}{ Time to cast-off/clear (Tc/c) } & & 5 \\
\hline \multicolumn{2}{|c|}{ Connectors per spot (fully utilized, no queue) } & 11.79 & & 4.0 \\
\hline Spots required/provided & & 0.17 & & 4.0 \\
\hline Load offloaded loading cycle & & 0.17 & & 0.2 \\
\hline Productivity (load/min) & & 0.00 & & \\
\hline \multicolumn{2}{|c|}{ Time to complete offload (hrs) given 1 spots (McAllister) } & 255.56 & & 127.78 \\
\hline & & & & 127.78 \\
\hline
\end{tabular}


3A Non-self deploying aircraft (NSDA) movement CONUS to AB/SeaBase

3A.0 NSDA SeaState

3A.1 Time to reposition NSDA at APOE in CONUS (hrs)

3A.1.1 Time to assemble airlift

3A.2 Time to disassemble NSDA for transport flight to AB (hrs)

3A.3 SubOutput: Transport flight time CONUS APOE to AB (hrs)

3A.3.1 NSDA Transport Distance (NM)

3A.3.2 NSDA Transport Speed (kts)

3A.3.3 Airlift time by circulation model (hrs - compute offline)

3A.4 SubOutput: Time for NSDA ready for onload HSC (hrs)

3A.4.1 Reassembly time of NSDA at AB (hrs)

3A.4.2 Flight test of NSDA at AB (hrs)

3A.4.3 Preparation of NSDA for onload to HSC (hrs)

3A.5 NSDA Delay at AB awaiting HSC (hrs)

3A.5.1 Dedicated HSC available for NSDA?

3A.6 NSDA onload to HSC

3A.7 NSDA transit on HSC from AB to MPFF/SeaBase (hrs)

3A.7.1 Distance (NM)

3A.7.2 HSC burdened speed (kts)

3A.7.2.1 HSC NSDA Effective Speed

3A.8 NSDA transfer from HSC to MPFF (hrs)

$3 A .9$ Output: NSDA close at SeaBase (hrs)

4 Assembly of Force Package

4.1 Mating-up of Troops and unit equipment (hrs)

4.2 Output: Time force package available for transport MPFF to shore (hrs)

4.3 SubOutput: Delay awaiting NSDA for foreward movement (hrs)

5 Deploy Force Package to Objectives Ashore

5.0 Assault Package Deployment Time (hrs)

5.0.1 Vertical Battalion Deployment Times (hrs)

5.0.2 First Surface Battalion Deployment Time (hrs)

5.0.3 Operational Pause/Crew-Rest delay (hrs)

5.0.4 Second Surface Battalion Deployment Time (hrs)

5.1 Output: Time to put Troops at objective area - since deployment order (hrs)

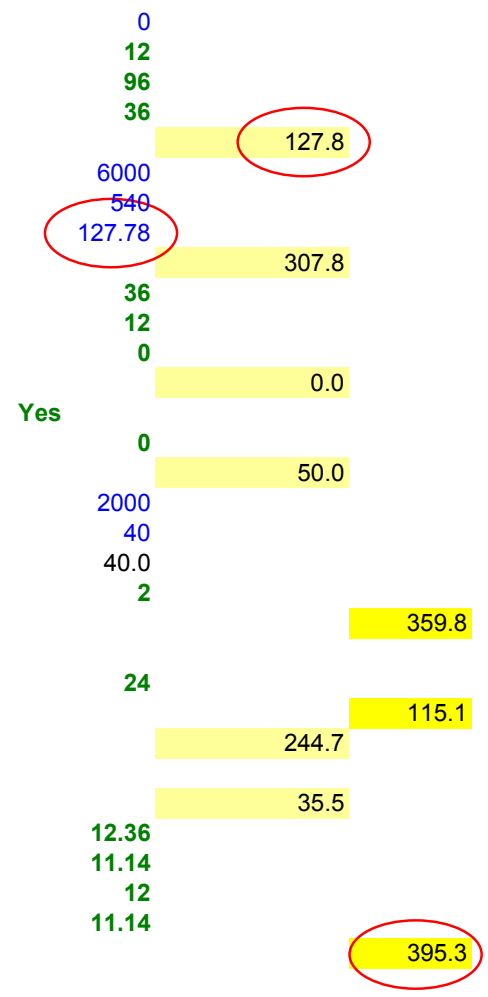




\section{Example 1.3}

In this example, all the conditions of Example 1.2 persist, but it is recognized that in addition to the $\mathrm{CH}-53 \mathrm{~s}$, the MEB's $32 \mathrm{AH} / \mathrm{UH}$ tactical helos must also be transported by strategic airlift. These 32 additional helos require 8 additional strategic airlift sorties, and are reflected in the Movement Model. For this example, the ultimate closure time increased to 446.4 hours.

\begin{tabular}{|c|c|c|c|}
\hline \multicolumn{4}{|l|}{ Movement Model } \\
\hline \multicolumn{4}{|l|}{ Problem parameters } \\
\hline Number of Cargo/Pax (total units) & 28 & $\lambda$ & • \\
\hline Number of Connectors (total units) & 4 & 4 & D \\
\hline Number of Loading Spots & 1 & 1 & - \\
\hline One-way distance to objective (NM) & 6000 & 4 & เ \\
\hline Sea State & 0 & & \\
\hline Load Type & CH_53 & & \\
\hline Connector Type & C_17 & & \\
\hline \multicolumn{4}{|l|}{ Calculated/Look-up Factors } \\
\hline Equivalent factor (McAllister) & 2 & & \\
\hline eq \# of connectors (McAllister) & 2.0 & & \\
\hline Time per cycle (hrs) (Tc) & 25.56 & & \\
\hline Load time $(\mathrm{hrs})(\mathrm{Tl})$ & & 2.167 & \\
\hline Offload Time (hrs) (To) & & 1.167 & \\
\hline Ingress transit time (hrs) (Tin) & & 11.111 & \\
\hline \multirow[t]{6}{*}{ Egress transit time (hrs) (Tout) } & & 11.111 & \\
\hline & \multicolumn{2}{|c|}{ Time to approach/moor $(\mathrm{Ta} / \mathrm{m})$} & 5 \\
\hline & \multicolumn{2}{|c|}{ load rate (min/unit) $(\mathrm{RI})$} & 120.000 \\
\hline & \multicolumn{2}{|c|}{ discharge rate $(\mathrm{min} / \mathrm{veh})(\mathrm{Rd})$} & 60.000 \\
\hline & \multicolumn{2}{|c|}{ cargo/load units per lift (nv) } & 1 \\
\hline & \multicolumn{2}{|c|}{ Time to cast-off/clear (Tc/c) } & 5 \\
\hline \multicolumn{2}{|c|}{ Connectors per spot (fully utilized, no queue) } & 11.79 & 4.0 \\
\hline Spots required/provided & & 0.17 & 4.0 \\
\hline Load offloaded loading cycle & & 0.17 & 0.2 \\
\hline Productivity (load/min) & & 0.00 & \\
\hline \multicolumn{2}{|c|}{ Time to complete offload (hrs) given 1 spots (McAllister) } & 357.78 & 178.89 \\
\hline & & & 178.89 \\
\hline
\end{tabular}


3A Non-self deploying aircraft (NSDA) movement CONUS to AB/SeaBase

3A.0 NSDA SeaState

3A.1 Time to reposition NSDA at APOE in CONUS (hrs)

3A.1.1 Time to assemble airlift

3A.2 Time to disassemble NSDA for transport flight to AB (hrs)

3A.3 SubOutput: Transport flight time CONUS APOE to AB (hrs)

3A.3.1 NSDA Transport Distance (NM)

3A.3.2 NSDA Transport Speed (kts)

3A.3.3 Airlift time by circulation model (hrs - compute offline)

3A.4 SubOutput: Time for NSDA ready for onload HSC (hrs)

3A.4.1 Reassembly time of NSDA at AB (hrs)

3A.4.2 Flight test of NSDA at AB (hrs)

3A.4.3 Preparation of NSDA for onload to HSC (hrs)

3A.5 NSDA Delay at AB awaiting HSC (hrs)

3A.5.1 Dedicated HSC available for NSDA?

3A.6 NSDA onload to HSC

3A.7 NSDA transit on HSC from AB to MPFF/SeaBase (hrs)

3A.7.1 Distance (NM)

3A.7.2 HSC burdened speed (kts)

3A.7.2.1 HSC NSDA Effective Speed

3A.8 NSDA transfer from HSC to MPFF (hrs)

3A.9 Output: NSDA close at SeaBase (hrs)

4 Assembly of Force Package

4.1 Mating-up of Troops and unit equipment (hrs)

4.2 Output: Time force package available for transport MPFF to shore (hrs)

4.3 SubOutput: Delay awaiting NSDA for foreward movement (hrs)

5 Deploy Force Package to Objectives Ashore

5.0 Assault Package Deployment Time (hrs)

5.0.1 Vertical Battalion Deployment Times (hrs)

5.0.2 First Surface Battalion Deployment Time (hrs)

5.0.3 Operational Pause/Crew-Rest delay (hrs)

5.0.4 Second Surface Battalion Deployment Time (hrs)

5.1 Output: Time to put Troops at objective area - since deployment order (hrs)

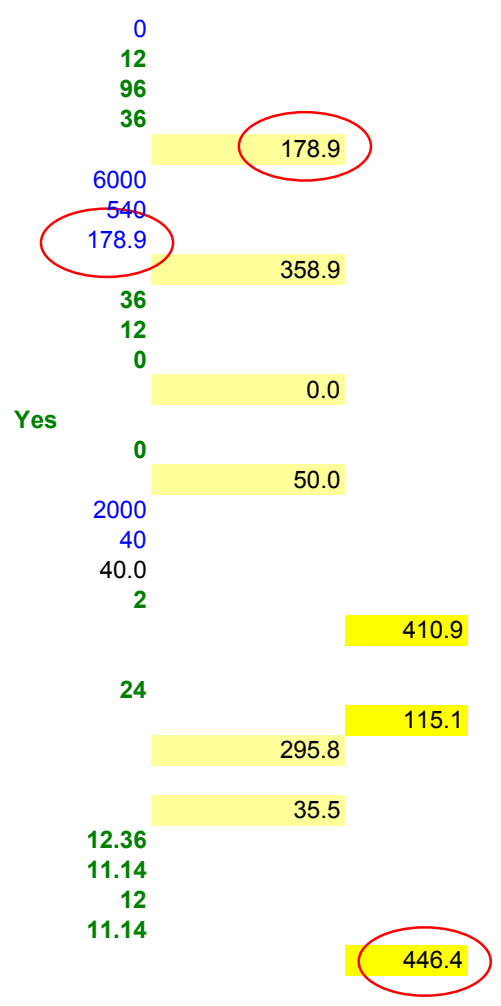

\subsection{Example 2}

In this example, rapid strategic lift ships (RSLS) on-load troops, NSDA, and non-prepositionable cargo in CONUS and transit directly to the sea base. As in Example 1, the MPF(F) transit directly from their preposition site to the sea base. When both the RSLSs and MPF(F) have arrived at the sea base, the troops transfer from the RSLS to the MPF(F) (see Figure 7). 


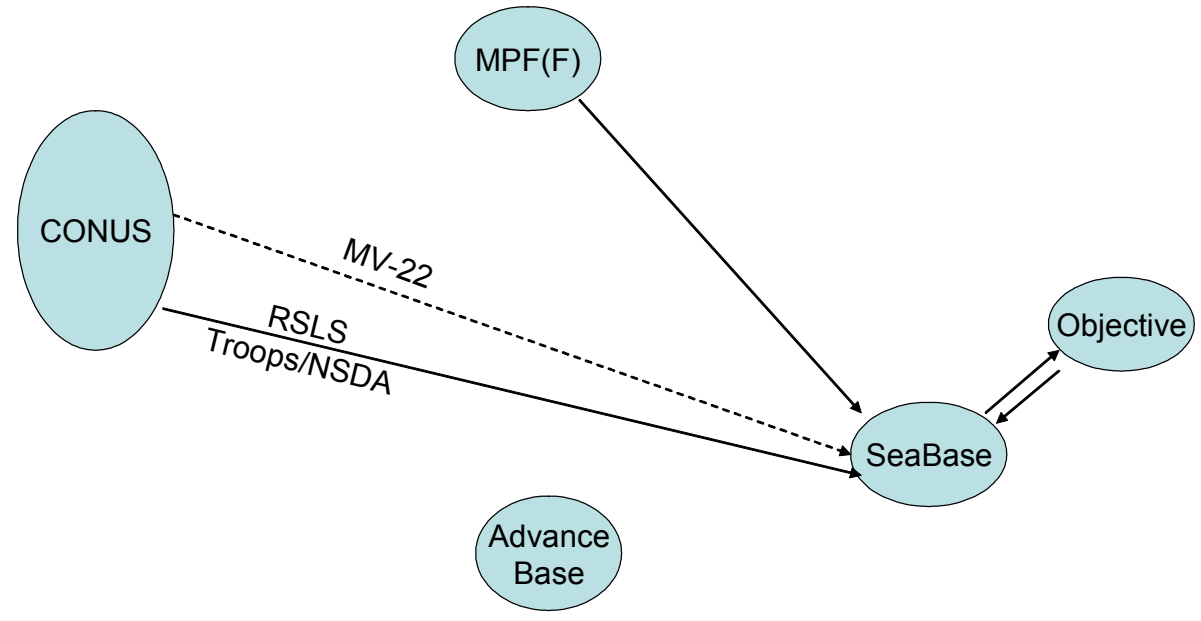

Figure 7. MPF(F) Direct to Sea Base, RSLSs Utilized

Output from the JELO Flow model for this example is shown in Figure 8. MPF(F) transit is identical to Example 1, again taking 75.0 hours to transit to the sea base. Troop and NSDA movement aboard the RSLSs follows logic similar to the strategic airlift of Example 1. Both troops and NSDA reposition and then load aboard the RSLSs, followed by a distance/speed calculation for the voyage to the sea base. The RSLSs close at the sea base after 193.0 hours (eight days), and then transfer of the troops to the MPF(F) occurs as described by the JELO movement model (Section 6) in 9.95 hours. After a 24-hour period to mate-up with equipment, the troops are ready for onward movement at 227 hours (9.5 days). Deployment takes place as previously described (Section 8) and closure occurs at 262.5 hours (10.9 days). 

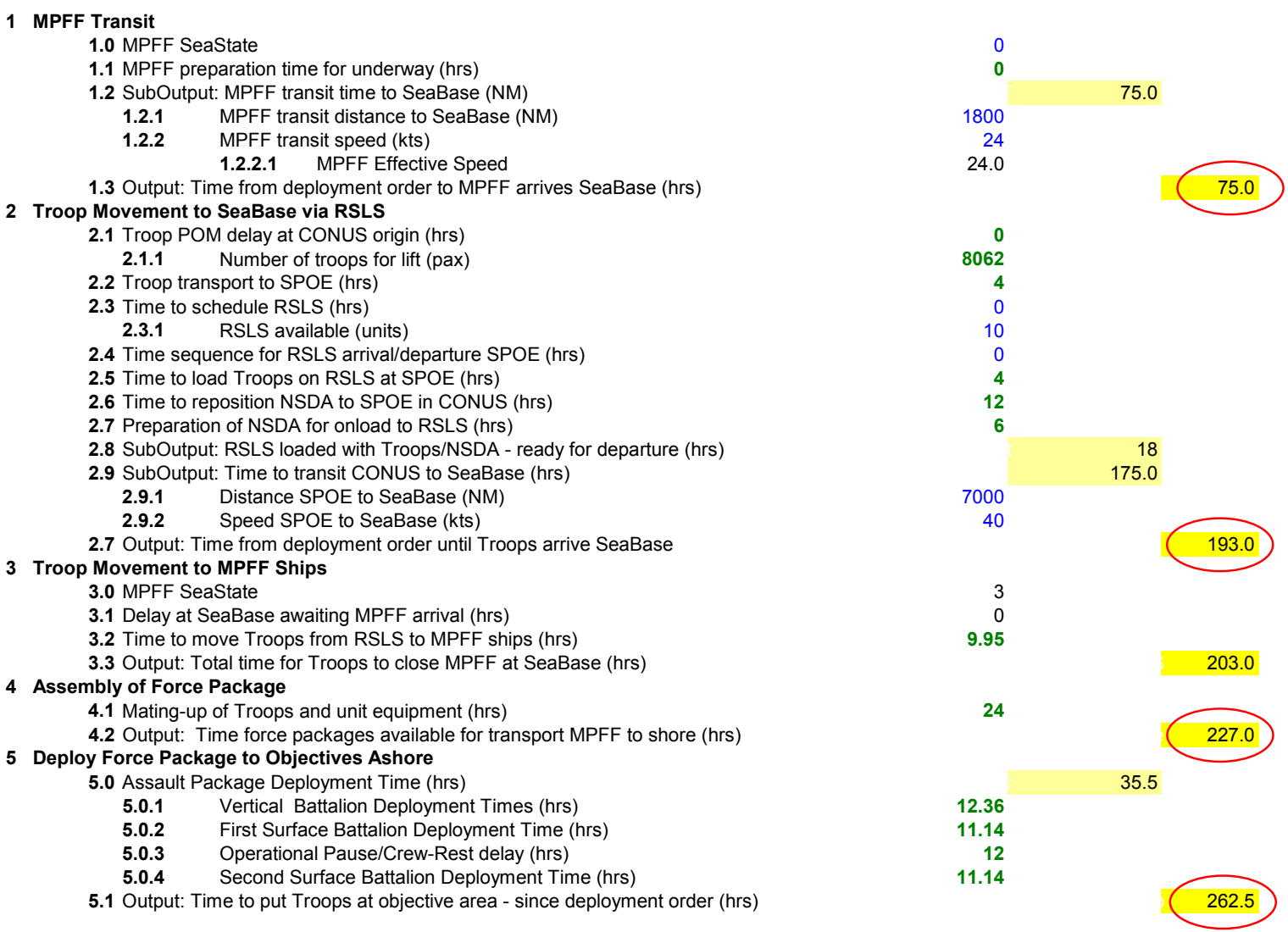

Figure 8. JELO Excel Model, Example 2: MPF(F) Direct to Sea Base, RSLSs Utilized

\subsection{Example 3}

In this example, forces are still flown to the advance base, but the $\operatorname{MPF}(\mathrm{F})$ sails from its preposition site to the advance base and thus serves as the connector. The MPF(F) ships would then sail for the sea base as soon as the troops and cargo could be loaded at the advance base. NSDA would still be flown by strategic airlift to the advance base and made flight-ready there (see Figure 9). If they are able to arrive at the advance base within a designated waiting period, NSDA could be transported by MPF(F). If the NSDA arrive too late for the $\operatorname{MPF}(\mathrm{F})$, they could still be loaded when ready onto HSCs for transport to the sea base. Once within range of the sea base, these aircraft could launch and fly to the $\operatorname{MPF}(\mathrm{F})$ ships. 


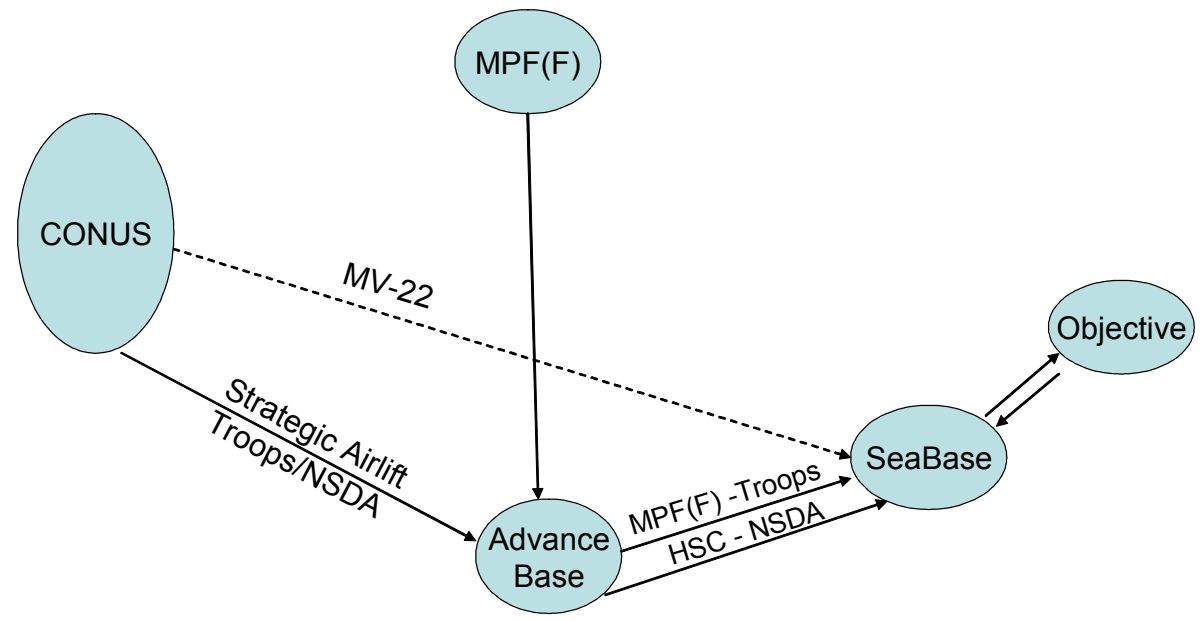

Figure 9. $\operatorname{MPF}(\mathrm{F})$ Calls at Advance Base En route to Sea Base

The JELO Flow model for Example 3 is shown in Figure 10. MPF(F) transit is a distance/speed event taking 83.3 hours to transit to the advance base (depending, of course, on user-specified $\mathrm{MPF}(\mathrm{F})$ transit speed and distance from preposition site to the advance base). Troop arrival at the advance base at 19.1 hours, plus their eight-hour delay to deplane and move to the $\mathrm{MPF}(\mathrm{F})$ loading point, still leaves a 56.2-hour delay awaiting the $\operatorname{MPF}(\mathrm{F})$ arrival. This observation argues for the $\operatorname{MPF}(\mathrm{F})$ and advance base to be collocated. A 20-hour window for NSDA has been modeled-since the actual delay calculates as 23.8 hours, the $\operatorname{MPF}(\mathrm{F})$ will sail without embarking the NSDA at the advance base. This max allowable waiting period is, of course, user selectable.

In this example it was again assumed that sufficient strategic airlift for the NSDA is available immediately after the deployment order is given-a most convenient circumstance. Nonetheless, the NSDA are not available for load aboard the MPF(F) until 107.1 hours, so the NSDA will be sealifted by HSC. Note that the HSC will arrive at the sea base at 159.1 hours, while the $\operatorname{MPF}(\mathrm{F})$ will not arrive until 170.7 hours. The HSC's greater speed (40 kts versus $24 \mathrm{kts}$ for the $\mathrm{MPF}(\mathrm{F})$ ) allows the quicker transit. In this case, it seems likely that the NSDA will fly aboard the MPF(F) prior to arrival at the sea base, though no explicit calculation is performed for that event. Since the troops went aboard the $\operatorname{MPF}(\mathrm{F})$ at the advance base, there is no mate-up time with equipment. Finally, deployment to the ashore objective proceeds as before, and results in a force closure to objective time of 206.2 hours (8.6 days). 
1.1 MPFF preparation time for underway (hrs)

1.2 SubOutput: MPFF transit time to $A B(N M)$

1.2.1 MPFF transit distance to $A B(N M)$

1.2.2 MPFF transit speed (kts)

1.2.2.1 MPFF Effective Speed

1.3 Output: Time from deployment order to MPFF arrives AB (hrs)

2 Troop Movement to $A B$

2.1 Troop POM delay at CONUS origin (hrs)

2.1.1 Number of troops for lift (pax)

2.2 Troops transported to APOE (hrs)

2.3 Time to schedule airlift (hrs)

2.4 Time sequence for airlift arrival/departure APOE (hrs)

2.5 Time to load airlift at APOE (hrs)

2.6 SubOutput: Time to fly CONUS to $A B$ (hrs)

2.6.1 Distance APOE to $A B(N M)$

2.6.2 Speed APOE to AB (kts)

2.7 Output: Time from deployment order until Troops arrive AB

3 Troop Movement to MPFF Ships

3.0 MPFF SeaState

3.1 Troops deplane at AB, move to MPFF (hrs)

3.2 SubOutput: Troop delay awaiting MPFF (hrs)

3.3 MPFF parameters:

3.3.1 Vessel capacity (pax)

3.3.2 Number of vessels (units)

3.3.3 SubOutput: MPFF shuttle required (Yes/No)

3.4 Troop onload to MPFF (hrs)

3.4.1 Max allowable delay awaiting NSDA for lift on MPFF

3.4.2 Actual delay incurred awaiting NSDA for lift on MPFF

3.5 SubOutput: MPFF Transit time AB to SeaBase (hrs)

3.5.1 MPFF transit distance $A B$ to SeaBase (NM)

3.5.2 MPFF transit speed (kts)

3.5.2.1 MPFF burdened Effective Speed

3.6 SubOutput: Time to move Troops from AB to SeaBase (hrs)

3.7 Output: Total time Deployment Order to Troops close MPFF at SeaBase (hrs)

3A Non-self deploying aircraft (NSDA) movement CONUS to SeaBase

3A.0 NSDA SeaState

3A.1 Time to reposition NSDA at APOE in CONUS (hrs)

3A.2 Time to disassemble/load NSDA for transport flight to AB (hrs)

3A.3 SubOutput: Transport flight time CONUS APOE to AB (hrs)

3A.3.1 NSDA Transport Distance (NM)

3A.3.2 NSDA Transport Speed (kts)

3A.4 SubOutput: Time for NSDA ready for onload MPFF (hrs)

3A.5 Reassembly time of NSDA at AB (hrs)

3A.6 Flight test of NSDA at AB (hrs)

3A.7 Preparation of NSDA for onload to MPFF (hrs)

3A.7.1 Potential delay of MPFF awaiting NSDA (hrs)

3A.8 HSC transit time to $A B$ (hrs)

3A.8.1 HSC distance to $A B$ at deployment order (NM)

3A.8.2 HSC transit speed (kts)

3A.8.2.1 HSC unladen Effective Speed

3A.9 NSDA onload to HSC

3A.10 NSDA transit on HSC from AB to MPFF/SeaBase (hrs)

3A.10.1 Distance (NM)

3A.10.2 HSC burdened speed (kts)

3A.10.2.1 HSC NSDA Effective Speed

3A.11 NSDA transfer from HSC to MPFF (hrs)

3A.12 Earliest NSDA Arrival

3A.12 Output: NSDA close at SeaBase (hrs)

4 Assembly of Force Package

4.1 Mating-up of Troops and unit equipment (hrs)

4.2 Output: Time force packages available for transport MPFF to shore (hrs)

4.3 SubOutput: Delay awaiting NSDA (hrs)

5 Deploy Force Package to Objectives Ashore

5.0 Assault Package Deployment Time (hrs)

5.0.1 Vertical Battalion Deployment Times (hrs)

5.0.2 First Surface Battalion Deployment Time (hrs)

5.0.3 Operational Pause/Crew-Rest delay (hrs)

5.0.4 Second Surface Battalion Deployment Time (hrs)

5.1 Output: Time to put Troops at objective area - since deployment order (hrs)

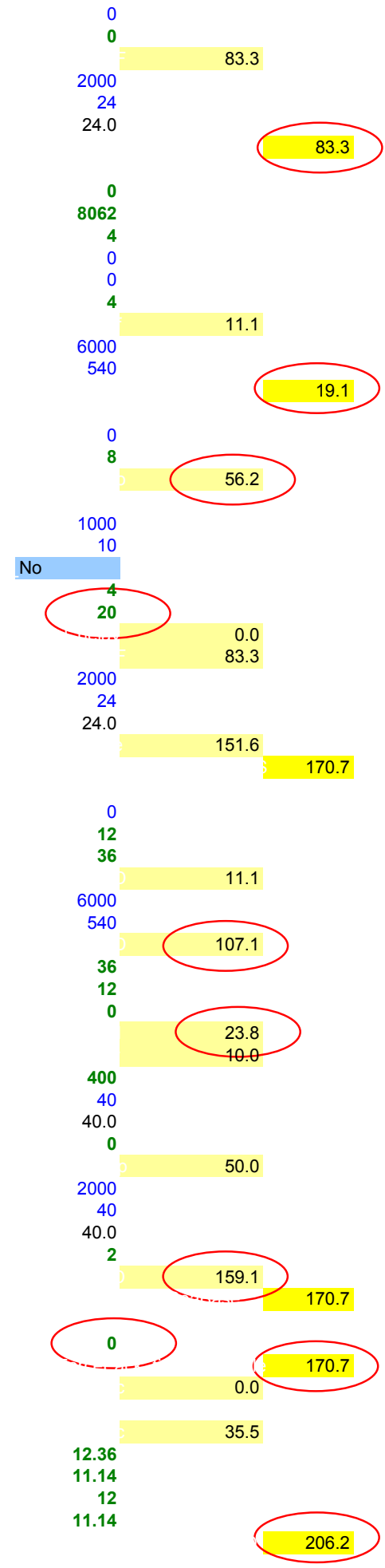

Figure 10. JELO Excel Model, MPF(F) Calls at Advance Base En route to Sea Base 


\section{Example 3.1}

In this example, troops and NSDA are transported on RSLSs to the advance base and the $\operatorname{MPF}(\mathrm{F})$ sails from its preposition site to the advance base and serves as the connector. The $\operatorname{MPF}(\mathrm{F})$ ships would then sail for the sea base as soon as the troops, NSDA, and cargo could be loaded at the advance base (see Figure 11). Note that the NSDA may be transported in folded, but not partially disassembled, condition.

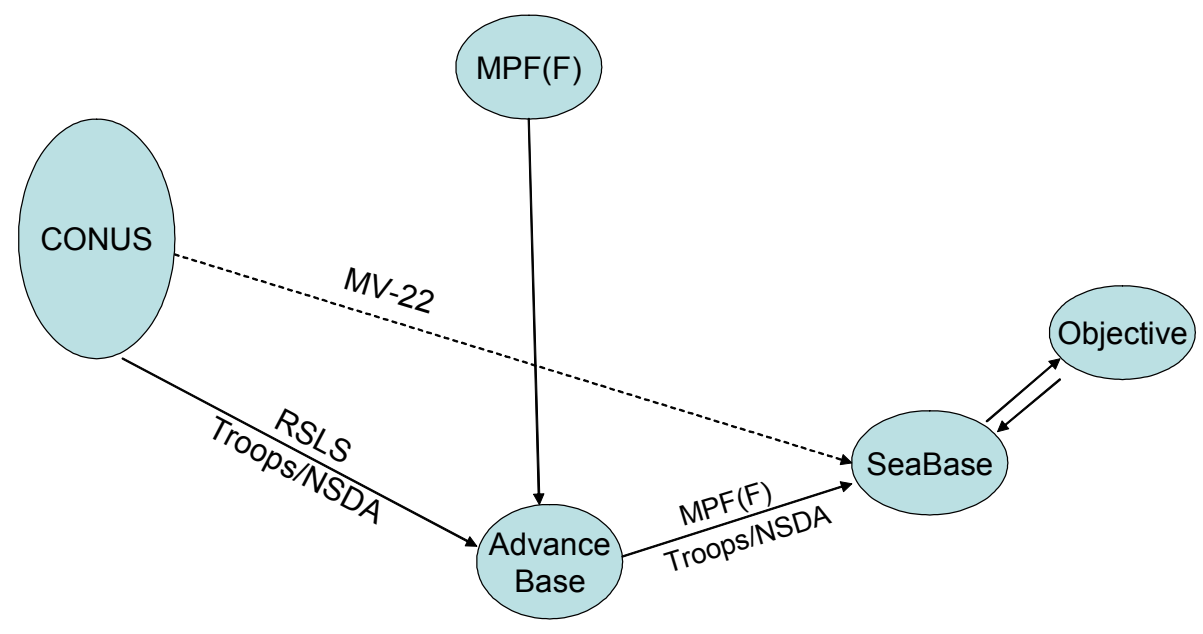

Figure 11. RSLS and MPF(F) Rendezvous at Advance Base

The JELO Flow model for this example is shown in Figure 12. MPF(F) transit is a distance/speed event taking 83.3 hours to transit to the advance base. $\mathrm{MPF}(\mathrm{F})$ speed is input as $24 \mathrm{kts}$ here. Troops and NSDA arrive at the advance base at 158.0 hours. They debark, move to and load onto the $\operatorname{MPF}(\mathrm{F})$ in 12 hours, and then sail to arrive at the sea base at 253.3 hours. Note that there was no delay awaiting the $\operatorname{MPF}(\mathrm{F})$ due to the RSLSs' six-day transit to the AB. Because the troops have been aboard the MPF(F) since the advance base, there is no mate-up time with equipment. Finally, deployment to the ashore objective proceeds as before and results in a force closure to objective time of 288.8 hours (12.0 days). 

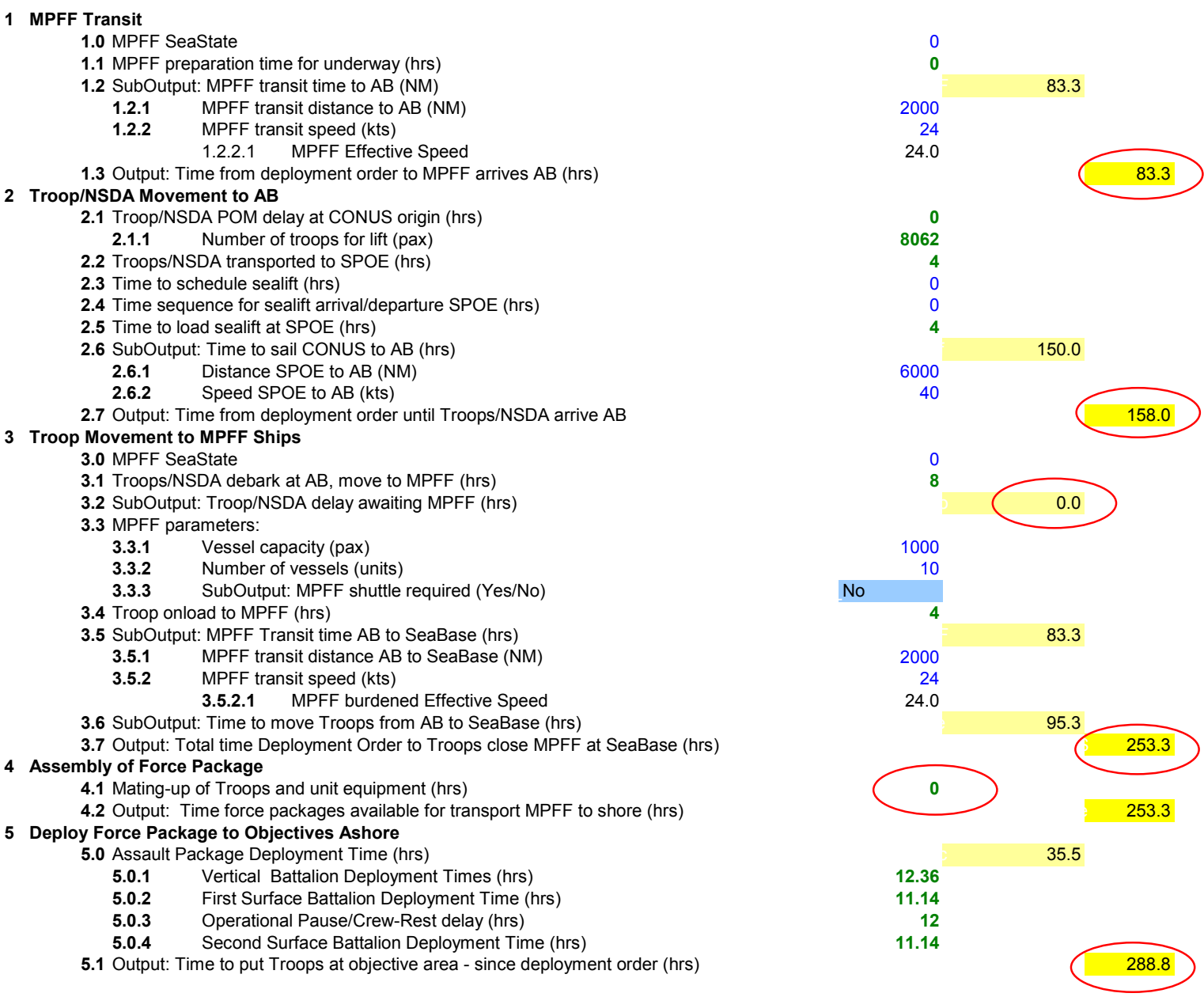

Figure 12. JELO Excel Model, RSLSs and MPF(F) Rendezvous at Advance Base

\subsection{Summary}

The few examples demonstrated here are summarized in the table below where $\mathrm{AB}$ denotes the advance base and SB denotes the sea base. Time to close to objective varies from 8 to 18 days, depending on the closure option selected and other assumptions. The two smallest times to close to objective assume Air Mobility Command (AMC) aircraft to transport NSDA are immediately available and in sufficient number, and this is the major, and possibly unrealistic, reason their closure times are the smallest. Example 1 and its derivatives employ a HSC operating between the advance base and the sea base and involve troop transfer at sea. Examples 2 and 3.1 involve RSLSs operating from CONUS - one with at-sea troop transfer and the other without. At-sea transfer of troops to the $\operatorname{MPF}(\mathrm{F})$ is avoided entirely if the $\operatorname{MPF}(\mathrm{F})$ calls at the advance base to embark troops prior to sailing to the sea base, as in Examples 3 and 3.1.

The columns of the table contain only the major features. There was no variation of the large number of parameters of sea-based logistics operations; e.g., geographical distances, sea state, and platform characteristics. Clearly, a plan to evaluate all combinations is not sensible. Rather, the model should be employed to investigate 
particular conditions and tradeoffs of interest. The goal in this project was not to conduct sea basing platform and capabilities tradeoffs, but to build a tool for doing such analyses. The examples illustrated the use of the JELO model, but did not in any sense demonstrate a preferred solution.

\begin{tabular}{|c|c|c|c|c|c|c|c|c|c|}
\hline & \multicolumn{2}{|c|}{ MPF(F) Prepo Site } & \multicolumn{3}{|c|}{ Airlift - CONUS to AB } & \multicolumn{2}{|c|}{ RSLS from CONUS } & \multirow{2}{*}{$\begin{array}{c}\text { HSC } \\
A B \text { to } S B\end{array}$} & \multirow{2}{*}{$\begin{array}{c}\text { Closure to } \\
\text { Objective Time }\end{array}$} \\
\hline & To SB & To $A B$ & No Delay & Delay & Multi-Wave & To SB & To $A B$ & & \\
\hline 1 & $x$ & & $\mathrm{X}$ & & & & & $\mathrm{X}$ & 8.2 days \\
\hline 1.1 & $\mathbf{X}$ & & & $\mathbf{X}$ & & & & $\mathbf{X}$ & 11.6 \\
\hline 1.2 & $\mathbf{X}$ & & & $\mathbf{X}$ & $\mathbf{X}$ & & & $\mathbf{X}$ & 16.5 \\
\hline 1.3 & $\mathrm{X}$ & & & $\mathrm{X}$ & $\mathrm{X}$ & & & $\mathbf{X}$ & $18.6^{*}$ \\
\hline 2 & $\mathbf{x}$ & & & & & $\mathbf{X}$ & & & 10.9 \\
\hline 3 & & $\mathbf{X}$ & $\mathbf{X}$ & & & & & & 8.6 \\
\hline 3.1 & & $\mathbf{X}$ & & & & & $\mathbf{X}$ & & 12.0 \\
\hline
\end{tabular}

\section{Sustainment}

Once the sea-based maneuver elements have been deployed to their objectives ashore, attention shifts to sustainment. The maneuver elements require daily replenishment of their provisions, water, fuel, and ammo. The $\mathrm{MPF}(\mathrm{F})$ ships, whose stocks of combat stores provide the commodities for the daily resupply of the ground forces, will also require replenishment as their stocks are drawn down to the reserve levels. Finally, the other ships of the sea base-the CSG ships and the ESG ships-require replenishment periodically.

\subsection{Resupply of the Maneuver Forces Ashore}

Once ashore, the maneuver forces consume MREs and water daily, along with fuel to power their vehicles, generators, and weapon systems, and the ammo used in combat. Running out of any of these commodities is a combat stopper. Daily resupply from the $\mathrm{MPF}(\mathrm{F})$ ships is intended to replace the commodities used. If the ground forces deploy with two days of supply and the reserve level is one day of supply, the order quantity is one day of supply and the safety level is one day of supply. Deploying with two days of supply is suggested in the literature, but deploying with three days of supply and daily replenishment of one day of supply results in a safety level of two days of supply. The two days of supply safety level is not modeled, but easily could be.

Daily provisions requirements are easily estimated as three MREs per Marine per day. An MRE weighs 1.86 pounds, three of them weigh 5.58 pounds and this then is the planning factor for provisions in pounds per Marine per day (PMD) [4]. Water requirements are also computed PMD with a planning factor of 4-6 gallons per day. The model uses six gallons PMD and a gallon of water weighs 8.3 pounds. The planning factor for water is thus approximately 50 PMD. Water could be provided in bulk in 250-gallon bladders, or in bottled form on pallets. Palletized bottles are modeled so the daily requirement is quoted in pounds rather than gallons. Use of water bladders requires a different load-packaging algorithm. 
While the daily food and water requirements of the SBME are easily estimated, the daily fuel requirement is, along with the daily ammo requirement, much more difficult to estimate. Estimates or planning factors in the literature vary by almost an order of magnitude. Some of the estimates are based on the older Marine Corps Bulletin 3501 table of organization and table of equipment for a MEB. The HIMARS and EFSS weapon systems are new to the Marine Corps and ammo-planning factors for them are not available. The $2015 \mathrm{MPF}(\mathrm{F})$ and its SBME are new and fuel and ammo planning factors have not been published. The $2015 \mathrm{MPF}(\mathrm{F}) \mathrm{MEB}$ is different in numbers, kinds of units, and table of equipment from the Marine Corps Bulletin 3501 MEB. The published logistics planning factors for the consumption of fuel and ammo are based on the $3501 \mathrm{MEB}$ or even earlier versions. The $2015 \mathrm{MPF}(\mathrm{F}) \mathrm{MEB}$ SBME is smaller and lighter than the 3501 Ground Combat Element (GCF). Whereas the former has 500 vehicles of all types, the latter had 1,711 vehicles. Clearly, the fuel requirements of the SBME will be less than the published logistics planning factors for the $3501 \mathrm{GCE}$. Likewise, the SBME has only two artillery batteries rather than an artillery battalion and will have smaller ammo requirements than the $3501 \mathrm{GCE}$.

The methodology adopted for estimating SBME daily fuel and ammo requirements is to take the existing planning factors and the existing table of organization personnel numbers for each type of unit (infantry battalion, artillery battery, LAV company, etc.) and compute the commodity use planning factor in terms of pounds or gallons per Marine per day. These factors are then applied to the SBME table of organization for each of the three reinforced infantry battalions and their small number of direct support personnel. For example, in [12] an infantry regiment of 2,993 troops is estimated to use 1,790 gallons of fuel per day (gpd). This works out to 0.6 gallons per Marine per day (GMD). In [14] a battalion of 1,072 troops was assumed to use 596 gallons per day. This works out to $0.56 \mathrm{GMD}$. A planning factor of $0.6 \mathrm{GMD}$ was selected and applied to the 934 troops of an SBME infantry battalion yielding an estimate of 560 gallons per day. GMD fuel-use planning factors for other types of units range up to 12.59 GMD for tank companies and 16 GMD for artillery batteries.

The only source of ratios between assault and sustained rates is in [4], and then only for fuel. In [4], the ratios range from 1.5 for infantry to 6.15 for amphibious assault vehicle units. These ratios were used to estimate assault rate fuel use planning factors by type of unit. Summed over the numbers and types of units in the SBME, the estimates of assault rate and sustained rate daily fuel requirements of the SBME ashore are 26,500 gallons during the assault phase of the operation and 11,300 gallons as the sustained operations rate. Twenty percent of these totals are ascribed to the Vertical battalion and $40 \%$ to each of the Surface battalions. This methodology produces smaller daily requirements for fuel and ammo than most of the numbers in the literature, but they are perhaps consistent with the changes being made to sea base smaller, lighter maneuver forces. Currently, N42 [5] estimates the MEB will use 1,560 bbl or 65,500 gallons of fuel daily. [4] provides a planning factor for the fuel used daily by a Marine division as 113,000 gallons (assault rate). The SBME daily fuel requirement (assault rate) estimate here is 26,500 gallons. The SBME certainly has smaller fuel requirements than either a Marine division or a full MEB and thus the estimate used here may not be unreasonable. 
The same methodology was used to estimate daily ammo resupply requirements. No source of assault/sustain ratios was found, so only sustained rates could be estimated. The PMD planning factors ranged from 2.51 PMD for infantry to 48.35 PMD for artillery. Applied to the kinds of units, the estimates of daily ammo resupply requirements were 7,981 pounds in the Vertical battalion and 14,747 pounds in each of the Surface battalions for a daily total ammo resupply requirement of 37,475 pounds, or nearly 19 tons.

It is assumed that daily replenishment will be delivered vertically and that surface delivery will be used only if the vertical replenishment capability cannot meet all requirements. There will be at least two destinations for the resupply delivery trips: the location of the Vertical battalion and the location of the two Surface battalions. We cannot know the actual geometries, but we do know the desire to keep the sea base well out of harm's way, so the resupply operations are modeled as $110 \mathrm{~nm}$ distances from the sea base to either destination. This assumption also allows the daily resupply requirements of the different battalions to be merged into a single requirement that is conservative in the sense that the actual requirement, as far as distance is concerned, could be less demanding.

Doing the arithmetic of $5.58 \mathrm{lbs}$ of MREs PMD and six gallons of water PMD, plus, at assault rates, 26,500 gallons of fuel daily and 37,475 lbs of ammo daily, the total daily resupply requires the movement of nearly 300,000 pounds of dry cargo and 55500 -gallon fuel bladders. The movement model says this will take 5.9 hours utilizing $10 \mathrm{CH}-53 \mathrm{Xs}$ and $10 \mathrm{MV}-22 \mathrm{~s}$. If vertical daily resupply is feasible at assault rates, it will also be feasible at sustained rates. 
Sustainment at 110 NM / 24 MV22 / 10 CH53 / 2 loading spots

\begin{tabular}{|l|r|r|r|r|r|r|r|r|}
\hline Loads & Start Total & Start Time & End Time & End Total & Spot \#'s & Connector & $\begin{array}{c}\text { \# of } \\
\text { connectors }\end{array}$ & $\begin{array}{c}\text { Crew Day } \\
\text { Used }\end{array}$ \\
\hline & & & & & & & & \\
\hline Dry Cargo (20k sling) & 15 & 0 & 3.27 & 0 & 1 & $\mathrm{CH}$ & 10 & 25.3 \\
\hline Fuel Bladder (500g) & 55 & 0 & 3.27 & 27 & 2 & $\mathrm{MV}$ & 8 & 26.16 \\
\hline Fuel Bladder (500g) & 27 & 3.27 & 5.9 & 0 & 1,2 & $\mathrm{MV}$ & 10 & 26.3 \\
\hline
\end{tabular}

\begin{tabular}{|r|r|r|}
\hline Time & Dry Cargo & Fuel \\
\hline 0 & 0 & 0 \\
\hline 3.27 & 15 & 28 \\
\hline 5.9 & 15 & 55 \\
\hline
\end{tabular}

\begin{tabular}{|l|r|r|r|r|}
\hline Crew Day Used & \# units & hrs/unit & Total hrs & Used \\
\hline $\mathrm{CH}$ & 10 & 8 & 80 & 25.3 \\
\hline $\mathrm{MV}$ & 24 & 8 & 192 & 52.46 \\
\hline
\end{tabular}

\begin{tabular}{|l|r|r|r|r|r|r|r|}
\hline \multicolumn{7}{|c|}{ Choices considered for number of CH/MV and Spots per load } \\
\hline Loads & Total req & CH & MV & Spots & Time & CH CD Used & MV CD Used \\
\hline Dry Cargo (20k sling) & 15 & 5 & & 1 & 6.54 & 32.7 & 0 \\
\hline & 15 & 10 & & 1 & 3.27 & 32.7 & 0 \\
\hline & 15 & 10 & & 2 & 3.27 & 32.7 & 0 \\
\hline Fuel Bladder (500g) & 55 & & 8 & 1 & 6.83 & 0 & 54.64 \\
\hline & 55 & & 13 & 2 & 4.03 & 0 & 52.39 \\
\hline & 27 & & 10 & 1 & 2.63 & 0 & 26.3 \\
\hline
\end{tabular}

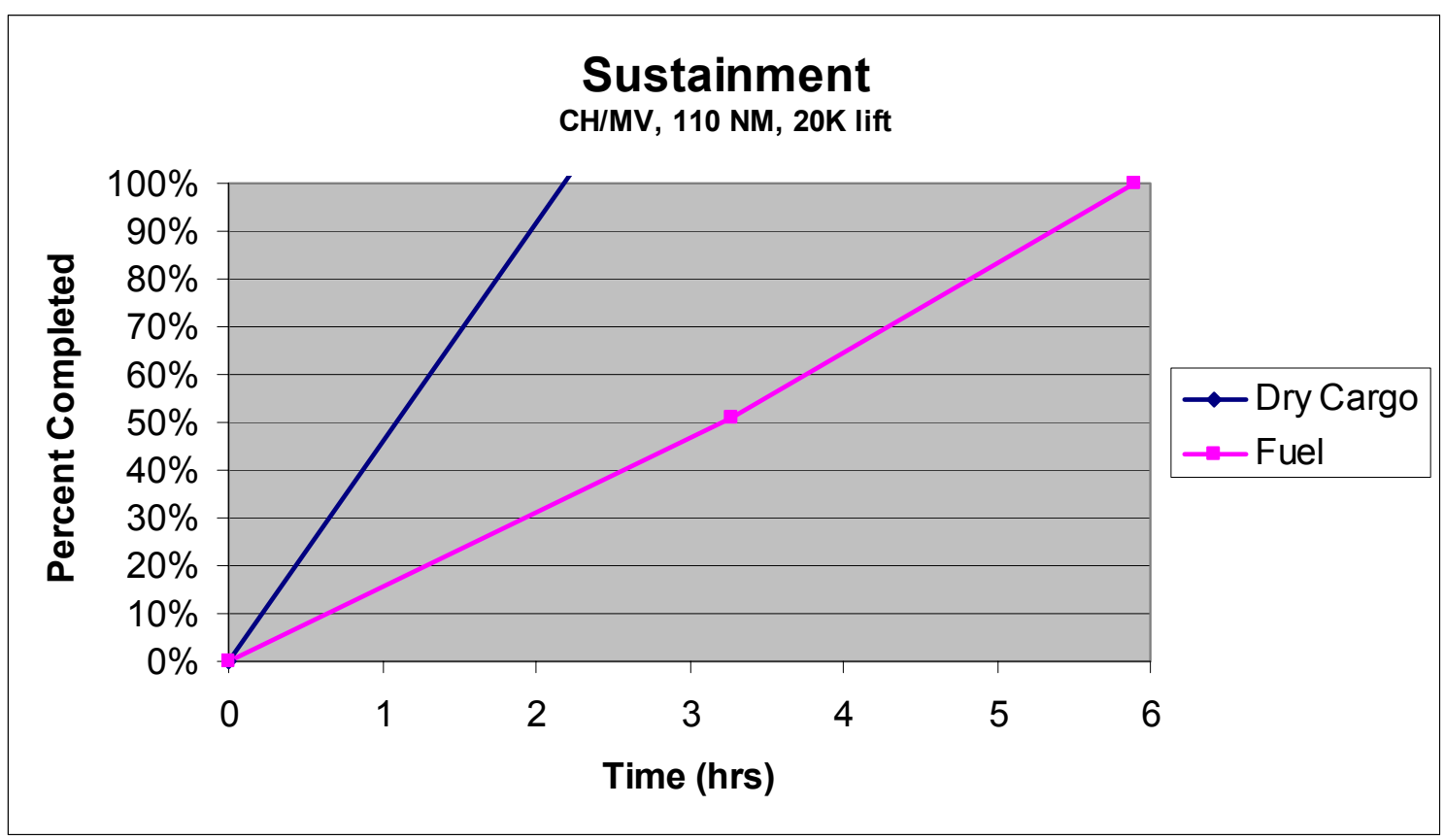




\subsection{Resupply of the MPF(F) Ships}

In the previous section, the daily resupply requirements of the forces ashore were estimated. The food, water, fuel, and ammo are supplied from the stores of the MPF(F) ships. After some time, the levels of these commodities in the $\operatorname{MPF}(F)$ ships will fall to their reserve levels $(50 \%$ is assumed for the reserve levels) and the MPF(F) ships will themselves require replenishment. [3] uses a requirement for the $\operatorname{MPF}(\mathrm{F})$ squadron to have 20 days of supply of all commodities for the MEB. (It is unclear whether the MPF(F) squadron is to contain 20 DOS for the whole MEB or just the Seabased Echelon; the whole MEB is not presently seen as embarking the ships of the MPF(F) squadron.) This implies that the reserve levels will be reached on the $10^{\text {th }}$ day of operations. By the $10^{\text {th }}$ day, the total amount of combat stores supplied from MPF(F) ships would be 135 tons of MREs, 1,176 tons of water, 265,000 gallons of fuel, and 187 tons of ammo. $\operatorname{MPF}(\mathrm{F})$ replenishment requirements, however, depend on the cargo capacities of the MPF(F) ships for each of the commodities.

The $\operatorname{MPF}(\mathrm{F})$ ship implicit in the descriptions here is constrained-size ship with rotary wing $(\mathrm{R} / \mathrm{W})$ and tiltrotor $(\mathrm{T} / \mathrm{R})$ aircraft only from the $\mathrm{MPF}(\mathrm{F})$ Analysis of Alternatives final report [3]. Each of these ships has a cargo fuel capacity of 36,000 barrels. It is assumed that the fuel carried is the standard single fuel, JP-5, that powers both the combat vehicles ashore and the aircraft and LCACs of the MPF(F) ships. If each MPF(F) ship has $36,000 \mathrm{bbl}$ of fuel, the squadron of eight ships has $288,000 \mathrm{bbl}$. of cargo fuel and the $50 \%$ reserve level will be reached when total consumption reaches $144,000 \mathrm{bbl}$. MPF(F) cargo fuel supports operations of the SBME ashore, MV-22 and CH-53 aircraft operations by aircraft of the MPF(F) squadron, and LCAC operations. Because of the deployment of the SBME, first day fuel consumption is larger than that of subsequent days.

On the first day of operations, MPF(F) aircraft and LCACs are heavily utilized in the deployment of the SBME maneuver forces. The movement model results in Section 8.1 predicted $342 \mathrm{MV}-22$ flight hours and $147 \mathrm{CH}-53$ flight hours. A nominal fuel burn rate for the MV-22 is 500 gallons per hour. Likewise, the $\mathrm{CH}-53$ might be expected to burn 600 gallons per hour. These numbers imply a total aircraft fuel consumption for deployment of 6,171 bbl. Likewise, the movement model results in Section 8.2 indicate a total of 127 LCAC operating hours. At 1,000 gallons per hour [14], and for deploying both Surface battalions, the total LCAC fuel use was 6,048 bbl. In Section 9.1, the SBME assault rate fuel use was 26,500 gallons or $631 \mathrm{bbl}$. Thus, the estimate of total fuel use on the first day is 12,219 bbl. For subsequent days, the MV-22 and CH-53 fuel uses are associated with resupplying the forces ashore and with supporting other operations. Just half of the aircraft were devoted to resupply operations in the model of Section 9.1 and they flew 59.6 MV-22 hours and $25.3 \mathrm{CH}-53$ hours for a total fuel use of 45,000 gallons or $1,071 \mathrm{bbl}$. We might assume the other half of the aircraft had a similar flight hour program, though for other purposes, and therefore the total aircraft fuel use on days after deployment is $2142 \mathrm{bbl}$. After their heavy use in deploying the two Surface battalions, it is assumed that 20 LCAC trips are made daily for a total fuel 
consumption of $1,300 \mathrm{bbl}$. On the other hand, if the $\operatorname{MPF}(\mathrm{F})$ ships withdraw to 75-100 miles offshore, it could be argued that there is no LCAC use at all.

To summarize, total first day fuel use is estimated as $12,219 \mathrm{bbl}$. and following day fuel use totals 4,073 bbl. The reserve fuel level in the $\operatorname{MPF}(\mathrm{F})$ squadron would then be reached on the $33^{\text {rd }}$ day of the operations, not the $10^{\text {th }}$ day. The large amount of cargo fuel in this $\mathrm{MPF}(\mathrm{F})$ ship design provides for far more than 20 days of supply (more like a 65-day supply). Fuel replenishment to the $\mathrm{MPF}(\mathrm{F})$ ships could be provided by commercial tankers operating skin-to-skin in sea states up to 4, as is commercial practice with very large crude carrier operations off the West Coast of the United States.

The constrained-size, rotary wing- and tiltrotor-only design description in [3] does not indicate the amount of dry stores and ammo each ship would carry. Therefore, the 20 days of supply description is used and, along with a $50 \%$ reserve level, implies that resupply is needed by day 10 of the operation. With palletized MREs, bottled water, and ammo loaded into containers, and if containers can be transferred from commercial container ships at sea in open ocean-either through skin-to-skin transfer or stabilized crane-replenishment could be accomplished with commercial ships. If the time line is such that it takes at least ten days to close to the sea base and a day for force assembly, the $10^{\text {th }}$ day of operations is 21 days after the deployment order. This may be sufficient time to allow the charter of container ships, their loading, and their transit to the sea base. The impact of this, if correct, is that there may not be a requirement for ships dedicated to replenishing the $\mathrm{MPF}(\mathrm{F})$. Alternatively, resupply of the $\mathrm{MPF}(\mathrm{F})$ could be provided by a ship of the squadron being offloaded to the other ships in the squadron and then serving as a shuttle ship.

\subsection{Resupply of the CSG and ESG Ships of the Sea Base}

Exclusive of the submarine, the Navy Fact File describes a carrier strike group as a CVN-68 class carrier, a GC-52 class cruiser, two DDG-51 class destroyers, and a T-AOE-6 class station ship. An expeditionary strike group, exclusive of the supporting submarine, is described as an LHD or LHA, an LPD, an LSD, a CG-52 class cruiser, a DDG-51 class destroyer, and a FFG-7 class frigate [15]. Notably, the ESG has no station ship.

Using OPNAV N42 logistics planning factors [5] the following data are compiled.

\begin{tabular}{|l|c|c|c|c|c|}
\hline & & Capacity (bbl.) & Daily Usage (bbl.) & DOS & Days to 50\% \\
\hline CSG & F-76 & 99,392 & 2,951 & 33.7 & 16.8 \\
\hline & F-44 & 118,283 & 5,034 & 23.5 & 11.8 \\
\hline & Ammo (tons) & 3,971 & $100^{*}$ & 39.7 & 19.9 \\
\hline & & & & & \\
\hline ESG & F-76 & 115,712 & 3,348 & 34.6 & 17.3 \\
\hline & F-44 & 19,306 & 1,062 & 18.2 & 9.1 \\
\hline & Ammo (tons) & 549 & $36^{*}$ & 15.3 & 7.6 \\
\hline
\end{tabular}


The asterisked numbers require amplification. The 100 tons of ordnance use by the CSG is the lower number in the N42 file. The lower number may still be too high. In Vietnam the planning factor was 188 tons of strike ordnance per day, in Desert Storm the number was a third of this daily tonnage, and the substitution of precision for mass continues through OEF and OIF. The 1,062 bbl. of F-44 is rather larger than the $348 \mathrm{bbl}$. in the N42 file. The 1,062 bbl. per day represents four flight hours by each of the ESG's $12 \mathrm{MV}-22 \mathrm{~s}$, four flight hours by each of the ESG's four CH-53s, and a 2.75-hour sortie by each of the ESG's four LCACs. Finally, the ESG's 36 tons of ordnance per day is the lower of the two numbers in the N42 file.

There is clearly a lot of anxiety over the right planning factors. The analyst using JELO can edit any of this as better information becomes available.

The least sustainability arises from the ESG's limited F-44 capacity, limited ammo capacity, and the fact that the ESG has no station ship. The CSG's station ship could help this situation if it serviced the ESG's F-44 needs and was loaded with both Navy strike ordnance and USMC strike and ground combat ordnance (this is not presently the case).

A pencil and paper analysis indicates that two T-AOs and one T-AKE shuttling to and from an advance base 2,000 $\mathrm{nm}$ distant from the sea base can more than satisfy the fuel and ordnance requirements of one CSG and one ESG. Multiples of the numbers of CSGs and ESGs do not scale the requirements linearly, however. An integer program implemented in the General Algebraic Modeling System (GAMS) has been used offline to evaluate the numbers and types of shuttles required to maintain commodity levels for various combinations of CSGs and ESGs, assuming every CSG has a T-AOE station ship [16]. The table is presented below.

\begin{tabular}{|c|c|c|c|c|c|}
\hline & & \multicolumn{2}{|c|}{ Req'd/no F-44 reserve violation } & \multicolumn{2}{c|}{ Req'd/limited F-44 violation } \\
\hline \#CSGs & \#ESGs & T-AKE & T-AO & T-AKE & T-AO \\
\hline 1 & 1 & 1 & 2 & 1 & 1 \\
\hline 1 & 2 & 1 & 2 & 1 & 1 \\
\hline 2 & 2 & 1 & 3 & 1 & 2 \\
\hline 3 & 3 & 1 & 3 & 1 & 2 \\
\hline 4 & 4 & 1 & 4 & 1 & 3 \\
\hline 5 & 4 & 1 & 5 & 1 & 4 \\
\hline
\end{tabular}

\section{Conclusion}

Some of the major logistics issues associated with sea basing expeditionary maneuver warfare have been described in this report. A spreadsheet model of the end-to-end process of force closure to the sea base and deployment to objectives ashore has been developed. In all of this there are significant uncertainties about platform specifications and capabilities and about logistics planning factors for combat stores usage. While every effort was made to find or develop and use sensible data, almost all model parameters may be user specified. This report contains a number of examples that 
demonstrate the use of the movement model, the deployment model, and several of the possibilities for closing the force to the sea base. The goal of the project was to create a tool to evaluate platform and capability tradeoffs and support programmatic decision-making.

Some observations drawn not so much from exercising the model as simply from studying the problem are as follows. A requirement to keep the sea base $100 \mathrm{~nm}$ at sea because of the sea-skimming missile threat imposes serious difficulties. Among other things, it means that the LCACs and EFVs are disenfranchised unless there is some new high-speed assault connector that can carry them closer to shore. This is a problem at the intersection of Sea Shield and Sea Basing.

The issue of moving non-self-deploying aircraft to the sea base is important. Deployment and sustainment don't take place without them and they may be the last equipment to arrive at the sea base. More generally, where all the connectors - air and surface-are when the deployment order is given is an important issue.

It may turn out that for many scenarios, the $\mathrm{MPF}(\mathrm{F})$ preposition site is also the nearest advance base. In this case, holding the $\operatorname{MPF}(\mathrm{F})$ to wait for the arrival of the troops from CONUS may not delay things very much and avoids the need for a HSC and HSC to MPF(F) transfer operation. This may be attractive, but the problem of getting the NSDA to the sea base remains.

Finally, while there is much interest in high-speed sealift and high-speed connectors, the speed of the $\operatorname{MPF}(\mathrm{F})$ ships would seem to be an important variable in the problem. $\operatorname{MPF}(\mathrm{F})$ speed limits the early arrival of the $\operatorname{MPF}(\mathrm{F})$ to the sea base and is even more critical if the $\operatorname{MPF}(\mathrm{F})$ waits to embark troops at the advance base/preposition site before departing for the sea base.

The Navy and Marine Corps are striving to define the $\operatorname{MPF}(\mathrm{F})$ and determine what its capabilities and capacities need to be. Additionally, there are potentially other platforms to build in order to make Sea Basing a reality-high-speed connectors, assault connectors, and rapid strategic lift ships. JELO can be of use in evaluating the alternatives. 


\section{References}

1. Headquarters Marine Corps, PP\&O, Baseline 2015 MEB Table of Organization, 29 January 2004.

2. Initial Capabilities Document for a HSC for Joint Seabasing Support, Draft Version 1.0e, 20 April 2004; HSC CONOPS Draft, version 9.1, 4 February 2004; High Speed Connectors, draft for signatures of LTG Hanlon and VADM Nathman, undated, but after February 2004.

3. $\operatorname{MPF}(\mathrm{F})$ Analysis of Alternatives Final Summary Report, Center for Naval Analyses, CNR D0009814.A2/Final, April 2004.

4. MAGTF Planner's Reference Manual, MSTP Pamphlet 5-0.3, April 2001.

5. OPNAV N42 Excel files: “Approved LPFs icw 04 CLF study.xls,.” undated.

6. Sea Base CONOPS, N75, 18 March 2004.

7. Major William Hershberger, USMC, Mission Area Analysis, Studies and Analysis, MCCDC; August and September 2004 emails; Major Hershberger, a naval aviator, was assigned to the MV-22 flight test squadron, HMX-1, from October 2000 until September 2003.

8. Rapid Strategic Lift Ship (RSLS), N42 briefing, 8 March 2004.

9. Telecom with Marvin Miller, Underway Replenishment Department, NAVSEA, Port Hueneme, 7 September 2004.

10. Pat O'Bryan, MROC Executive Summary: MPFF Capabilities Update and CNA AoA IPR Update \#3, MCCDC, 17 September 2003.

11. Shallow Draft High Speed Sealift and Super Heavy Lift VTOL, Sikorsky, Vibtech, Harley Shipbuilding, and Ocean Dynamics briefing, 21 August 2003.

12. MPF 2010 Ship-to-Shore Movement and Seabased Logistics Support, Volume 1, Center for Naval Analyses, CRM 98-19, May 1998.

13. Report of the Task Force on Sea Basing, Defense Science Board, August 2003.

14. LCAC Description, Military Analysis Network, http://www.fas.org/man/dod101/sys/ship/lcac.htm.

15. Navy Fact File, http://www.chinfo.navy.mil/navpalib/news/.www/esg.html.

16. Integer Programming Model by LCDR Eric Morgan, SC, USN, Operational Logistics curriculum student, Department of Operations Research, Naval Postgraduate School, September 2004. 


\section{Initial Distribution List}

1. Research Office (Code 09) .1

Naval Postgraduate School

Monterey, CA 93943-5000

2. Dudley Knox Library (Code 013)

Naval Postgraduate School

Monterey, CA 93943-5002

3. Defense Technical Information Center

8725 John J. Kingman Rd., STE 0944

Ft. Belvoir, VA 22060-6218

4. Richard Mastowski (Editorial Assistant).

Department of Operations Research

Naval Postgraduate School

Monterey, CA 93943-5219

5. Gregory K. Melchor electronic copy Office of the Chief of Naval Operations N81

2000 Navy Pentagon

Washington, D.C. 20350-2000

6. Arthur H. Barber electronic copy

Office of the Chief of Naval Operations N81B

2000 Navy Pentagon

Washington, D.C. 20350-2000

7. VADM William J. Hancock, USN (Ret) electronic copy 5512 Ashleigh Road

Fairfax, VA 22030

8. Ms. Robbin Beall electronic copy Office of the Center of Naval Operations N816 2000 Navy Pentagon

Washington, D.C. 20350-2000

9. CDR Ernest Harden electronic copy Office of the Chief of Naval Operations N816 2000 Navy Pentagon

Washington, D.C. 20350-2000 
10. LCDR Phillip Pournelle... electronic copy Office of the Chief of Naval Operations

N816B1

2000 Navy Pentagon

Washington, D.C. 20350-2000

11. Mr. Jonathan Kaskin ... electronic copy Office of the Chief of Naval Operations

$\mathrm{N} 42$

2000 Navy Pentagon

Washington, D.C. $20350-2000$

12. Captain James Stewart electronic copy Office of the Chief of Naval Operations

$\mathrm{N} 421$

2000 Navy Pentagon

Washington, D.C. 20350-2000

13. LCDR Frank Futcher electronic copy Office of the Chief of Naval Operations

N421C

2000 Navy Pentagon

Washington, D.C. 20350-2000

14. Captain Arthur S. Mobley. electronic copy Chief of Staff COMNAVSURFGRU PACNORWEST

15. Commander, Third Fleet. electronic copy Attn: Dr. Greg Cox

16. Nicholas M. Linkowitz . electronic copy Logistics Vision \& Strategy Center HQMC 2 Navy Annex Washington, D.C. 20380-1775

17. Distinguished Professor David Schrady electronic copy Operations Research Department Naval Postgraduate School

18. Lecturer Matthew Boensel electronic copy Systems Engineering Department Naval Postgraduate School 